\title{
Balancing satisfaction, balancing health
}

Citation for published version (APA):

Roy, A. (2017). Balancing satisfaction, balancing health: challenges of satisfaction in the public-private mixed health system of Bangladesh. [Doctoral Thesis, Maastricht University]. Datawyse / Universitaire Pers Maastricht. https://doi.org/10.26481/dis.20170619ar

Document status and date:

Published: 01/01/2017

DOI:

10.26481/dis.20170619ar

Document Version:

Publisher's PDF, also known as Version of record

\section{Please check the document version of this publication:}

- A submitted manuscript is the version of the article upon submission and before peer-review. There can be important differences between the submitted version and the official published version of record.

People interested in the research are advised to contact the author for the final version of the publication, or visit the DOI to the publisher's website.

- The final author version and the galley proof are versions of the publication after peer review.

- The final published version features the final layout of the paper including the volume, issue and page numbers.

Link to publication

\footnotetext{
General rights rights.

- You may freely distribute the URL identifying the publication in the public portal. please follow below link for the End User Agreement:

www.umlib.nl/taverne-license

Take down policy

If you believe that this document breaches copyright please contact us at:

repository@maastrichtuniversity.nl

providing details and we will investigate your claim.
}

Copyright and moral rights for the publications made accessible in the public portal are retained by the authors and/or other copyright owners and it is a condition of accessing publications that users recognise and abide by the legal requirements associated with these

- Users may download and print one copy of any publication from the public portal for the purpose of private study or research.

- You may not further distribute the material or use it for any profit-making activity or commercial gain

If the publication is distributed under the terms of Article $25 \mathrm{fa}$ of the Dutch Copyright Act, indicated by the "Taverne" license above, 


\section{BALANCING SATISFACTION, \\ BALANCING HEALTH}

Challenges of satisfaction in the public-private mixed health system of Bangladesh

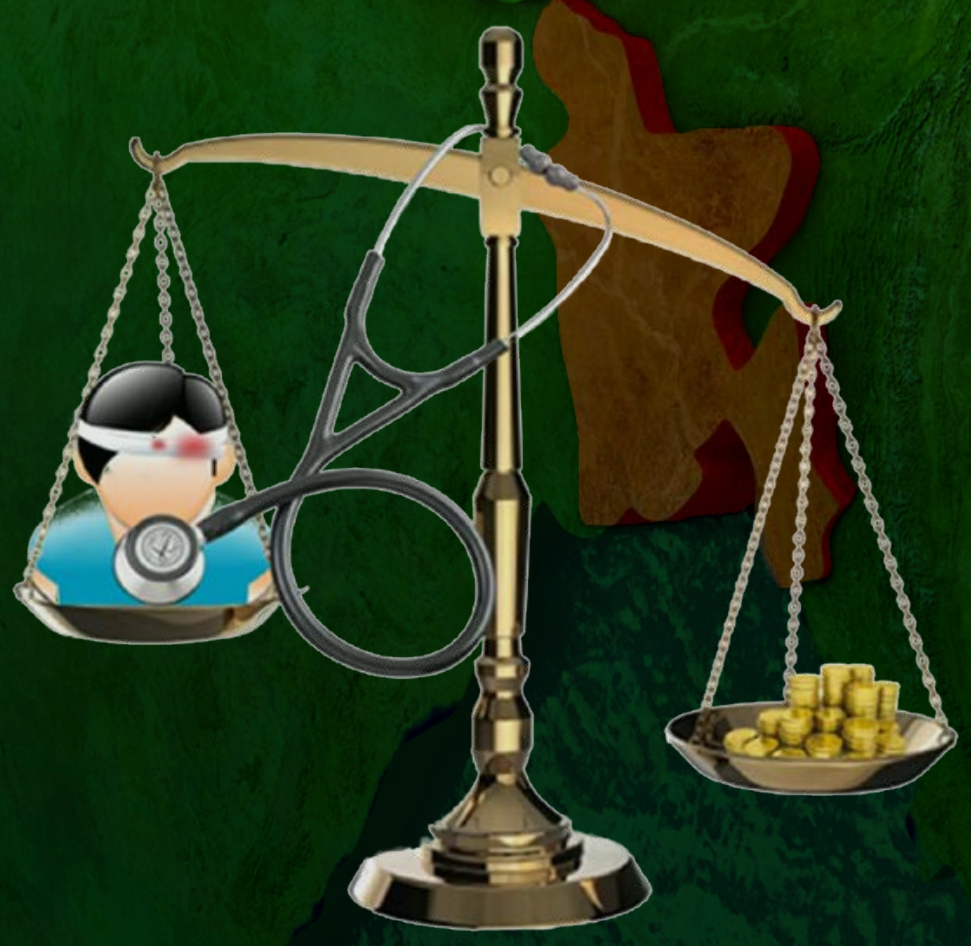

Ashim Roy (Andrew) 
The research presented in this dissertation was conducted at the School for Public Health and Primary Care (CAPHRI), Department of Health Promotion, Maastricht University. CAPHRI participates in the Netherlands School of Primary Care Research (CaRe), acknowledged by the Royal Dutch Academy of Science (KNAW). CAPHRI was classified as 'excellent' by the external evaluation committee of leading international experts that reviewed CAPHRI in December 2010.

This research described in this dissertation was funded by the Netherlands Fellowship Programme (Grant number: NFP-PhD CF8829/2013).

All rights are reserved. No part of this book may be reproduced or transmitted in any form or by any means, without the written permission from the author or where appropriate, the publisher of the article. 


\title{
BALANCING SATISFACTION, BALANCING HEALTH
}

\section{Challenges of satisfaction in the public-private mixed health system of Bangladesh}

\author{
DISSERTATION \\ To obtain the degree of Doctor at Maastricht University, \\ on the authority of the Rector Magnificus, Professor Dr. Rianne M. Letschert, \\ in accordance with the decision of the Board of Deans, \\ to be defended in public on Monday 19 June 2017 at 14.00 hours.
}

By

Ashim Roy Andrew

Born on 24 June 1967 at Khulna, Bangladesh 


\section{Promotors}

Prof. dr. Nanne K. de Vries

Prof. dr. Trudy van der Weijden

\section{Assessment committee}

Prof. dr. G. J. Dinant (Chairman)

Prof. dr. H. Brand

Dr. E. Grant, the University of Edinburgh, the UK

Prof. dr. P. Groenewegen, Utrecht University

Dr. M. Pavlova 


\section{Contents}

Chapter 1 General introduction

Chapter 2 The need for regulatory reform to improve rural people's access to health care: views of administrators of the public-private mixed health system of Bangladesh

Chapter 3 Predictors and consequences of rural clients' satisfaction level in the district health care system of Bangladesh

Chapter 4 Relationships of work characteristics to job satisfaction, turnover intention, and burnout among doctors in Bangladesh

Chapter 5 Challenges of satisfaction of key stakeholders of the district health system of Bangladesh and ways to improve: A qualitative study

Chapter 6 General discussion

Chapter 7 Summary

Samenvatting

Valorisation

Acknowledgements

Curriculum vitae

Publication lists 

Chapter

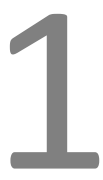

General introduction 

The concept of patient satisfaction that emerged with the rise of the consumer movement in the 1960s had two key underlying drivers: the practical relevance of its direct relation to treatment compliance, and the political interest of enhancing the efficiency of the public health system to meet ever-rising resource demands in health care (Williams, 1994). During the post-1980s era of globalisation through neo-liberal global economic policy, phenomenal changes took place in the form of privatisation and market-style reforms of diverse social sectors including health (WHO, n.d.-a). These transitions in global and local political economy underpin the modern consumerism characterised by provider-induced consumer desire that encourages consumption of services or goods irrespective of needs (Busch, 2008). This paradigm shift is clearly perplexing in light of the report by Robinson (2005) suggesting that in the health market, patient satisfaction is pivotal to the consumer-led concept of consumerism. Within a market, providers' investments and interest in creating clients' desire for and satisfaction with goods or services are often economic concerns, both in terms of providers' sustainability and the potential financial impacts on consumers (Barbier et al., 2013; Busch, 2008).

Following market-style reforms of health systems in many developed and developing countries, client satisfaction has become an increasingly complex issue as a result of the growing diversity in financing systems, service provision and stakeholders' interests. Mixed public-private provision and financing in health systems is common worldwide. With key focuses on competition, free choice and the efficiency of the private market, such reforms often pose challenges to the social solidarity of equitable access to health care, especially in developing countries (WHO, n.d.-a).

In many low and middle-income countries (LMICs), free markets have been adopted in health care without adequate regulatory structure and capacity (WHO, 2007). There is also a clear lack of resources in the public sector. Consequently, people must pay unpredictable and unaffordable health care costs with out-of-pocket payments (OPP). The vicious link between ill health and poverty is undeniable, and this effect contributes to that. Thus, a public-private mixed OPP model, the common health system in LMICs, is a potential barrier to equity as well as to patients' satisfaction and economic protection in health care (Rockefeller Foundation, 2009; Econex, 2011).

Because of its political, social, health and economic implications, (dis)satisfaction in global health systems has received vast attention from researchers, politicians, policymakers and academics for decades (Gill \& White, 2009). Numerous studies have been conducted to define and measure satisfaction in diverse markets including that of health; however, defining and developing a well-suited tool for measuring this cognitive and affective construct is an issue that remains to be solved (Turris, 2005). Crow et al. (2002) remarked that satisfaction in health care is an outcome of interpersonal relations and service process features. Heidegger et al. (2006) argued that in addition to clinical quality and health outcomes, economic results and patient satisfaction also be 
considered as part of service quality assessment. Again, Strasser and Aharony (1993) proposed patient satisfaction as a perceptual, multidimensional, relativistic, dynamic, patient-centred, attitudinal and individualistic process. With some controversy, patient satisfaction is widely used as a proxy indicator of perceived service quality, although a commonly held view identifies it as an under-theorised concept (Turris, 2005; Gill \& White, 2009); both of these elements are challenging to measure (Naidu, 2009).

Most of the studies on satisfaction in health care have focused on patient satisfaction, measuring this based on patients' views of perceived service quality (Heidegger et al., 2006). However, patient satisfaction alone is not enough, since satisfaction in health systems involves all stakeholders' satisfaction states. Empirically, health workers' satisfaction and motivation depend on the broader organisational environment. For example, the fit between health workers and the organisational context in which they operate is pre-condition for their satisfaction level and motivation, which ultimately determines organisational outcomes such as patient satisfaction (Bhandari et al., 2010).

Thus, it is obvious that evaluating patients' satisfaction by assessing their perception of health care quality alone is only a partial approach to determining overall satisfaction within a health system. Therefore, investigations exploring the factors which influence the satisfaction of different key stakeholders are essential in order to address policy interventions to optimise health system outcomes. This study aimed to carry out such an investigation in the health system of Bangladesh.

\section{BACKGROUND}

\section{Geographic and demographic remarks}

Bangladesh lies in one of the world's largest deltas and covers an area of 147,570 square kilometres. As a sovereign state in Southeast Asia since 16 December 1971, Bangladesh shares common borders primarily with India to the west, north and northeast, and with Myanmar to the south-east; at its southern coast, the Bay of Bengal receives a large network of rivers.

With a unitary parliamentarian government system, for smooth running of the state's administrative affairs the country is divided into seven divisions. Each division consists of various districts, totalling 64 nationally. Several upazillas (i.e. sub-districts) form a district. The union is the basic democratic unit of the local government; several unions form an upazilla. Each union consists of nine wards, with each ward made up of several villages (Ministry of Health and Family Welfare, 2012).

Bangladesh is the world's most densely populated country with over 150 million inhabitants in 2011 . The rural segment constitutes over $72 \%$ of the total population, and the 
majority of people subsist on farming. The average life expectancy is 67.7 years. The average literacy rate among age group $\geq 7$ years is $51.8 \%$ (Ministry of Health and Family Welfare, 2012; Bangladesh Bureau of Statistics, 2011).

\section{Economy}

Bangladesh is a developing country which ranks $146^{\text {th }}$ among 185 nations on the Human Development Index, having experienced progressive growth over the years (UNDP, 2013). In 2010, $31.5 \%$ of the total population (35.2\% rural; $21.3 \%$ urban) lived below the national poverty level (World Bank, 2013). Since embracing the globalisation process in the 1980s, Bangladesh has operated on the principle of an open-market economy with a public-private mixed-market system (Ahmed, 2008). The industrial sector's contribution to the gross domestic product (GDP) is gradually taking the lead over the country's traditional agrarian economy. Health has also been integrated into Bangladesh's national development strategies (World Bank, 2003).

\section{Health system: a brief overview}

The Ministry of Health and Family Welfare (MOHFW) sits at the top of the hierarchy of the centralised health system of Bangladesh, and is responsible for national health policy, planning and decision making. Health care services are delivered through a publicprivate mixed system. The Directorate General of Health Services (DGHS), the largest among all the organisations of the MOHFW, organises and delivers public health services and is authorised to control the private health sector (Ministry of Health and Family Welfare, 2012).

The countrywide health infrastructures under the jurisdiction of the DGHS are categorised into geographic tiers from national to community level. The district health system, the key source of health care for people in rural areas, is the pertinent interest of this study. The health care delivery system of a district consists of: (i) public components with a primary health care (PHC) system for each of its constituent sub-districts, along with a secondary level district hospital; and (ii) private components. The formal forprofit private sector is urbanised and rapidly growing, consisting mainly of secondary level clinics or hospitals at the district level (Ministry of Health and Family Welfare, 2012; Barkat \& Maksud, 2003).

Taxes and donations are the key financing sources of the public health sector, while the private sector is mainly funded by market-based individual or group investments. The public sector is the major source of preventive care; in contrast, the private sector is the majority provider of costly curative services. The global health expenditure database of the World Health Organization (WHO, n.d.-b) reported that over the course of a decade leading up to 2012, private health expenditures (PvtHE) consistently accounted for over 
two-thirds of total health expenditures in Bangladesh, of which over $97 \%$ constituted households' out-of-pocket payments. Only one-third of total health expenditures represented general government health expenditures. Private insurance amounted to only $0.3 \%$ of PvtHE. There is no social insurance system. THE were equivalent to $3 \%$ of the GDP (WHO, n.d.-b). These health financing scenarios conform to the OPP model of health system in Bangladesh.

In the public sector, available drugs, surgeries and hotel services are free of charge. However, both the rich and the poor alike must pay the defined user fees for diagnostics. Additionally, everyone must purchase drugs, medical treatments and diagnostics from the private market if they are not publicly available. Again, the richer segment of the population is privileged in both health sectors (Rockefeller Foundation, 2009). Health care costs in the private market are uncontrolled and considerably higher. Consumers are especially at risk of economic loss in an uncontrolled health market (Rockefeller Foundation, 2009). Nevertheless, nearly three-fourths of patients receive curative services from the private sector (World Bank, 2003). Despite their low health care costs, rural public health facilities are relatively underutilised; this is a regulatory and development concern. The health financing system creates inequity in the health system of Bangladesh, which is a barrier to poverty reduction and patient satisfaction.

The shortage of doctors in the public sector is a chronic problem in Bangladesh. Doctors prefer to work in urban environments (WHO, 2010), and the issue is intensified by absenteeism, especially in PHC facilities (Lewis, 2006). This may be linked to organisational factors such as low incentives, inferior working conditions, lack of performance evaluation and career prospects, and the public doctors' interest of private practice. Further, local authorities seem to lack power, relying on the central command and control system even for simple human and material resource management issues. Although such situations seem conducive to dissatisfaction among the key actors in the health system, they are nevertheless under-researched.

Despite facing limitations, Bangladesh has achieved remarkable successes in child immunisation coverage and reduction in infant and maternal mortality (UNDP, 2012). Actors in the district health system have made clear contributions to these achievements. Notably, some studies based on patients' opinions have reported that doctors' behavioural and technological deficits are the key factors of patients' dissatisfaction in Bangladesh (e.g. Aldana et al., 2001). Empirically, patient dissatisfaction often is linked to treatment non-compliance and changes of doctors, meaning new tests and new drugs along with unwanted word-of-mouth communications (Dagger \& Sweeney, 2006). These are the direct and indirect barriers to fulfilling health system goals and achieving the health and economic development of households and the country as a whole. Adverse effects on social capital and the dignity of the health care profession are also inevitable in such circumstances. 
Considering the overall situation, patients' opinions alone are not sufficient to judge the state of satisfaction in the health system. An investigation into the potential influences of macro- and micro-environmental factors on key stakeholders' satisfaction in this public-private mixed health system is essential in order to further evaluate their (dis)satisfaction, and thereby explore meaningful interventions for improvement.

\section{RESEARCH OBJECTIVES}

\section{General objective}

To explore key determinants of satisfaction of the administrators, doctors and patients in the district public-private mixed health system of Bangladesh, and to address evidence-based policy interventions for improving their satisfaction. The ultimate goal is twofold: firstly, to improve the rural population's equitable access to quality health care, and thus their health and economic protection as well; and secondly, to contribute to the enhancement of social capital in health care.

\section{Specific objectives}

1. To describe district public health administrators' and private facility owners' explanations of their roles and limitations in ensuring the rural population's health care needs.

2. To identify key predictors and consequences of satisfaction of rural patients in the district public and private health sectors of Bangladesh.

3. To explore key factors influencing the overall well-being of doctors in the district public and private health sectors.

4. To identify evidence-based policy interventions to improve satisfaction in the health care system of Bangladesh.

\section{METHODS}

Four studies were conducted in order to fulfil the study objectives. Each study had distinct features with regard to its setting, design, population, conceptual, and statistical models. This section briefly describes the study characteristics.

Objective 1: An exploratory mixed-method study using a self-administered mostly quantitative and a few qualitative questionnaire along with an audit survey was conducted in three northern districts of Bangladesh: Gaibandha, Naogaon, and Joypurhat. District and sub-district public health administrators $(n=26)$ and private facility owners/managers 
( $n=32$ ) were selected as the respondents. Descriptive statistics (percentages and ratios) and Chi-squared tests were the statistical models.

Objective 2: A quantitative study using an interviewer-administered questionnaire was conducted with 400 rural patients (public, $n=200$; private, $n=200$ ) in Joypurhat district. Multiple regression and mediation were used as key statistical models.

Objective 3: A quantitative study with a sample size of 384 doctors (public primary, $n=$ 128; public secondary, $n=128$; private, $n=128$ ) was conducted. Doctors came from 29 out of a total of 64 districts from all seven divisions of Bangladesh. Multivariate analysis of variance, bivariate correlations and multiple regression were utilised as statistical models.

Objective 4: A qualitative study was conducted involving administrators, doctors and patients in the public and private sectors, and civil society agents. Data were sourced from six homogenous focus group discussions (total $n=37$ ) with participants from three of the country's districts. A directed content analysis approach was used to analyse the data.

\section{DATA MANAGEMENT}

All quantitative data were processed and analysed using SPSS (versions 20 and 21), while NVIVO (version 10) was used for the qualitative data. All data collection tools and discussions were in the local Bengali language. All focus group discussions were videotaped and transcribed verbatim into English by an expert. For confidentiality reasons, data have been secured with limited access for the investigators.

\section{ETHICAL CONSIDERATIONS}

Ethical clearance was obtained from the ethics committee of the Faculty of Social Science of University of Rajshahi, Bangladesh. Written permissions were acquired from the district authority of health services of the study districts (References: CS. Nao2013/1840/1(2); CS. Joy- 2013/1089/6; CS. Gai- 2013/1805/8). Informed consent was given by all respondents.

\section{THESIS OUTLINE}

This thesis presents the empirical findings of one mixed-method, one qualitative and two quantitative studies with objectives focused on assessing the satisfaction of admin- 
istrators, owners, doctors and patients in the district public-private mixed health system of Bangladesh.

Chapter 2 highlights the district and sub-district public administrators' and private owners' views of challenges in carrying out their roles efficiently and effectively, as well as the barriers to a perfect private market.

Chapter 3 presents the key structural and service process-related predictors of satisfaction of rural patients in the district public and private health sectors. Using an adapted conceptual model of patient satisfaction, this quantitative study reports on interrelations between clients' perceived service quality, perceived utility value and satisfaction level, and ultimate reactions with respect to current providers, facilities and repurchase intentions, along with economic consequences.

Chapter 4 highlights the connections between work characteristics and three work design outcomes - job satisfaction, turnover intention and burnout - along with the potential predictors of these outcomes of interest among the public and private doctors of the district health system, based on nationally representative data.

Chapter 5 describes in-depth views of the key stakeholders of the health system which reinforce and deepen the findings of the quantitative studies. The chapter also highlights potential evidence-based policy interventions to improve overall satisfaction in the health care system and enhance the rural population's equitable access to health care and health.

Chapter 6 contains general discussions including methodological considerations.

Chapter 7 highlights the summary; after which the key social and scientific contributions of this dissertation are briefly described in the valorisation section. Finally, the thesis concludes with acknowledgements and a brief biography of the candidate. 


\section{REFERENCES}

Ahmed, S. (2008). Bangladesh and Global Economy: Does Bangladesh Keep Pace with Economic Globalization ? Retrieved from http://orp.aiub.edu/WorkingPaper/WorkingPaper.aspx?year=2008.

Aldana, MJ., Piechulek, H., \& Al-Sabir, A. (2001). Client satisfaction and quality of health care in rural Bangladesh. Bulletin of the World Health Organization, 79(6), 512-517.

Bangladesh Bureau of Statistics. (2011). Report on Sample Vital Registration System-2010. Retrieved from http://203.112.218.65/WebTestApplication/userfiles/Image/LatestReports/SVRS-10.pdf.

Barbier, B. J., Noronha, A., \& Dixit, A. (2013). Assessing the Economic Value of Making the Right Customer Satisfaction Decisions - and the Impact of Dissatisfaction on Churn. Retrieved from http://www.cisco. com/web/about/ac79/docs/re/Value-of-Customer-Satisfaction.pdf.

Barkat, A. \& Maksud, A. K. M. (2003). The Private Sector Health Services in Bangladesh : An Exploratory Study. Retrieved from http://www.hdrcbd.com/pcs_pdf/1. Health/15. Private Sector Health Services in Bangladesh_An Exploratory Study.pdf.

Bhandari, P., Bagga. R., \& Nandan, D. (2010). Levels of job satisfaction among healthcare providers in CGHS dispensaries. Journal of Health Management, 12, 403-422.

Busch, M. (2008). Adam Smith and Consumerism's Role in Happiness: Modern Society Reexamined. Retrieved from http://business.uni.edu/economics/Themes/Busch.pdf.

Crow, R., Gage, H., Hampson, S., Hart, J., Kimber, A., Storey, L., \& Thomas, H. (2002). The measurement of satisfaction with healthcare: implications for practice from a systematic review of the literature. Health Technology Assessment, 6(32), 1-244.

Dagger, T.S. \& Sweeney, J. C. (2006). The Effect of Service Evaluations on Behavioral Intentions and Quality of Life. Journal of Service Research, 9(1), 3-18.

Econex. (2011). National Health Systems: Public Service vs . Insurance-Based Models. Retrieved from http://www.econex.co.za/index.php?option=com_docman\&task=doc_download\&gid=89\&ltemid=60.

Gill, L., \& White, L. (2009). A critical review of patient satisfaction. Leadership in Health Services, 22(1), 8-19.

Heidegger, T., Saal, D., \& Nuebling, M. (2006). Patient satisfaction with anaesthesia care: What is patient satisfaction, how should it be measured, and what is the evidence for assuring high patient satisfaction? Best Practice and Research: Clinical Anaesthesiology, 20(2), 331-346.

Lewis, M. (2006). Governance and Corruption in Public Health Care Systems. Retrieved from http://www.cgdev.org/sites/default/files/5967_file_WP_78.pdf.

Ministry of Health and Family Welfare. (2012). Health Buletin 2012. Retrieved from http://dghs.gov.bd/bn/ licts_file/images/Health_Bulletin/HealthBulletin2012_full.pdf.

Naidu, A. (2009). Factors affecting patient satisfaction and healthcare quality. International Journal of Health Care Quality Assurance, 22(4), 366-381.

Robinson, J. C. (2005). Managed Consumerism In Health Care. Health Affairs, 24(6), 1478-1489. http://doi.org/10.1377/hlthaff.24.6.1478.

Rockefeller Foundation. (2009). Public Stewardship of Private Providers in Mixed Health Systems. Development. Retrieved from http://www.resultsfordevelopment.org/sites/resultsfordevelopment.org/ files/resources/Public Stewardship of Private Providers in Mixed Health Systems_0.pdf.

Strasser S., \& Aharony L. (1993). The patient satisfaction process: moving toward a comprehensive model. Medical Care Review, 50, 219-248.

Turris, S. A. (2005). Unpacking the concept of patient satisfaction: A feminist analysis. Journal of Advanced Nursing, 50(3), 293-298.

UNDP. (2012). Bangladesh MDGs Progress Report 2011. Retrieved from http://www.undp.org.bd/info/pub/ MDG Progress Report 11.pdf.

UNDP. (2013). Human Development Report 2013. Retrieved from http://hdr.undp.org/en/sites/default/files/ reports/14/hdr2013_en_complete.pdf human development report 2013 pdf.

WHO. (n.d.-a). Globalization and Health Systems Change. Retrieved from https://www.globalhealthequity.ca/ webfm_send/14. 
WHO. (n.d.-b). Global health expenditure database. Retrieved from http://apps.who.int/nha/database/View Data/Indicators/en.

WHO. (2007). Globalization, global governance and the social determinants of health a review of linkages and agenda for action. Retrieved from http://www.who.int/social_determinants/resources/gkn_lee_al.pdf.

WHO. (2010). Health System in Bangladesh. Retrieved from http://www.ban.searo.who.int/en/Section25.htm. Williams, B. (1994). Patient satisfaction: A valid concept? Social Science and Medicine, 38(4), 509-516.

World Bank. (2003). Bangladesh Private Sector Assessment for Health, Nutrition and Population (HNP) in Bangladesh. Retrieved from http://wwwwds.worldbank.org/external/default/WDSContentServer/WDSP/ IB/2003/12/23/000112742_20031223170041/Rendered/PDF/270050BD.pdf.

World Bank. (2013). World Development Indicators: Poverty rates at national poverty lines. Retrieved from http://wdi.worldbank.org/table/2.7. 



\section{Chapter}

\section{The need for regulatory reform to improve rural people's access to health care: views of administrators of the public-private mixed health system of Bangladesh}

Published as:

Roy, A., van der Weijden, T., Hossain, ME., \& de Vries, N. (2016). The need for regulatory reform to improve rural people's access to healthcare : views of administrators of the public-private mixed health system of Bangladesh. Divers Equal Heal Care.13(4):269-78. 


\section{ABSTRACT}

Introduction: Nearly 35\% out of approximately 108 million rural population of Bangladesh live below the poverty level. Resource shortages and limited access to the public health care facilities are common in rural areas, accompanied by high out-of-pocket payments and a nominally controlled rapidly growing private market. This study aims to describe public and private health care services and to investigate public health administrators' and private facility owners' explanations of their roles and limitations to ensure rural people's access to health care.

Methods: An exploratory questionnaire and audit study was conducted in three remote Gaibandha, Naogaon and Joypurhat districts of Bangladesh. 22 public health administrators and 20 private facility owners were the respondents. Audit data on health care structure, availability and utilization of services were collected from the public and private facilities' records in 2012.

Findings: Inefficient utilization of available resources in the centrally regulated public health system was found as an obvious problem. This was associated with wide gaps in power between the central and local authorities, and disparities between supply and demand with consequent wastage and misuse of scarce resources. In the private sector, the effectiveness of regulation of costs and quality is sub-optimal. The licensing and accreditation system is outdated; hence, ineffective. Local authorities' compliance to the stringent central bureaucracy and their satisfaction seem mutually exclusive.

Conclusion: Regulatory reform is essential to ensure rural people's health and economic protection in health care. Thus, optimally utilizing the existing primary health care resources is a high priority. A potential market failure could be prevented and controlled by amending the licensing and accreditation rules involving multisectoral public-private mixed regulatory actors. A 'deconcentration' type of regulatory reform with capacity building of the local authority and implementation of reward and sanction-based policy seems a promising strategy to improve the rural population's health and economic wellbeing in Bangladesh.

Keywords: Health system reform; rural; public-private mix; market failure; decentralization 


\section{INTRODUCTION}

The ultimate goal of the health care system is to meet the health needs of the population and fairness of financial contributions (WHO, 2000). Achieving those goals has become an ever more complex socioeconomic and political issue for many countries including Bangladesh. Privatization, marketization and involvement of diverse players in health care are global changes which are closely linked to growth of regulation in the health care sector (Walshe, 2002; Beaz-Camargo and Jacobs, 2011). The extent of health care cost and quality control and productivity with given resources are the key indicators of regulatory efficiency and effectiveness (Witter, 2000, p.5-6). Thus, health care regulation concerns both the regulators' and providers' accountability and transparency towards the citizen's health and economic protection. Achieving the expected outcomes of health system are challenging both in developed and developing countries which is often due to economic interests of regulators and providers. Administrative and bureaucratic hierarchy and market harnessing are the two broad methods of health system regulation. With the evolution of the free-market economy, public-private mixed health care provision is dominant worldwide. In developing countries this type of system can be a real concern for the poor patients because of the imperfect market mechanisms and undergoverned macro-institutional structure. Effective regulatory mechanisms for enforcing providers' liabilities are still inadequate in developing countries; thus, health care cost and quality remain as potential health and economic threats for the people in needs (Leonard et al., 2013; Begum et al., 2000).

Bangladesh has been operating as an open-market economy since the 1980s; a steady autonomous growth of the private health market has resulted in a public-private mixed health care system (Ahmed, 2008; Barkat and Maksud, 2003). Based on financing sources, out of the three categories of public-private mix health care provision in Bangladesh, as defined by Begum et al. (2000), the tax and donor-financed public sector and the privately financed for-profit-private sector is the key interest of this study. The public and private sectors are the main sources of curative health care services; in addition, the public sector is the major provider of preventive health care (e.g. expanded programme on immunization) (WHO, 2010; World Bank, 2003).

Nearly 108 million (72\%) of a total 150 million population of Bangladesh constitute the rural segment. Of the total population, 31.5\% (rural 35.2\% and urban 21.3\%) live below the poverty line (Ministry of Health and Family Welfare (MOHFW), 2012a; World Bank, 2013). Resource shortage is a chronic problem in the public health sector. The private health sector is rapidly growing and has captured the major financial share of total health expenditures.

The public health care facilities of a district consist of a secondary level district hospital with 100 bed capacity and three-tier primary health care (PHC) facilities. The Communi- 
ty Clinic (CC) is the community level basic outdoor facility of the PHC system; others are Union Sub-Centre (USC) - one for each selected union (i.e. a basic rural local government unit consists of several villages), and Upazilla Health Complex (UHC), the referral PHC facility with a 50 bed capacity at each upazilla (i.e. a sub-district consists of several unions) (MOHFW, 2012a). Geographic distribution and capacity (quantity) of health facilities and resource allocation in public sector are political decisions; however, these are the autonomy of the investors in the private sector.

Absence of health insurance forces the poor to pay beyond their ability. In 2009, private health expenditure (PvtHE) constituted $67.1 \%$ of the total health expenditures (THE); of which, 96.5\% was households' out-of-pocket payments (OPP) (WHO, 2011). The remaining 32.9\% public share of the THE is insufficient to meet the public sector clients' health care needs. Therefore, clients of the public health care facilities have to purchase unmet drugs and diagnostics from the private sector. Econex (2011) described this common phenomenon in many developing countries as 'out-of-pocket payments (OPP) -model' of health system and a potential risk of inequity and impoverishment. Nearly $75 \%$ of rural clients use the private market for curative care. However, high health care costs, low quality, and inappropriate diagnostic tests and medications are the potential health and economic threats in the private market. In Bangladesh, the basic regulatory Acts/Rules are in place; however, gaps between the legal provision and implementation exist (WHO, 2010; World Bank, 2003).

\section{An overview of the health care regulation}

The key regulatory actors of the health system of Bangladesh are the public regulators, provider associations, providers and clients. The MOHFW is the top of the hierarchy responsible for the national health policy and planning. The Directorate of Health Services, headed by the Director General of Health Services (DGHS), is the central authority to execute the regulatory policies of the MOHFW through its seven divisional and sixty four district (local) health authorities namely the Director and the Civil Surgeon respectively. The Civil Surgeon is the head of a district health care system. The Civil Surgeon has authorized roles in the process of license issuing and renewal of private health facilities. The Upazilla Health and Family Planning Officer (UH\&FPO) is the manager of an upazilla primary health care system (MOHFW, 2012a). UH\&FPO is directly accountable to the Civil Surgeon. The Bangladesh Medical and Dental Council (BMDC) is a regulatory body under the MOHFW that controls personnel licensing. Provider associations are: the Bangladesh Medical Association, the formal association of doctors, and the Bangladesh Private Clinic and Diagnostic Owners' Association. Providers are either public or private employees. Notably, the public doctors are the key providers of specialized services in the private sector as well. There is no consumer association. The health care professional and provider organizations tend to protect the interests of their members 
and businesses; however, protection of citizens' welfare in health care are neglected (MOHFW, 2012a; World Bank, 2003).

The MOHFW has different regulatory instruments at its disposal to guarantee the quality of medical care. BMDC registration is mandatory for practicing medical doctors following graduation and completion of a one year internship. Doctors have to renew their licenses every 5-yearly on simple submission of a renewal-fees; thus, standard set of skills and performances assessment are not needed. The "Ordinance - IV of 1982 for Medical Practice and Private Clinics and Laboratories (Regulation)" is the regulatory instrument for issuing and renewal of licenses of the private facilities (DGHS, 2002). All private health facility owners have to apply for a license to the Directorate of Health Services. The district private facility inspection team exclusively consists of public personnel such as the Civil Surgeon or Deputy Civil Surgeon, Medical Officer of Civil Surgeon office, and either a specialist surgeon or gynaecologist and obstetrician (DGHS, 2002). This team visits private facilities prior to license issue and yearly renewal. Notably, the private facility inspection reports are based on the submitted documents rather than upon the verification of inputs, process and outputs (World Bank, 2003). The key requirements for license issue and renewal are identical and include: for each 10 patients, 3 doctors, 6 nurses and 3 cleaners should be available with a minimum 80 square feet space per patient, and defined equipment and surgical facilities. Certificates of income tax and bank transaction for license issue / renewal-fees are essential. Written consent of either public or private specialist doctors regarding their willingness to work in the private facilities are also mandatory which legalizes dual-practice of the public doctors out of public working-time.

Within this situation, health is prioritised and integrated in the national poverty reduction strategy (Andaleeb et al., 2007). The key national health policy objectives are to provide equitable and patient-centered universal primary health care (MOHFW, 2012b). An investigation is essential to assess the opportunities and barriers to health care regulation for achieving those objectives. This study aims to describe public and private health care services in three remote districts and to investigate public health administrators' and private facility owners' potential explanations of their roles and limitations for ensuring rural people's health care needs. We assess the district health care regulators' and private providers' accountability towards rural people's health and economic wellbeing. 


\section{METHODS}

\section{Study design, settings and sampling}

A descriptive exploratory questionnaire and audit survey was conducted in three districts of Bangladesh: Gaibandha, Naogaon and Joypurhat. These three districts were purposively selected based on their geographic situation representing the remote rural districts of the country. Table 1 shows the basic socio-demographic data of the sample districts.

Table 1: Basic demographic data of the sample districts (Sources: Bangladesh Bureau of Statistics (BBS), 2013a; BBS, 2013b; BBS, 2013c)

\begin{tabular}{llcccl}
\hline District & Area in Sq. km & Total population & Urban \% & ${ }^{*}$ Poor \% & Literacy \% \\
\hline Gaibandha & $2,114.77$ & $2,503,507$ & 5.2 & 29.71 & 42.8 \\
Naogaon & $3,435.65$ & $2,633,694$ & 7.2 & 14.45 & 48.2 \\
Joypurhat & $1,012.41$ & 862,252 & 15.33 & 24.75 & 57.5 \\
\hline
\end{tabular}

Notes: Sq. $\mathrm{Km}$ = Square kilometres; ${ }^{*}$ Poor is indicated as permanent insolvency

The local public health administrators and private proprietors/managers were the respondents. There were in total 26 public administrators including three Civil Surgeons and 23 UHFPOs. As all administrators were invited, no sampling procedure was needed. However, to reduce the risk of information bias, administrators with less than two years administrative experience $(n=9)$ were excluded. Public administrators who had retired within three years prior to the data collection were also invited to participate. Finally, 22 selected public administrators (17 in-service and 5 retired) were included.

Out of a total 98 private clinics/hospitals in the sample districts, 32 were found eligible based on the following criteria: facilities had actively functioning specialized doctors for specialized services and at least one graduate doctors for daily follow-up care; they were licensed for more than 3 years and currently functioning. Any private facility employing medical assistants as daily follow-up care providers was excluded. All 32 administrators of the eligible private facilities were approached for data collection. Informed written consent was taken from all respondents.

\section{Instruments and data collection}

Two distinct self-administered semi-structured questionnaires, each with a mixture of quantitative closed and more qualitative open-ended items, were prepared for the local public and private health administrators. Since no instrument specific to the healthcare system of Bangladesh was available on this issue, the items of the questionnaires were developed using an e-book chapter of Busse et al. (2003), the work of Begum et al. 
(2000) and discussions with the senior doctors. The questionnaires were distributed to and collected from the public and private respondents in person. The following key variables were probed to assess the respondents' opinion on factors influencing their functions and performances: prioritization of the rural healthcare needs and interventions, human and material resources management, healthcare costs and quality control, and relations among the key actors of healthcare. The quantitative data on infrastructure, workforce, distribution, capacity, and availability and utilization of healthcare both in the public and private facilities in 2012 were collected from the sample districts' Civil Surgeon offices and summary estimates based on the number of registered patient records in the annual report 2012 of the private facilities. Data entry was conducted by an assistant that was cross-checked by the Principal Investigator regularly. Data was collected during July to August 2013.

\section{Statistical analysis}

SPSS version- 20 was used for data analysis. The characteristics of the study sample were described as percentages. Descriptive statistics such as means, percentages and ratios were generated for other variables. Chi-square tests were done to determine differences between proportions of the performed normal and caesarean deliveries at public and private facilities. A comparison between the proportions of the indoor interventional and conservative management at public and private facilities was also conducted. A p-value $<0.05$ was regarded as significant.

\section{RESULTS}

\section{Respondents}

The response rate among the public and private respondents was $100 \%$ and $62.5 \%$ respectively. Except two, all were men. All public respondents had over 20 year experience of working in the public sector and were promoted from general physician to administrator. The private respondents $(n=20)$ consisted of ten doctors and ten nondoctors. Four of the doctors were self-employed and six doctors, being public employees, were investors since direct private facility ownership of the public doctors is restricted by the Ordinance-1982 (DGHS, 2002). Among the non-doctors, 7 were proprietors and 3 salaried managers.

\section{Structuring the district healthcare system: distribution and capacity}

Table2 shows that, each with a 100 bed capacity, the Naogaon and Gaibandha district hospitals covered nearly equal populations, which was nearly three times larger than in 
Joypurhat. The calculated average population coverage per PHC facility was nearly equal over the sample districts. Total bed capacity in the public sector was about 1.3 times higher than in the private sector. Bed to population ratio in the public sector of Gaibandha district was nearly two and three times smaller than in Naogaon and Joypurhat respectively; in the private sector, again Gaibandha was the smallest among the sample districts.

Table 2: Reported infrastructure of the district healthcare system in the sample districts in 2012 (Sources: Civil Surgeon Office (CSO), 2013a; CSO, 2013b \& CSO, 2013c)

\begin{tabular}{|c|c|c|c|c|c|c|c|c|c|}
\hline \multirow[t]{3}{*}{ District } & \multicolumn{7}{|c|}{ Public sector } & \multicolumn{2}{|c|}{ Private sector } \\
\hline & \multirow{2}{*}{$\frac{\text { SHC facilities }}{\mathrm{DH} \text { (bed) }}$} & \multicolumn{4}{|c|}{ PHC facilities } & \multirow{2}{*}{$\begin{array}{l}\text { Total bed } \\
\text { capacity }\end{array}$} & \multirow{2}{*}{$\begin{array}{c}\text { Bed/10,000 } \\
\text { population } \\
\text { (app) }\end{array}$} & \multirow{2}{*}{$\begin{array}{c}\text { Total bed } \\
\text { capacity }\end{array}$} & \multirow{2}{*}{$\begin{array}{l}\text { Bed/10,000 } \\
\text { population } \\
\text { (app) }\end{array}$} \\
\hline & & UHC (bed) & USC & $\mathrm{CC}$ & Pop / PHC & & & & \\
\hline Gaibandha & $1(100)$ & $7(225)$ & 137 & 299 & 5,651 & 325 & $1.3 / 10,000$ & 140 & $0.56 / 10,000$ \\
\hline Naogaon & $1(100)$ & $11(540)$ & 166 & 295 & 5,591 & 640 & $2.4 / 10,000$ & 710 & $2.7 / 10,000$ \\
\hline Joypurhat & $1(100)$ & $5(220)$ & 33 & 111 & 5,826 & 320 & $3.7 / 10,000$ & 160 & $1.8 / 10,000$ \\
\hline Grand total & $3(300)$ & $23(985)$ & 336 & 705 & 5,689 & 1,285 & $2.1 / 10,000$ & 1,010 & $1.7 / 10,000$ \\
\hline
\end{tabular}

Notes: $\mathrm{SHC}=$ Secondary health care, $\# \mathrm{PHC}=$ Primary health care, $\mathrm{DH}=$ District hospital, $\mathrm{Pop} / \mathrm{PHC}=$ Population / primary health care facility

All of the sample private facilities were licensed to operate 10 beds, except two in Naogaon which had 20 beds permission. The following three factors were commonly considered for private facility-site selection: availability of specialist doctors, higher income groups, and transport facilities.

\section{Prioritization of healthcare needs and interventions}

Nearly $82 \%$ of the public sector respondents commented that the PHC system is wellstructured. All public respondents remarked that health promotion with limited curative services is the key objective of the PHC system. However, approximately $64 \%$ of the public and $90 \%$ of the private sector respondents stated that curative rather than preventive services were the primary demand of the population. All private respondents reported that they were not providing preventive services of public interest such as the expanded programme on immunization (EPI). Of them, $85 \%$ stated that preventive services are not profitable; while $30 \%$ suggested public support for preventive services.

\section{Human and material resources management}

Serious shortage of human resources was commonly reported by both the public and private respondents. Nearly $62 \%$ of the public doctors' posts were identified vacant. Vacancies were found directly related to the remoteness of facilities (Table 3 ). The following were the underlying factors of doctor shortage in rural facilities as reported by 
the public respondents: lack of suitable working and living facilities (91\%), low salary and non-provision of incentives (91\%), insufficient recruitment (95\%), political influence for transferring doctors (91\%) and lack of local authority's power to deploy and transfer doctors (82\%).

In the private sector, $90 \%$ of respondents reported difficulties to employ full-time doctors and $60 \%$ reported the same for nurses. Notably, these are the key requirements for issuing and renewal of private facility license. Lack of skilled man-power and high expenses of employing skilled manpower were the underlying causes mentioned by $90 \%$ and $60 \%$ private respondents respectively. Remarkably, $70 \%$ of private respondents complained that the private facility licensing/accreditation criteria for human resources would also disqualify public facilities, thus creating a double standard causing discrimination and dissatisfaction in this mixed healthcare sector.

Table 3: Reported number of sanctioned and deployed, and calculated proportions of vacancies in the posts of the public doctors at three different types of facilities in the sample districts as of 2012 (Sources: Civil Surgeon Office (CSO), 2013a; CSO, 2013b \& CSO, 2013c)

\begin{tabular}{|c|c|c|c|c|c|c|c|c|c|}
\hline \multirow[t]{2}{*}{ Districts } & \multicolumn{3}{|c|}{ USC } & \multicolumn{3}{|c|}{ UHC } & \multicolumn{3}{|c|}{ District hospital } \\
\hline & San. & Dep. & Vac. (\%) & San. & Dep. & Vac. (\%) & San. & Dep. & Vac. (\%) \\
\hline Gaibandha & 85 & 32 & 62 & 57 & 37 & 35 & 22 & 18 & 18 \\
\hline Naogaon & 103 & 19 & 81 & 165 & 41 & 75 & 19 & 19 & 0 \\
\hline Joypurhat & 33 & 8 & 76 & 61 & 23 & 62 & 43 & 30 & 30 \\
\hline Total & 221 & 59 & $73^{*}$ & 283 & 101 & $64^{*}$ & 84 & 67 & $20 *$ \\
\hline
\end{tabular}

Notes: USC = Union sub-centre; UHC = Upazilla Health Complex; San. = Sanctioned; Dep. = Deployed; Vac. = Vacancy; Asterisks $\left({ }^{*}\right)$ indicate average vacancies of the doctors' posts.

Nearly $64 \%$ of the public sector respondents stated that often expensive equipment and medicines were supplied centrally without local requisition and need assessment, resulting in misuse and wastage of resources. All UH\&FPOs evaluated UHCs as materially better equipped than many private facilities to perform surgeries; however, no operations were performed in any UHC except caesarean sections in those with the demand side financing (DSF) programme. Notably, DSF programme has provision of financial incentives to both providers and clients for caesarean as well as normal deliveries (MOHFW, 2012a). Three common barriers were identified: firstly, inefficient posting and deployment of specialist doctors; secondly, uncoordinated or individual interestbased posting of surgeons and anesthesiologists at different facilities to reduce workload in the public and to facilitate private practice; and lastly, work volume or performance was not linked to service benefits for the public doctors but rather the duration of service. Notably, except one, all in-service UH\&FPOs reported non-functioning of XRay machines over months to years. Informal talks revealed the following key reasons: in the public sector, neither efficient use of medical equipment is related to reward nor asset damage to liability rather malfunctioning of the public equipment leads to in- 
crease referral of patients to the private facilities as well as income from private practice. All of the public participants stated that centralizing the authority for maintenance and repair caused delays in repairing ambulances and medical equipment that impedes rural people's equitable access to healthcare. Conversely, maintenance and efficient utilization of resources were revealed as regular activities in the private sector to increase profit within minimum investment as well as survival in the market.

\section{Regulating healthcare costs/prices}

About $91 \%$ of the public respondents reported insufficient budget to meet population healthcare needs. Both rich and poor pay equally the politically decided minimum user fees in the public sector; however, due to shortage of public diagnostic facilities and medicines, clients have to purchase those privately. Strikingly, all participants responded that there was no effective control of pricing for the private market. Though a feeschedule has to be publicly displayed, charges often mismatch the schedule since all private respondents reported their autonomy of fixing prices. They also stated that the prices of the major services e.g. surgeries, are usually fixed by the dual-practitioners. Due to lack of information and cost-capping in the private sector, healthcare prices are commonly agreed through bargaining between clients and providers. We identified the following key factors of defining prices: considering service quality $(60 \%)$, clients' affordability (60\%) and sustainability in the market (80\%); consequently, both cost and quality often are compromised.

Again, it was commonly mentioned that due to the absence of gatekeeping and ineffective referral systems in the public sector, clients enjoy freedom of selecting providers. Additionally, lack of limitation or specification of activities for the specialized and graduate doctors often resulted in inappropriate treatment and poor quality. Out of two payment systems in the private sector, while the itemized-bill often resulted in oversupply including prolonged hospitalization, conversely, total-contract prices resulted in under-supply with early discharge. About $80 \%$ of private respondents stated that return was inadequate mainly because of the high investment and maintenance costs. However, about $95 \%$ of the public health administrators favoured increased price-control in the private market.

\section{Healthcare quality control}

\section{Effects of regulation on process and output:}

Regulation of providers, either prospective or retrospective or both, is information and resource intensive. All public respondents considered the new management information system of the MOHFW as a remarkable initiative that provided a wide range of information of the public sector. However, information about the private market re- 
mains limited due to three key barriers: firstly, shortage of skilled human and financial resources for regulation; secondly, often the license issue/renewal inspection team members are either investors and/or specialized dual-practitioners of the private facilities under inspection; and lastly, double-standard registration of services provided was not uncommon to escape taxation. Continuous Professional Development (CPD), clinical protocols and auditing are crucial process-oriented tools for assessing evidence-based clinical practices and service quality as well. However, all respondents confirmed that these tools were not used, since those indicators are not required for facilities and personnel accreditation.

All public respondents admitted that health care quality was often compromised because of the over-crowded outdoor, emergency and indoor clinics along with serious shortage of manpower. In 2012, the reported average bed occupancy rate in the public facilities was $151.6 \%$. This indicates that the public facilities accommodate beyond their actual capacity. However, $90 \%$ of the private respondents reported non-admission and transfer of emergency patients to public facilities. They mentioned the following reasons: concern for reputation and difficulties in cost reimbursement if a bad outcome resulted.

To assess over or under-supply of services, we compared the frequencies of interventional (e.g. surgeries, caesarean section and normal childbirths) to conservative management in the sample district hospitals and private health facilities. Table 4 shows that number of normal childbirths in district hospitals was nearly 3-times higher than caesarean sections; oppositely, in the private sector number of caesarean sections was nearly 4.5-times more than normal vaginal childbirths. The frequency of caesarean section to normal childbirths in the sample private facilities was significantly higher than in the sample district hospitals $(p<0.001)$. The calculated combined share of the interventional management in the sample private facilities was quite high, $87.6 \%$ of all reported indoor services, but only $13.7 \%$ in the district hospitals $(p<0.001)$ (Table 4).

Table 4: A compare of the distribution of conservative to interventional management of the admitted patients in the sample district hospitals and sample private facilities in 2012

\begin{tabular}{lcccccc}
\hline Facility & Bed capacity & \multicolumn{4}{c}{ Indoor patients } \\
\hline & & CM & \multicolumn{2}{c}{ Interventional management } & Total \\
\cline { 3 - 5 } & & & Surgery & CS & NVC & \\
\hline DH & 300 & 51,676 & 2,974 & 1,346 & 3,871 & 59,867 \\
Pvt. cl/hos. & 220 & 2.565 & 8,390 & 7,999 & 1,791 & 20,745 \\
\hline
\end{tabular}

Notes: $\mathrm{CM}=$ Conservative management; $\mathrm{CS}=$ Caesarean sections; NVC= Normal vaginal childbirths; $\mathrm{DH}=$ District Hospital; Pvt. cl/hos. = Private clinic/hospital

Again, the number of surgeries in the sample private facilities was nearly three times more than in the sample district hospitals, even though, bed capacity in the sample 
district hospitals was nearly 1.4 times more than in the sample private facilities and the same specialized dual practitioners performed the operations in both public and private of facilities.

\section{Relationship among key health care actors}

Central-local power relations in health care:

All public respondents identified the healthcare regulation system as strictly centralized with associated delays in decision making and implementation (95\%), transfer of rural doctors without notifying the local authority (95\%), deployment of doctors not meeting the local needs (95\%) and central policy makers lack knowledge of local health needs (68\%). As a consequence, district and upazilla level public health administrators are trapped between the pressure of the citizens' unmet demands and compliance to the stringent bureaucracy. They recommended gradual administrative decentralization in the above areas to improve rural people's equitable access to healthcare.

Public-private interaction in healthcare:

All private respondents claimed that their contributions to the health sector achievements were not recognized. $80 \%$ of the private respondents identified the Ordinance1982 as outdated and in need of consensus-based amendment. All private respondents favoured shifting of the exclusive public to a public-private mix healthcare regulatory body.

Clients' participation in health care:

Approximately $80 \%$ of the public respondents strongly agreed that the clients' participation in the healthcare regulation had yet to materialize. They mentioned the following key effects of non-participation of clients: population's healthcare demands remain unknown to the policy-makers/providers, and lack of awareness of resource constraints often contributes to clients' high or irrational expectations and results in low levels of satisfaction. Moreover, the communication gap between healthcare authorities and providers often was related to inadequate responsiveness of providers to clients. Ultimately, lack of room for clients' involvement perpetuates mistrust and disturbed provider-client relationship in the healthcare.

\section{DISCUSSION}

The key interest of this study is to describe the district public and market-based private healthcare structure and respective authorities' and owners' opinion regarding their roles and limitations to meet rural people's healthcare needs. The PHC structure of Bangladesh is well organized. However, optimal productive utilization of human and 
material resources of PHC system has yet to be developed to improve the rural people's equitable access to healthcare. There are gaps between healthcare policy decision and implementation. Incoordination, demotivation and non-participation of the key actors of healthcare regulation challenge to achieve health policy objectives.

Uncoordinated promotion and transfer of doctors along with absenteeism indicate inefficiencies in the human resource management in the public healthcare sector, especially at the PHC level. Doctors are demotivated to work in rural facilities. Combined with insufficient employment, there is ineffective regulation to retain doctors at rural areas which is often aggravated by unfair professional politics. Motivational incentives to retain rural doctors are essential, which have been proved effective elsewhere, for example, provision of free housing, equipment and career-path in Romania (Busse et al., 2003) and rural doctors' preference of locum relief incentive and retention payment in Australia (Li et al., 2014). Central allocation of resources without assessing local needs and outcomes seriously damages efficiency. Additionally, prolonged non-functioning of $X$-ray machines and ambulances indicates lack of accountability in managing the public resources. This is associated with low staff morale with personal interest as well as imbalanced power- relations between the central and local public health authorities resulting in incoordination. These findings of technical inefficiency in human and material resources management relating to the intense bottle-necks in the public sector are also consistent with the work of Begum et al. (2000). Efficiencies in resource management in the public sector could be improved by allocating more autonomy to the local level. According to the public respondents' opinion, strategic shift of managerial autonomy to the local authority (e.g. deconcentration) could improve human and material resource management efficiency. Notably, the experiences of decentralization in $\mathrm{Vi}$ etnam, Indonesia and Philippines show encouraging results in some services but no change in others. However, Leonard et al. (2013) \& Lieberman et al., (Undated) suggest that decentralization needs to be institutionalized and for making the mechanism effective, formal and value-led informal actors' representation in the decentralized unit is crucial for making strategic decisions about organizational rules, norms, values and incentives aiming to shape the market actors behaviour. Again, evidence shows that if incentives are not related to workload and accountability, they may induce absenteeism, weak motivation to work hard and a tendency to find extra income sources (Mills and Ranson, 2001, p.515 - 559). Therefore, provision of performance-based incentives rather than paying by service duration may improve public employees' productivity.

The current licensing process is ineffective in controlling the urban distribution of the private facilities since it is under the control of the private investors. Urban-based facilities and curative care are not cost-effective for rural people. The concentration of the private market in urban areas is an explicit risk of 'supplier-induced demand' that lacks external control. Omissions in the healthcare regulation may have contributed to the higher out-of-pocket payments with consequent impoverishment. The need-based legal 
control over the distribution of private facilities prior establishment e.g. "ex-ante approach" as is practiced in the Netherlands (Busse et al., 2003) along with public-private partnership for achieving public health goals in the private sector may improve the situation. Notably, unlike the public sector, the profit-maximizing private sector remains free from the bureaucratic trap; hence, more efficient in cost-containment. However, cost containment in the private sector is often linked with employing unskilled rather than skilled workforces, which contradicts the license issuing or renewal rules and compromises service quality.

Cost and quality control and trust-building in this public-private mixed healthcare system are crucial achieving effectiveness of regulation. In the public sector, clients irrespective of socio-economic strata have to pay equally. Because of this regressive payment system, inequity exists in the public sector. Health is treated as a commodity in the private market where information asymmetry, profit maximization and the absence of an anti-trust system enhance the threats of cost-shifting, inappropriate over-supply with consequent health and economic damage. Moreover, since costs and quality are often compromised, consumers' right to quality care is sacrificed by business interests. Further, non-participation of consumers in an organizational structure and the absence of consumer associations inhibit service efficiency and quality control, and impact on consumers' voice, trust and satisfaction in healthcare. Institutionalization of consumers' participation; thus, voice in healthcare along with system of signalling quality-ranking of providers and facilities is potentially effective in preventing market imperfection and improving health and economic wellbeing of the vulnerable population (Leonard et al., 2013; Ensor \& Weinzierl, 2007).

Providers' and facilities' performance in terms of service quality and volume are commonly assessed and controlled by accreditation. The traditional private facilities license renewal process does not ensure the competence of providers. Therefore, publicly disseminating providers' quality ratings is unrealistic; as a consequence, consumers lack correct choice of providers.

Out of all inpatient services, conservative management in the sample private facilities is approximately 7-times higher than in the sample district hospitals. Moreover, the reported ratio of caesarean to normal delivery in the sample private facilities is quite high (nearly 4.6), which is clearly alarming in terms of the consumers' health and economic consequences. Again, 3-times more surgeries in the sample private facilities with nearly 1.4-folds lower bed $(n=220$ ) capacity than in the sample district hospitals ( $n=300$ ) is also noticeable since service providers are the same public dual practitioners. Further, the involvement of the regulatory team members with the private market often results in nominal control over the private market; hence, ineffective in harnessing of market. These findings warrant further empirical exploration of the underlying influences, which are implicit but not impractical in this mixed-provision of healthcare, such as the rela- 
tion between income-interest of dual practitioners and higher conservative management in the public with strategic shifting of patients to private facilities. Noticeably, an average bed occupancy rate in the sample public facilities is approximately 1.5-times higher than bed capacity which indicates that the demands for the public facilities exist.

The evidence-based prospective and retrospective process-oriented accreditation practice as present in Germany and the UK (Busse et al., 2003) could be effective to improve quality of care and providers' responsiveness. However, wide public-private representation in the accreditation team, skills of the members, financial sustainability and a defined set of standard care are the prerequisites for effective accreditation. The experiences in Mumbai (Nandraj, 1999) and Zambia (Bukonda et al. 2002) suggest that a regulatory team including government, non-government, consumer, and provider participation can be effective. However, sufficient legal authority to implement either rewards or sanction for standard or poor performance respectively along with financial support is crucial for the team (Ensor \& Weinzierl, 2007).

According to the public respondents' statement, because of the stringent bureaucracy, compliance with administrative procedures and satisfaction of all key stakeholders in the public health sector are mutually exclusive. However, the hierarchical power gradient does not affect the private market because of the outdated regulatory ordinance and public regulators' interests as private entrepreneurs or providers. Even so, private providers perceive it as unfair that their contribution in the healthcare is not recognized; hence, they are dissatisfied too.

\section{Strengths and limitations}

No earlier study was traced that included district level public and private healthcare administrators in Bangladesh. The relatively low response rate along with lack of opportunity to validate the data of the private sector, together with the selection of only three of 64 districts, limits generalizability of the findings. However, since this is a descriptive exploratory study and a unitary centralized healthcare regulation exists in a relatively homogenous socio-demographic context, this study is expected to be effective in describing needs for strategic regulatory reform. The practical experience-based information from the local healthcare authorities is a strength of this study. In a strong bureaucratic institutional culture with its practices at all levels of the public healthcare regulatory system, the open-secret notion of systematic corruption could not be explored. Probing into subjective opinions of both clients and providers is crucial for an indepth assessment of the effectiveness of the healthcare regulation that was beyond this study. 


\section{CONCLUSION}

Inefficiency is a major issue in the healthcare system of Bangladesh. While the public segment of this OPP-model of the healthcare system does not provide adequate services to the poor, the rapidly growing market-based private segment aims to maximize profit. To increase rural people's access to healthcare, improvement in the regulatory efficiency for using the available PHC resources is more important than increase in the resource allocation. However, prevention of information asymmetry and unhealthy competition in private market are high priority. Inequity rules the healthcare sector of the country. Although the private market supplements the public inadequacy of healthcare coverage, the economic consequence is that the majority of clients in this mixed market are at the potential risk of impoverishment. Power imbalance among the players with consequent dissatisfaction thrives on the inadequately effective healthcare regulation. Implementation of evidence-based regulatory practices elsewhere in the world is essential to improve the healthcare delivery system.

To improve rural people's equitable access to healthcare, reform in health system regulation is needed. A strategic administrative decentralization would reduce central-local power gaps and improve efficiency of resources management in the public sector. An independent district healthcare inspection team including public and private sector representations is essential for evaluating private providers' performance; accordingly, implementing reinforcement-based (i.e. reward and sanction) regulation along with channeling a provider-rating system would improve private market actors' compliance and reduce threats of market failure. Provision of both financial and non-financial incentives is recommended to retain doctors in the PHC facilities. A consensus and evidencebased amendment to the Ordinance-1982 involving all key actors is also a high priority. Rural clients' feedback mechanism has to be in place to improve their voice; thereby, their health and economic wellbeing as well. 


\section{REFERENCES}

Ahmed, S. (2008). Bangladesh and Global Economy: Does Bangladesh Keep Pace with Economic Globalization. Retrieved from http://orp.aiub.edu/WorkingPaper/WorkingPaper.aspx?year=2008 [Accessed 30/06/2013].

Andaleeb, S. S., Siddiqui, N. \& Khandakar, S. (2007). Patient satisfaction with health services in Bangladesh, Health Policy and Planning. 22, pp. 263-273.

BBS. (2013a). District Statistics 2011, Gaibandha. Retrieved from http://www.bbs.gov.bd/WebTestApplica tion/userfiles/Image/District\%20Statistics/Gaibandha.pdf [Accessed 28/08/2014].

BBS. (2013b). District Statistics 2011, Naogaon. Retrieved from http://www.bbs.gov.bd/WebTestApplication/ userfiles/Image/District\%20Statistics/Naogaon.pdf [Accessed 28/08/2014].

BBS (2013c). District Statistics 2011, Joypurhat. Retrieved from http://www.bbs.gov.bd/WebTestApplication/ userfiles/Image/District\%20Statistics/Joypurhat.pdf [Accessed 28/08/2014].

Barkat, A. \& Maksud, A.K.M. (2003). Private Sector Health Services in Bangladesh: An Exploratory Study. Retrieved from http://www.hdrcbd.com/pcs_pdf/1.\%20Health/ 15.\%20Private\%20Sector\%20Health\%20 Services\%20in\%20Bangladesh_\%20An\%20Exploratory\%20Study.pdf [Accessed 15/01/2014].

Beaz-Camargo, C. \& Jacobs, E. (2011) A framework to assess governance of health systems in low income countries. Retrieved from. http://www.baselgovernance.org/fileadmin/docs/publications/working_pa pers/Governance_of_Health_Systems.pdf [Accessed 20/12/2013].

Begum, S.A., Ensor, T. \& Dave-Sen, P. (2000) The public-private mix in health care in Bangladesh . Retrieved from http://www.heu.gov.bd/phocadownload/ Research\%20 Note\%20No.17.pdf [Accessed 10/05/2013].

Bukonda, N., Tavrow, P., Abdallah, H. et al. (2002) Implementing a national hospital accreditation program: The Zambian experience, International Journal for Quality in Health Care. 14(Supplement 1), pp. 7-16.

Busse, R., Hafez-Afifi, N., \& Harding, A. (2003) Regulation of Health Services. In: Harding, A., \& Perker, A.S. (eds) Private Participation in Health Services. Retrieved from http://books.google.com.bd/books? $\mathrm{id}=\mathrm{bZ}$ wasbxXSAC\&printsec=frontcover\&source=gbs_ge_summary_r\&cad=0\#v=onepage\&q\&f=true [Accessed 13/05/2013].

Chowdhury, A.M.R., Bhuiya, A., Chowdhury, M.E. et al. (2013). The Bangladesh paradox: exceptional health achievement despite economic poverty, Lancet. (382), PP. 1734-45.

Civil Surgeon Office. (2013a). Ministry of Health and Family Welfare, District Health Bulletin 2012, Gaibandha district: The Stationery Office.

Civil Surgeon Office. (2013b). Ministry of Health and Family Welfare, District Health Bulletin 2012, Naogaon district: The Stationery Office.

Civil Surgeon Office. (2013c). Ministry of Health and Family Welfare, District Health Bulletin 2012, Joypurhat district: The Stationery Office.

Directorate General of Health Services. (2002). Accreditation: Private hospitals/clinics, X-Ray and diagnostic laboratories. Dhaka: The Stationery Office.

Econex. (2011). National Health Systems: Public Service vs. Insurance-Based Models. Retrieved from http://www.econex.co.za/index.php?option=com_docman \&task=doc_download\&gid=89\&ltemid=60 [Accessed 23/02/2014].

Ensor, T. \& Weinzierl, S. (2007). Regulating health care in low- and middle-income countries: Broadening the policy response in resource constrained environments, Social Science \& Medicine. 65, pp. 355-366.

Leonard, D.K., Bloom, G., Hanson, H. et al. (2013). Institutional Solutions to the Asymmetric Information Problem in Health and Development Services for the Poor, World Development. 48, pp.71-87.

Lewis, M. (2006). Governance and Corruption in Public Health Care Systems Retrieved from http://www.cgdev.org/sites/default/files/5967_file_WP_78.pdf [Accessed 10/08/2013].

Li, J., Scott, A., McGrail, M. et al. (2014). Retaining rural doctors: Doctors' preferences for rural medical workforce incentives, Social Science \& Medicine. 121, pp. 56-64. 
Lieberman, S.S., Capuno, J.J. \& Minh, H.V. (Undated). Decentralizing Health: Lessons from Indonesia, the Philippines, and Vietnam. Retrieved from http://siteresources.worldbank.org/ INTEAPDECEN/Resources/ Chapter-8.pdf [Accessed 24/08/2015].

Mills, A.J. \& Ranson, M.K. (2001, p.515 - 559). The design of health systems. In: Merson, M.H., Black, R.E. and Mills, A.J. International Public Health. USA: Aspen Publishers.

MOHFW. (2012a). Health Bulletin 2012, Bangladesh. Retrieved from http://dghs.gov.bd/bn/licts_file/images/ Health_Bulletin/HealthBulletin2012_en.php [Accessed 13/05/2013].

MOHFW. (2012b). National Health Policy-2011, Bangladesh. Retrieved from http://www.mohfw.gov.bd/ index.php?option=com_docman\&task=doc_download\&gid=1475\&lang=en [Accessed 13/09/2013].

Nandraj, S. (1999). Self-regulation of hospitals: A private sector initiative in Mumbai City, India, QA Brief. 8(2), pp.18-20.

Walshe, K. (2002). The rise of regulation in the NHS, BMJ. 324, pp. 967-70.

WHO. (2011). Bangladesh - national expenditure on health. Retrieved from http://www.who.int/nha/ country/bgd.pdf [Accessed 06/09/2013].

WHO. (2010). Health system in Bangladesh. Retrieved from http://www.ban.searo.who.int/en/Section25.htm [Accessed 07/07/2013].

WHO. (2000). The World Health Report 2000, Health Systems: Improving Performance. Retrieved from http://www.who.int/whr/2000/en/ [Accessed 20/12/2013].

Witter, S. (2000, p.5-6). Introduction to health economics. In: Witter, S., Ensor, T., Jowett, M. and Thompson, $\mathrm{R}$ (eds). Health Economics for Developing Countries. Oxford: Macmillan Publishers Limited.

World Bank. (2013). World Development Indicators: Poverty rates at national poverty lines Retrieved from http://wdi.worldbank.org/table/2.7 [Accessed 10/08/2013].

World Bank. (2003). Bangladesh - Private sector assessment for health, nutrition and population (HNP) in Bangladesh. Retrieved from http://wwwwds.worldbank.org/external/default/WDSContentServer/WDSP/ IB/2003/12/23/000112742_20031223170041/Rendered/PDF/270050BD.pdf [Accessed 31/08/2013]. 


\section{Chapter}

\section{Predictors and consequences of rural clients' satisfaction level in the district health care system of Bangladesh}

Submitted as:

Roy, A., van der Weijden, T., \& de Vries, N. Predictors and consequences of rural clients' satisfaction level in the district health care system of Bangladesh. 


\section{ABSTRACT}

Introduction: Clients' satisfaction is a common concern across diverse global health systems. We investigated predictors of the rural clients' satisfaction level (CSL), and interlinks between perceived specific service quality (PSSQ), perceived utility value (PUV), CSL, and clients' reactions (CR) towards current and future utilization of providers and facilities in the public-private mixed health system of Bangladesh.

Methods: A quantitative study using interviewer-administered questionnaire was conducted in a remote district interviewing 400 rural patients (public $n=200$; private $n=$ 200). CSL was measured both directly and indirectly. Clients' opinion of PSSQ relating to healthcare structure (tangibility, availability, accessibility) and process features (responsiveness, reliability, empathy, communication and courtesy) were measured for indirectly assessing their satisfaction. PUV and CR were also measured indirectly. 5-point Likert scales were used to measure PSSQ, PUV, CSL and CR. Multiple regression and mediation were the models operated using SPSS version-21.

Results: Clients' satisfaction level was low in both health sectors with significantly lower in the public sector. Accessibility (financial) predicted commonly high variations in CSL both in the public sector (18.2\%) and in the private sector (25.0\%). Availability predicted noticeably high variations in CSL in the public sector (34.6\%). Structural factors predicted higher than process-features in the public sector which was vice versa in the private sector. Clients' reaction was the ultimate outcome of PSSQ mediated through PUV and CSL. PUV mediated the effects of PSSQ on clients' reaction stronger than CSL.

Conclusion: Financial accessibility is a crucial risk of impoverishment in both the public and the private sector. Both structure and process features of healthcare are in ample needs for addressing existing low satisfaction in patients in rural Bangladesh. This study would be a benchmark of healthcare service quality in other districts.

Keywords: Clients' satisfaction; health system; public-private mixed; service quality; utility value; clients' reaction; Bangladesh 


\section{INTRODUCTION}

'Clients' satisfaction' is of central interest for sustainability in the competitive market economy worldwide (Barbier et al., 2013). The emerging market economy is directly related to the privatization and marketization of the health care sector. In a market, clients' satisfaction is a complex phenomenon often influenced by clients' perception of the quality of goods or services in terms of extrinsic (e.g. brand, marketing) and/or intrinsic (e.g. contents) features (Busch, 2008; Zeithaml, 1988). However, clients' (i.e. patients') satisfaction in the healthcare market is a relatively more complex and controversial issue than in other markets because of its loose link to technical quality of health services (Hafez-Affifi et al., 2003). Although Robinson (2005) suggested that patientcentered care is the essence of clients' satisfaction in healthcare, Zeckhauser \& Sommers (2013) argued that it may raise tension and mutual frustration because of the gaps between needs and demands. Further, Crow et al. (2002) highlighted that individual patients' socio-demography with health conditions and choices are also linked to their satisfaction level. The debate on clients' satisfaction has become further complicated in the public-private mixed out-of-pocket payments (OPP) model of health systems, in which individuals or households have to pay either fully or a large part of healthcare costs regardless of affordability. The OPP model health system is common in developing countries and a potential barrier to clients' satisfaction as well as to poverty reduction (Econex, 2011).

While clients' satisfaction is associated with positive social and economic outcomes (Dagger \& Sweeney, 2006) their dissatisfaction may lead to ill health, economic loss, and mistrust between client and provider (Andaleeb et al., 2007). Thus, clients' satisfaction has been identified as a common health, economic and political interest in global health systems and has received substantial attention of policymakers, researchers and academicians over decades.

Among the four constructs of the patients' satisfaction model of Choi et al. (2004), perceived service quality was suggested as the prime cognitive construct influencing perceived utility value (another cognitive construct), satisfaction (an affective construct) and ultimately clients' reactions (a conation) in terms of adherence and ratings to the current treatment and provider, and repurchase intention. Utility value is the clients' perceptions of benefits compared to sacrifices (Crow et al., 2002; Zeithaml, 1988). A widely used definition of clients' satisfaction is the extent to which the service quality meets clients' expectations. Thus, if expectations are greater than the perceived service quality, then clients' dissatisfaction occurs. Expectation is often an outcome of prior experience but also of non-experiential information such as word-of-mouth communication (WOM) and publicity (Fornell et al., 1996). 
Concepts and approaches of measuring clients' satisfaction differ among researchers. A common approach is to measure clients' satisfaction indirectly through assessing their expectations and perceptions of health service quality. Again, due to the limits of health outcomes to measure service quality, often healthcare structure and process features are assessed as indirect indicators of quality (Donabedian, 2005; Crow et al., 2002). Also, a combined direct and indirect measurement of satisfaction is evidenced for investigating interrelationships among clients' perception of service quality, utility value, clients' satisfaction and their ultimate reactions to health care (e.g. Choi et al., 2004). Figure 1 illustrates the conceptual model of the present study.

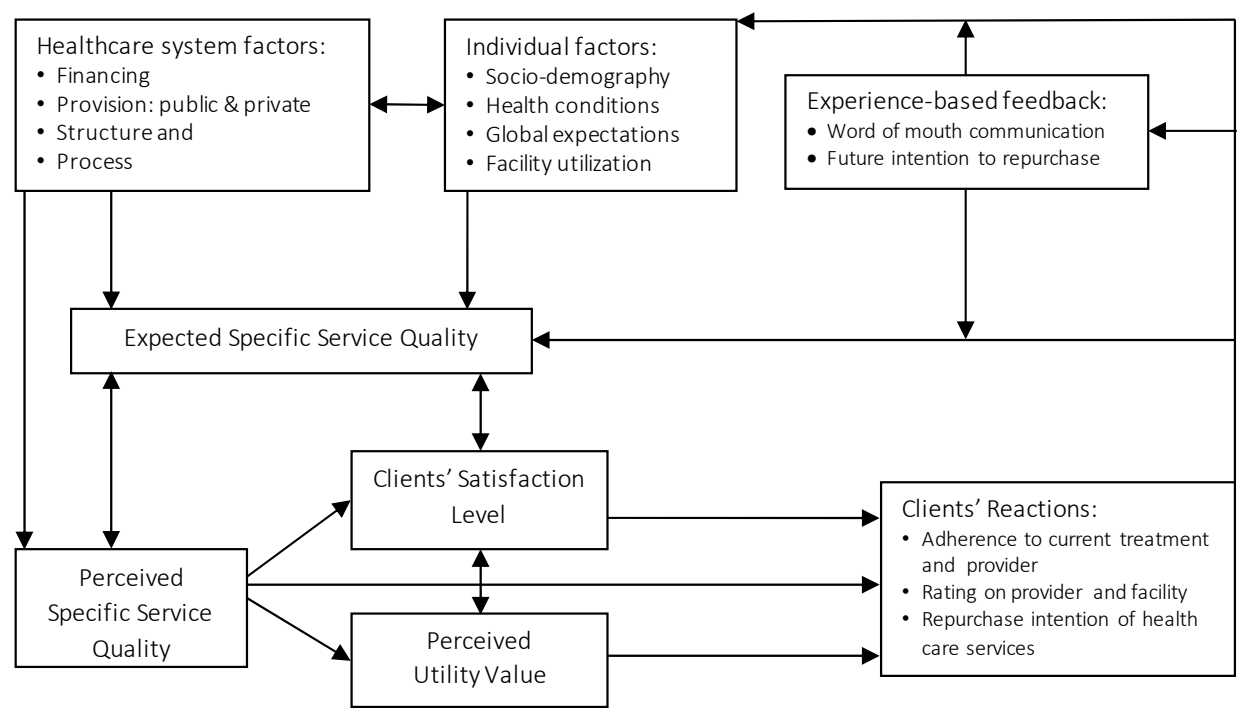

Figure 1: Modified conceptual framework of clients' satisfaction with health care (Sources: Crow et al., 2002; Choi et al., 2004; Patterson \& Spreng, 1997).

In Bangladesh, there is a clear financing distinction between the public and private health sector. Financing in the public health sector is tax and donor funded, that in the formal private sector is market-based (Barkat \& Maksud, 2003). Only public doctors are entitled as health service providers in the public sector and almost all of them are also involved in the private sector as dual-practitioners. Thereby, dual-practitioners and private-only doctors are the care providers in the private sector. In the public sector, clients pay fixed user fees for defined health services such as diagnostics, but other services e.g. surgeries, bed, foods and available medicines are free. Oppositely, in the private sector, clients usually pay fee-for-services for ambulatory cares directly to the private practitioners and for indoor cares they either pay to the facility owners or to the doctors, mostly specialist dual-practitioners. 
Private health expenditure is the larger part, nearly $62 \%$ of total health expenditures, of which $96.6 \%$ is households' out-of-pocket payments (WHO, 2014). Although the costs of the available public health services are far lower than in the private sector, nearly $70 \%$ of all clients and even $75 \%$ of rural clients seek healthcare from the private sector (World Bank, 2003; Barkat \& Maksud, 2003). Notably, nearly 72\% of over 151 million population of Bangladesh are rural dwellers (Ministry of Health and Family Welfare, 2013), of which $35.2 \%$ are below the poverty line (World Bank, 2013). Thus, the burden of healthcare costs on rural people is a major development concern in Bangladesh.

Therefore, identification of the influence of healthcare structure and process-related factors on clients' satisfaction is essential to limit the impending health and economic threats in this public-private mixed OPP-model health system. This study aimed: to identify the key influences of clients' expectations and utilization of the district public and private health facilities; to identify the rural clients' global expectations to the district public and private health sectors; to detect the key factors influencing expected and perceived specific service quality as the predictors of clients' satisfaction in the public and the private health sector, and to assess the relationships between perceived specific service quality, perceived utility value, satisfaction level, and reactions of the clients in the district health system.

\section{METHODOLOGY}

\section{Study design and settings}

A quantitative questionnaire study was conducted in Joypurhat district of Bangladesh. Joypurhat was selected purposively because of the following reasons: firstly, the district's socio-demographic situations match the country's rural settings. Secondly, the public health system performance of Joypurhat is one of the best among all 64 districts (Civil Surgeon Office, 2014). However, performance of the public health facilities is usually assessed comparing service quantity to a global budget. A system of assessing service quality has yet to be developed; thus, findings of this study would be a benchmark of health service quality and clients' satisfaction as well for other districts of the country.

Out of a total 913,768 population in the district, nearly $85 \%$ are rural residents (Bangladesh Bureau of Statistics, 2013). Joypurhat consists of 5 upazillas (i.e. subdistricts). A 150-bedded district hospital (DH) is the secondary level public health facility. An 'upazilla health complex' (UHC) with 50 beds serves as a referral facility of the primary health care (PHC) system of each upazilla. General Physicians and Specialist Doctors are the key service providers of the DH and UHCs. There were fourteen registered private clinics in the district (Civil Surgeon Office, 2014). 


\section{Study population}

The rural patients/clients of Joypurhat district were the target population. General physicians (GPs), internal medicine and general surgery practices usually serve nearly an equal proportion of male and female patients; therefore, those three departments were selected. Presence of qualified doctors along with outdoor and indoor services was considered for the inclusion of the public and private facilities. Accordingly, among the public facilities, the district hospital and four UHCs were selected. In the private sector, ten out of fourteen registered clinics had private practice facilities for GPs, internal medicine specialists and general surgeons along with indoor services; thus, these were approached to participate. Patients of providers who had at least five years of professional experience, aged $\geq 18$ years with good physical and mental fitness to provide valid consent were included.

\section{Sample size and sampling strategy}

A sample size of 400 was estimated using the published sampling table of (Israel, 1992) for an infinite population, $95 \%$ confidence interval, $\pm 5 \%$ precision and $50 \%$ degrees of variability. A convenience sampling method was used to select the rural clients from mixed rural-urban crowds. An equal number of clients were sampled from the public and private health facilities ( $\mathrm{n}=200$ each). Indoor and outdoor patients were also equal ( $n=200$ each). An equal number of clients were sampled from the public primary and secondary level facilities ( $n=100$ each).

The 'probability proportionate to size' sampling method was used to estimate the study units of individual facilities and providers. The total number of registered patients of the sample UHCS in 2015 was used as the sampling frame. No sampling frame was needed for the single district hospital. For the private indoor patients, immediate past one month records of the admitted patients who were treated by the selected doctors were used as the sampling frame and that for the private outdoor patients, seven days records were used. Nearly equal numbers of patients of the selected public doctors were sampled since no doctor-specific patient records were available.

\section{Data collection tools, techniques and quality control}

An interviewer-administered questionnaire was developed containing mostly closed quantitative items. A few qualitative open-ended items also were included; for example, acceptable and experienced approximate waiting time, and sources of health care expenses. Items were mainly based on previous studies. The authors initially amended the tool through discussions. Then a piloting was conducted with 18 clients to confirm the instrument's usability as well as skills of the research assistants. All closed items used 
five-point Likert scales (1=strongly disagree, 2 = disagree, $3=$ neither agree nor disagree, $4=$ agree, $5=$ strongly agree). No further adaptations were needed. The following were the key domains, variables and items of the tool-

Influences of rural clients' expectations and utilization of health facilities:

A semi-structured multi-response scale was used to explore any effects of the clients' past experience, WOM communication, and external communication (e.g. publicity; signboard degrees) on their expectations and utilization of current providers. Clients' global expectations were investigated using an open-ended scale.

Expected and perceived specific service quality:

Expected specific service quality (ESSQ) and perceived specific service quality (PSSQ) were measured using the following identically matched eight variables with twenty one items of the two key domains, i.e. structural and process factors:

\section{Structure related variables and items}

Tangibility: outlook of infrastructure, equipment, and records, and cleanliness; Availability: supply of drugs and diagnostic tests; Accessibility (financial): ability to pay the costs of consultancy, medicines, and diagnostics.

\section{Process related variables and items}

Responsiveness: availability of doctor, and promptness of service delivery; Reliability: doctors' skills, rationale of the advised drugs, and diagnostic tests; Empathy: doctors' attentiveness to patients' problems, concerns of clients' financial situation, and mental supports; Communication: explanation of diagnosis, treatment plan, and prescription; Courtesy: respect to clients, and maintenance of privacy.

Perceived utility value:

Three items were used: I feel physically well after treatment, I appropriately invested money for treatment, and the quality of services was worth more than what I paid.

Direct measure of clients' satisfaction level:

Three items were used: how satisfied were you with the treatment, how satisfied were you with overall dealings of the doctor, and how satisfied were you with the overall services of the hospital/clinic.

Clients' reaction:

Four items were queried: I shall follow the current treatment, I shall recommend others to my doctor, I shall recommend others to use this facility, and I shall use this service in future if I need. 
Three teams each consisting of one male and one female qualified medical assistant with working experience in NGO health projects collected data. All research assistants were given intensive training on data collection with focuses on to reduce information bias and effective communication. The research assistants invited target clients for interviewing while they were either visiting the selected doctors or admitted in sample facilities. Data was collected at least after one to no later than three weeks from the date of the last visit to the doctors or discharge from sample facilities. Respecting clients' choice and privacy, data were collected mostly at home and also in facilities. Informed consent was taken from all respondents. Confidentiality was maintained. Each interview took an average of 40 minutes. Two computer experts entered data and cross-checked each other's work regularly; also the Principal Investigator checked a random sample. Data was collected during August and October 2016.

\section{Statistical analysis}

SPSS (version 21) was used for data processing and analysis. Means and standard deviations of all variables were computed. As recommended by (Nunnally, 1978, p.245), Cronbach's a statistic was used to assess the internal consistency of different scales. Overall internal consistency of the data was acceptable. Cronbach's $\alpha$ of ESSQ and PSSQ variables are presented in Table 1. Alpha statistics for CSL, PUV, and CR were 0.67, 0.65 and 0.67 respectively.

Any significance differences in gap scores in means of PSSQ and ESSQ variables, and mean scores of PUV, CSL and CR in the public and private sectors were tested using independent-samples t-test. Chi-squared test was used finding any differences in the public and private clients' global expectations. Multiple regression models were used identifying predictors of CSL. The interrelationships between PSSQ, PUV, CSL and CR were assessed in simple and multiple mediation models.

Table 1: Cronbach's Alpha of the variables of the perceived specific service quality (PSSQ) and expected specific service quality (ESSQ) domains

\begin{tabular}{lccc}
\hline Variables & \multicolumn{2}{c}{ Cronbach's $\alpha$} & Items \\
\cline { 2 - 3 } & PSSQ & ESSQ & \\
\hline Tangibility & 0.66 & 0.81 & 4 \\
Availability & 0.69 & 0.73 & 2 \\
Accessibility & 0.69 & 0.67 & 3 \\
Responsiveness & 0.79 & 0.81 & 2 \\
Reliability & 0.67 & 0.80 & 3 \\
Empathy & 0.66 & 0.62 & 3 \\
Communication & 0.77 & 0.72 & 2 \\
Courtesy & 0.71 & 0.80 & 2 \\
\hline
\end{tabular}


Risk of biases relating to outliers and assumptions were tested. Normality of residuals was tested using histograms and P-P plots confirmed. Linearity and homoscedasticity were checked with scatterplots of standardized residuals against standardized predicted values and also partial plots. Leverage value and Cook's distance statistics were used to test outliers for predictors and influential outliers (Stevens, 2002). Variance inflation factor and tolerance statistic were used to test multicollinearity (Field, 2014, p.307347). Finally, cross-validity predictive power of the model was tested using Stein's formula (Stevens, 2002). No problems became apparent. The order of block entry in the hierarchical regression approach was based on the gap-scores between the corresponding PSSQ and ESSQ variables; variables with the greater negative gap-values were entered earlier than smaller ones.

The 'causal steps strategy' of (Baron \& Kenny, 1986) was used to test individual paths in the mediation model. As described by Preacher \& Hayes (2008), the Sobel test statistics, i.e. the estimates of the unstandardized indirect effects and their 95\% bias corrected and accelerated bootstrap confidence intervals along with $p$-values, were used to assess mediation. The total indirect effect of multiple mediation was calculated by adding the specific indirect effects of PSSO on CR via PUV and CSL. The kappa-squared $\left(k^{2}\right)$ was used to assess the size of the indirect effects in simple mediation models (Preacher \& Kelley, 2011). Missing data were analyzed using the 'exclude cases listwise' option of SPSS. A $p$-value $<.05$ was considered as significant.

\section{RESULTS}

\section{Sample characteristics}

To interview 400 rural clients, a total of 497 were approached. Extra approaches were required because of following reasons: clients were absent at the given addresses ( $n=$ $11)$, interviews were postponed due to clients' cognitive problems ( $n=13)$, refusal of interview $(n=24)$, and clients outside of the study area $(n=49)$. Patients of a total 37 doctors (public $n=21$; private $n=16$ ) of all the sample public and private facilities participated. The ratio of GPs to Specialists in the public sector was 17:4, which in the private sector was 9:7. Of the 16 private sector doctors, the ratio of private-only to dualpractitioners was 6:10. The ratio of patients with acute to chronic disorders in the public and private sector were 84:116 and 111:89 respectively. Patients from wide sociodemographic characteristics were selected (Table 2). 


\section{Chapter 3}

Table 2: Socio-demographic characteristics of the full sample, public and private clients

\begin{tabular}{|c|c|c|c|}
\hline $\begin{array}{l}\text { Variable } \\
\text { Categories }\end{array}$ & $\begin{array}{l}\text { Full sample } \\
(\mathrm{n}=400) \\
\text { Number }(\%)\end{array}$ & $\begin{array}{l}\text { Public } \\
(n=200) \\
\text { Number }(\%)\end{array}$ & $\begin{array}{l}\text { Private } \\
(\mathrm{n}=200) \\
\text { Number }(\%)\end{array}$ \\
\hline \multicolumn{4}{|l|}{ Age (in years) } \\
\hline $18-<30$ & $81(20.25)$ & $35(17.5)$ & $46(23.0)$ \\
\hline $30-<40$ & $84(21.0)$ & $46(23.0)$ & $38(19.0)$ \\
\hline $40-<50$ & $109(27.25)$ & $60(30.0)$ & $49(24.5)$ \\
\hline $50-<60$ & $64(16.0)$ & $28(14.0)$ & $36(18.0)$ \\
\hline$>60$ & $62(15.5)$ & $31(15.5)$ & $31(15.5)$ \\
\hline \multicolumn{4}{|l|}{ Sex } \\
\hline Male & $218(54.5)$ & $110(55.0)$ & $108(54.0)$ \\
\hline Female & $182(45.5)$ & $90(45.0)$ & $92(46.0)$ \\
\hline \multicolumn{4}{|l|}{ Marital Status } \\
\hline Married & 309 (77.25) & $157(78.5)$ & $152(76.0)$ \\
\hline Unmarried & $32(8.0)$ & $11(5.5)$ & $21(10.5)$ \\
\hline Widowed & $18(4.5)$ & $10(5.0)$ & $8(4.0)$ \\
\hline Others & $41(10.25)$ & $22(11.0)$ & $19(9.5)$ \\
\hline \multicolumn{4}{|l|}{ Educational status } \\
\hline Illiterate & $91(23.0)$ & $61(30.5)$ & $30(15.0)$ \\
\hline Primary level & $132(33.0)$ & $81(40.5)$ & $51(25.5)$ \\
\hline High school level & $112(28.0)$ & $44(22.0)$ & $68(34.0)$ \\
\hline Above high school level & $65(16.0)$ & $14(7.0)$ & $51(25.5)$ \\
\hline \multicolumn{4}{|l|}{ Monthly income (Taka) } \\
\hline$<3,000$ & $26(6.5)$ & $23(11.5)$ & $3(1.5)$ \\
\hline $3,000-<7,000$ & $155(38.75)$ & $103(51.5)$ & $52(26.0)$ \\
\hline $7,000-<15,000$ & $130(32.5)$ & $54(27.0)$ & $76(38.0)$ \\
\hline$>15,000$ & $89(22.25)$ & $20(10.0)$ & $69(34.5)$ \\
\hline \multicolumn{4}{|l|}{ Occupation } \\
\hline Housewife & $112(28.0)$ & $52(26.0)$ & $60(30.0)$ \\
\hline Farming & $128(32.0)$ & $73(36.5)$ & $55(27.5)$ \\
\hline Day-labour & $36(9.0)$ & $27(13.5)$ & $9(4.5)$ \\
\hline Business & $53(13.25)$ & $17(8.5)$ & $36(18.0)$ \\
\hline Official job & $29(7.25)$ & $8(4.0)$ & $21(10.5)$ \\
\hline Others & $42(10.5)$ & $23(11.5)$ & $19(9.5)$ \\
\hline \multicolumn{4}{|l|}{ Housing condition } \\
\hline $\begin{array}{l}\text { Muddy wall with grass- } \\
\text { shade }\end{array}$ & $85(21.25)$ & $49(24.5)$ & $36(18.0)$ \\
\hline $\begin{array}{l}\text { Muddy wall with tin- } \\
\text { shade }\end{array}$ & $89(22.25)$ & $48(24.0)$ & $41(20.5)$ \\
\hline Brick-wall with tin-shade & $166(41.5)$ & $77(38.5)$ & $89(44.5)$ \\
\hline Concrete building & $60(15.0)$ & $26(13.0)$ & $34(17.0)$ \\
\hline
\end{tabular}




\section{Influences of clients' expectations and health facility utilization}

Whereas cheap healthcare costs and geographic accessibility were the factors unique for the public clients' expectations and facility utilization, which in the private clients were external communications, specifically publicity. There were significant differences in effects of 'WOM-communication' and 'past pleasant experiences' on constructing the public and private clients' expectations and choice of utilizing facility with higher odds ratios for the private clients (Table 3 ).

Table 3: Frequencies of the factors influence on the public and private clients' expectation and utilization of health facilities with chi-square statistics

\begin{tabular}{|c|c|c|c|}
\hline Factors & $\begin{array}{l}\text { Public } \\
n=200(\%)\end{array}$ & $\begin{array}{l}\text { Private } \\
n=200(\%)\end{array}$ & $\begin{array}{l}X^{2} ; p \text {-value; odds ratio } \\
(\mathrm{n}=400 ; \mathrm{df}=1)\end{array}$ \\
\hline *Past pleasant experience & $38(19.0)$ & $60(30.0)$ & $6.54 ; .01 ; 1.83$ \\
\hline *WOM-communication & $52(26.0)$ & 119 (59.5) & $45.85 ;<.001 ; 4.18$ \\
\hline Cheap health care cost & $132(66.0)$ & - & - \\
\hline Near-home health facility & $58(29.0)$ & - & - \\
\hline \multicolumn{4}{|l|}{ External communication } \\
\hline Publicity & - & 99 (49.5) & - \\
\hline Signboard degree & - & $23(11.5)$ & - \\
\hline
\end{tabular}

Notes: Asterisk $\left({ }^{*}\right)$ indicates significant difference; WOM $=$ Word of mouth; $X^{2}=$ Pearson's Chi-Square statistics; $\mathrm{df}=$ degrees of freedom

\section{Clients' global expectations}

Availability of common drugs and diagnostics, and free treatment were the most frequent and significantly differentiating global expectations for public clients' to the health sector. Affordable treatment was a highly frequent global expectation in both sectors but significantly higher in the private clients. Attentiveness and good behavior were markedly high expectations in both sectors without significant differences. However, quick service delivery, providers' skills and trustworthy treatment were significantly higher expectations in the private than in the public clients (Table 4). 
Table 4: Frequencies of clients' global expectations to the health care sectors and providers with chi-square statistics

\begin{tabular}{llll}
\hline $\begin{array}{l}\text { Domain } \\
\text { Variable }\end{array}$ & $\begin{array}{l}\text { Public } \\
\mathrm{n}=200(\%)\end{array}$ & $\begin{array}{l}\text { Private } \\
\mathrm{n}=200(\%)\end{array}$ & $\begin{array}{l}\mathrm{X}^{2} ; p \text {-value; odds ratio } \\
(\mathrm{n}=400 ; \mathrm{df}=1)\end{array}$ \\
\hline $\begin{array}{lll}\text { Global expectations to health sector } \\
\text { Free treatment }\end{array}$ & $68(34.0)$ & $0(0)$ & - \\
*Affordable treatment & $101(50.5)$ & $131(65.5)$ & $9.24 ; .002 ; 1.86^{\circledR}$ \\
*Availability of common diagnostics & $109(54.5)$ & $42(21.0)$ & $47.76 ;<.001 ; 0.22 \ddagger$ \\
*Availability of drugs & $97(48.5)$ & $10(5.0)$ & $96.57 ;<.001 ; 0.05 \ddagger$ \\
Cleanliness & $23(11.5)$ & $34(17.0)$ & $2.48 ; .11 ; 1.57^{\circledR}$ \\
Others & $10(5.0)$ & $14(7.0)$ & $0.71 ; .39 ; 1.43^{\circledR}$ \\
Global expectations to providers & & & \\
Attentiveness & $150(75)$ & $158(79)$ & $0.9 ; .34 ; 1.25^{\circledR}$ \\
Good behaviour & $60(30.0)$ & $75(37.5)$ & $2.52 ; .11 ; 1.40^{\circledR}$ \\
*Skills & $19(9.5)$ & $35(17.5)$ & $5.48 ; .02 ; 2.02^{\circledR}$ \\
*Quick service delivery & $52(26.0)$ & $82(41.0)$ & $10.1 ; .001 ; 1.97^{\circledR}$ \\
*Trustworthy treatment & $24(12.0)$ & $78(39.0)$ & $38.37 ;<.001 ; 4.69^{\circledR}$ \\
Others & $7(3.5)$ & $5(2.5)$ & $0.34 ; .55 ; 0.70 \ddagger$ \\
\hline
\end{tabular}

Notes: (Asterisks) ${ }^{*}=$ significant difference; ${ }^{\circledR}=$ higher odds in the private; $\neq=$ higher odds in the public; $X^{2}=$ Pearson's Chi-square statistics; $d f=$ degrees of freedom.

Clients' expectations and perceptions of specific service quality, satisfaction level, utility value and reactions

The overall means of the perceived specific service quality (PSSQ) domain in the full sample, public and private clients were clearly above the neutral value 3 of the fivepoint scale. The overall means of the expected specific service quality (ESSO) variables across the client groups were nearly identical but markedly greater than that of the matched PSSQ variables. The overall mean gaps in PSSQ and ESSQ were negative which in the public was nearly 1.5-times larger than in the private clients; the difference was significant $[t(373.27)=-6.80, p=<.001$, two-tailed] (Table 5). 
Table 5: Descriptive statistics including SERVIQUAL gap scores of the public and private samples

\begin{tabular}{|c|c|c|c|c|c|c|}
\hline \multirow[t]{2}{*}{ Variables } & \multicolumn{3}{|c|}{ Public client $(n=200)$} & \multicolumn{3}{|c|}{ Private client $(n=200)$} \\
\hline & $\begin{array}{l}\text { Mean ESSQ } \\
( \pm S D)\end{array}$ & $\begin{array}{l}\text { Mean PSSQ } \\
( \pm S D)\end{array}$ & Gap score & $\begin{array}{l}\text { Mean ESSQ } \\
( \pm S D)\end{array}$ & $\begin{array}{l}\text { Mean PSSQ } \\
( \pm S D)\end{array}$ & Gap score \\
\hline Tangibility & $4.22(0.33)$ & $3.39(0.53)$ & -0.83 & $4.60(0.39)$ & $3.82(0.37)$ & -0.78 \\
\hline Availability* & $4.95(0.18)$ & $3.05(0.62)$ & -1.90 & $4.86(0.30)$ & $4.21(0.36)$ & -0.65 \\
\hline Accessibility* & $4.92(0.21)$ & $3.62(0.41)$ & -1.30 & $4.92(0.19)$ & $3.78(0.57)$ & -1.14 \\
\hline Responsiveness* & $4.55(0.45)$ & 3.31 (0.99) & -1.24 & $4.57(0.44)$ & $3.71(0.89)$ & -0.86 \\
\hline Reliability & $4.84(0.31)$ & $3.86(0.54)$ & -0.98 & $4.94(0.17)$ & $3.98(0.54)$ & -0.96 \\
\hline Empathy & $4.67(0.34)$ & $3.68(0.61)$ & -0.99 & $4.71(0.33)$ & $3.80(0.45)$ & -0.91 \\
\hline Communication* & $4.25(0.43)$ & $3.22(0.80)$ & -1.03 & $4.26(0.48)$ & $3.69(0.72)$ & -0.57 \\
\hline Courtesy* & $4.57(0.47)$ & $3.74(0.64)$ & -0.83 & $4.79(0.35)$ & $4.26(0.53)$ & -0.53 \\
\hline Grand* mean & $4.62(0.18)$ & $3.48(0.52)$ & -1.14 & $4.71(0.18)$ & $3.91(0.36)$ & -0.80 \\
\hline
\end{tabular}

Notes: Asterisks $\left({ }^{*}\right)$ indicate variables with significant differences (two-tailed) in PSSQ and ESSQ gap-scores between the public and private sectors based on independent-samples t-tests. PSSQ = Perceived specific service quality; ESSQ = Expected specific service quality; SD = Standard deviation; GS / CSL = Gap score / clients' satisfaction level; (N.B.: the gap scores are the values produced by subtracting the means of the corresponding variables of the ESSQ domain from that of the PSSQ domain).

Means of clients' satisfaction level (CSL) in the full sample, public and private clients also were fairly higher than the neutral value, $3.51( \pm 0.49), 3.36( \pm 0.47)$ and $3.68( \pm 0.44)$ respectively. By definition the negative gaps between the means of ESSQ and PSSQ variables across the client groups imply dissatisfaction; however, since the overall means of PSSQ and CSL were fairly greater than neutral value, we conjecture it as 'clients' low satisfaction level' (synonymous to CSL). There was significant difference in mean scores of CSL for the public and private sector; $t$ (398) $=-7.00, p=<.001$ (twotailed).

The mean $( \pm$ SD) of PUV in the full sample was $3.87( \pm 0.48)$, that in the public and private clients were $3.73( \pm 0.52)$ and $4.03( \pm 0.37)$ respectively. In the total sample, perceived benefit (i.e. I feel in better health condition than before) scored notably higher $(3.83 \pm 0.67)$ than the neutral value. Client's reaction $(C R)$ in the full sample, public and private clients scored nearly equally, i.e. $3.68,3.58$ and 3.78 respectively. There were significant differences in mean scores in the public and private sectors for PUV $[t$ $(355.68)=-6.69, p=<.001]$ and CR $[t(395.65)=-5.10, p=<.001]$; two-tailed.

Overall, the sources of covering healthcare costs were as follows: self-financing- $66.8 \%$, NGOs (microcredit)/bank loans with interest- 6.3\%, debts without interest- $13.6 \%$, selling household goods- $8 \%$, and community philanthropy- $5.3 \%$. Selling household goods in private clients was nearly twice more frequent than in the public clients; oppositely, community philanthropy was 2.5 -times higher in the public than in the private clients.

The acceptable waiting-time (i.e. client-estimated time-gap between enlisting and meeting the doctor for treatment) was nearly identical for public ( $38 \pm 13$ minutes) and 
private clients (36 \pm 12 minutes). The average waiting-time was also nearly similar in the private (74 \pm 53 minutes) and in the public sector (72 \pm 48 minutes) and both were nearly double the accepted level. Notably, the range of waiting-time was markedly higher in the private (230 minutes) than in the public sector (175 minutes). Expected consulting-time in the private was marginally longer than in the public sector, nearly15 $( \pm 4)$ and $12( \pm 3)$ minutes respectively. Average perceived consulting-time was nearly 2times shorter in the public $(5.8 \pm 2.5$ minutes) than in the private sector $(10.6 \pm 4.4$ minutes) and both were clearly shorter than the expectation.

Inferential statistics: multiple regression of CSL

Normality of residuals, linearity and homoscedasticity were confirmed. The concerns of the influential outliers, independent error and multicollinearity were excluded.

Evaluating the model goodness-of-fit and model parameters:

Overall, $R^{2}$ in the public and private clients were notably high (Table 6). F-ratios in the final model for the public clients was $\left(F_{8,191}=2.12 ; p=<.001\right)$ and for the private clients was $\left(F_{8,191}=16.75 ; p=<.001\right)$ (Appendix 1\&2). The average adjusted values in the public and private clients were very close to the $R^{2}$ values (Table 6 ). This signifies a fairly high cross-validation predictive power of the model.

Beta-values in the final models of the full sample, public, and private clients were positive indicating the direct relationships among PSSQ variables and CSL. In the private client model, none of the $95 \% \mathrm{Cls}$ of $b$-values included zero and all $p$-values were <.05 indicating all predictors had statistically significant contributions to the model. However, 95\% Cls for availability, responsiveness, tangibility, and courtesy variables in the public clients included zero after entering reliability, tangibility and courtesy in the models 6,7 and 8 respectively, indicating they do not add to the prediction but overlap with the other variables (Appendix 1\&2).

Whereas availability and accessibility predicted over $73 \%$ of the variance explained in CSL for public clients, nearly $91 \%$ of explained variance for private clients was explained by accessibility, responsiveness, empathy and reliability. In the public clients, availability was the strongest predictor of CSL, among private clients it was the weakest. Accessibility was an important predictor in both client groups. Remarkably, reliability predicted incomparably high, over 13-times higher variations in CSL in private than in public clients (Table 6). 
Table 6: Proportions of the variation in the clients' satisfaction level with cross validity predictive power of multiple regression models in the public and private sector

\begin{tabular}{lcc}
\hline *PSSQ variable & Public & Private \\
\hline Availability & $34.6 \%$ & $0.2 \%$ \\
Accessibility & $18.2 \%$ & $25.0 \%$ \\
Responsiveness & $7.7 \%$ & $12.7 \%$ \\
Empathy & $5.0 \%$ & $14.8 \%$ \\
Communication & $4.9 \%$ & $2.3 \%$ \\
Reliability & $1.2 \%$ & $15.8 \%$ \\
Tangibility & $0.3 \%$ & $4.5 \%$ \\
Courtesy & $0.3 \%$ & $2.0 \%$ \\
Overall cross-validity: & & \\
Stein's formula statistic & 0.696 & 0.752 \\
$\left(R^{2}\right.$ value $)$ & $(0.722)$ & $(0.773)$ \\
\hline
\end{tabular}

Note: *PSSQ stands for perceived specific service quality.

\section{Inferential statistics: mediation}

Significant mediation effects were found in all the simple mediation models (Figure 2: A, $B, C \& D)$. The indirect effect of the PSSQ on CSL via PUV was small with a $k^{2}$-statistic indicating only $10.5 \%$ of the maximum possible indirect effect (Figure 2: A) and that for PUV on CR via CSL was markedly large having a $k^{2}$-statistic indicating $23.4 \%$ of the maximum possible indirect effect (Figure 2: B). The indirect effect of PSSQ on CR via PUV was larger than the indirect effect via CSL with $k^{2}$-statistics representing $18.1 \%$ and $11.4 \%$ of the maximum possible indirect effects respectively. Significant partial mediation was detected in multiple mediation. Of a total indirect effect of PSSQ on CR (27\%), PUV contributed nearly twice as much as CSL in the maximum possible indirect effects though marginally significant as the $95 \% \mathrm{BCa} \mathrm{Cl}$ of 'specific indirect effect contrast definition' included the null value (Figure 2: E).

PSSQ predicted significantly high and nearly equal variations in PUV and CSL, 67.5\% and $74.3 \%$ respectively which was $49.4 \%$ for CR. PUV predicted nearly equal variations of CSL and CR respectively $55.4 \%$ and $44.4 \%$. 
(A)

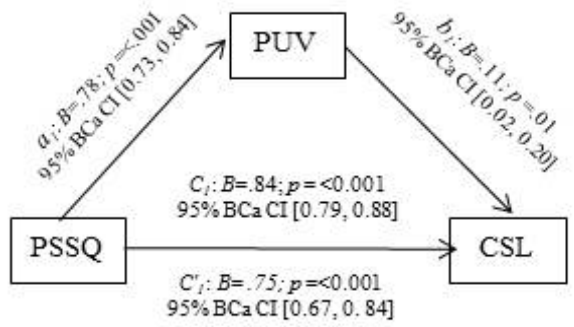

Indirect effect $1: B=.08 ; 95 \% \mathrm{BCa} \mathrm{CI}[0.01,0.16] ; k^{2}=.105$, $95 \% \mathrm{BCa} C I[0.01,0.19]$; Sobel test statistic: $p=.01$
(B)

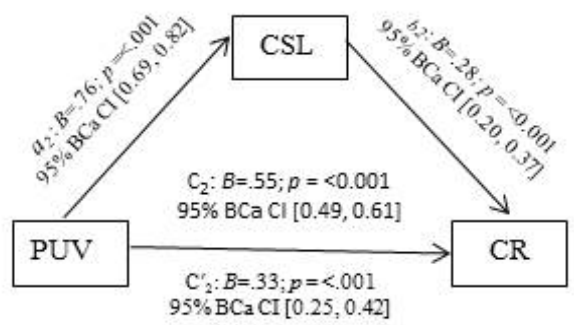

Indirect effect $2: B=.22 ; 95 \% \mathrm{BCaCI}[0.15,0.27] ; k^{2}=.234$, $95 \% \mathrm{BCa}$ CI $[0.17,0.29]$; Sobel test statistic: $p=<.001$
(C)

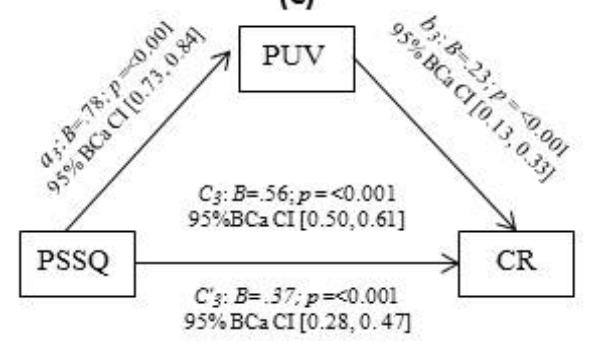

Indirect effect $3: B=.18 ; 95 \% \mathrm{BCa} \mathrm{CI}[0.10,0.25] ; k^{2}=.181$, $95 \%$ BCa CI $[0.10,0.25]$; Sobel test statistic: $p=<0.001$
(D)

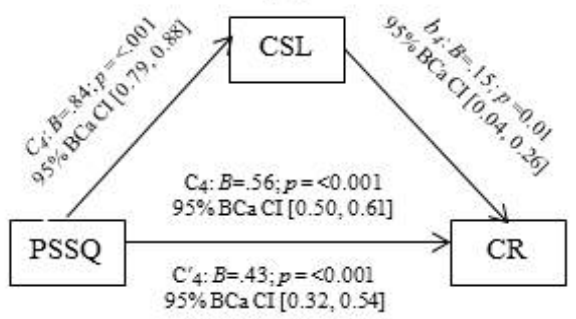

Indirect effect $4: B=.13 ; 95 \% \mathrm{BCa}$ CI $[0.04,0.23] ; k^{2}=.114$, $95 \% \mathrm{BCa}$ CI $[0.03,0.19]$; Sobel test statistic: $p=<0.001$

(E)

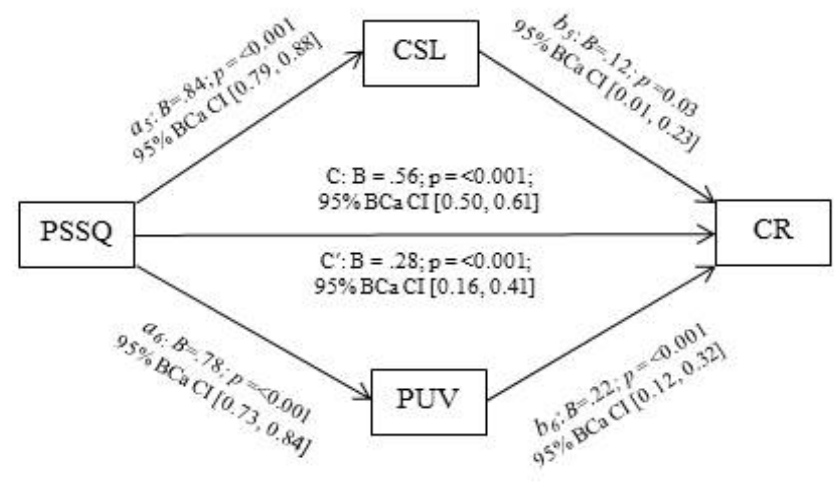

Total indirect effect $5: \mathrm{B}=.27(\mathrm{PUV}=.17 ; \mathrm{CSL}=.10)$; Specific indirect effect contrast definition: $\mathrm{B}=0.07 ; 95 \% \mathrm{BCa} \mathrm{CI}[-0.05 ; 0.19]$

Figure 2: Illustrations of simple mediation $A, B, C \& D$ and multiple mediation $E$.

Note: $95 \% \mathrm{BCa} C$ refers $95 \%$ bias corrected and accelerated confidence interval; $k^{2}$ stands for Kappa-squared 


\section{DISCUSSION}

This study aims to identify key influences of rural clients global expectations and utilization of health facilities, and to determine predictors of their satisfaction level in the public and the private sectors; furthermore, to assess the relationships among the presupposed causal linkage constructs namely: perceived specific service quality (PSSQ), perceived utility value (PUV), clients' satisfaction level (CSL), and clients' reactions (CR) in the overall district health system.

\section{Clients' global expectations versus expected and perceived specific service quality}

Listing the global expectations, respondents did not mention considerable numbers of the items of ESSQ variables we administered and on which they even scored markedly high. This indicates that clients' expectations are often pre-structured as well as instant context-led construct. While the public clients' global expectations and selection of facilities mainly were influenced by structural factors (e.g. cheaper and near-home services), which were word-of-mouth communication (a positive reaction), and publicity (a market competition feature) for the private clients. Approximately one-fourth of all clients reported that selection of providers was influenced by past-experiences. These findings indicate that both internal and external factors hold potential to construct clients' expectations as well as productivity and reputation of health system.

Although clients' expectations in healthcare are a multifactor construct, its intensity apparently does not differ across clients' of diverse socio-demographic and individual characteristics and health conditions or structural and process disparities. For instance, the overall means of ESSQ domain are quite high and similar in all groups with markedly small standard deviations (Table 5). This tendency of expectation dynamics was also noticed by Parasuraman et al. (1991); hence, there is a lack of variation regardless of heterogeneity in clients. For this reason, we agree with the critics that the SERVQUAL gap-model is not without risk of statistical unpredictability in assessing diverse clients' satisfaction in healthcare. However, the 'perception part' of the model is useful for indirectly measuring health services quality. We also claim that low quality services; thus, low perceptions rather than high expectations are the key drivers of clients' low satisfaction, a contradiction to Lewis \& Mitchell (1990). Moreover, it is more realistic to improve client's satisfaction through better services than through lowering expectations.

The overall means of CSL across the clients groups were not perfect; however, still were clearly over the neutral value, which is counterintuitive to the notion of clients' dissatisfaction with the Bangladesh's health system. This finding is consistent with other studies (e.g. Andaleeb et al., 2007; Rahman et al., 2002). 
Predictors of clients' low satisfaction level (CSL)

In the public sector, structural factors (availability, accessibility and tangibility) predicted nearly three times more of the variations in CSL than process factors (reliability, responsiveness, empathy, communication, and courtesy); in contrast, in the private sector, process features predicted nearly twice as strong as structural factors (Table 6).

Availability was the strongest predictor of CSL in the public sector. Low economic status along with high demands of the public clients aggravates the problem of scarce drugs and diagnostics supplies. This finding supports Rahman et al. (2002) that sufficient drugs and diagnostics are crucial to improve public clients' satisfaction.

Accessibility (financial) was a dominant predictor of CSL in both sectors, although somewhat stronger in the private than in the public sector (Table 6). People having a monthly income <7000 BDT (nearly 88 USD) utilized the public sector over 2-times more often than the private sector (Table 2). However, public clients have to purchase unavailable drugs and diagnostics from the private sector (Barkat \& Maksud, 2003). Moreover, since there is no health insurance system, clients have to bear healthcare costs regardless of their ability to pay. Remarkably, nearly one-thirds of all clients sourced treatment costs by loans with or without interest, selling household goods, and community philanthropy. Although two-thirds of all clients paid healthcare costs by themselves, this does not necessarily confirm affordability. Since only direct healthcare costs were queried, the real situation perhaps was a higher financial burden than was assessed. These findings indicate that financial accessibility in the OPP-model health system with a scarcely resourced public sector and under-controlled costs in a dominant private market is not only ominously predicting clients' low satisfaction but also leaving them at risk of poverty. Ample supply with efficient use of resources in the public sector and cost control in the private sector would improve clients' accessibility and satisfaction, and reduce the risks of a health catastrophe.

Responsiveness was a moderately strong predictor of CSL in both sectors though nearly twice as strong as in the public sector (Table 6). Although the perceived average waiting-time was nearly identical in both the sectors, its range in the private was 230 minutes, i.e. 50 minutes longer than in the public sector, a counterintuitive impression for the competitive private market. Among the total sample providers only nearly $16 \%$ were private-only doctors and the rest were dual-practicing public doctors. Out of the official public working-time, each dual-practitioner runs private practice, often at multiple private facilities (Andaleeb et al., 2007) and some are intercity practitioners, which understandably cause time management problems. It is explicable that the limited specialist dual-practitioners are the monopolists in the private market. As a result, clients' expectation of quick (ambulatory) services and providers' interest to exploit income are often mutually exclusive. Noticeably, nearly $87 \%$ of surgical treatments $(n=76)$, a major income source in the private sector, were done on the day of admission which was 
much quicker than in the public sector with an average operation delay of nearly 8.0 ( \pm 3.0) days $(n=25)$. Further, there is no appointment system, especially in the public sector and patients are treated on 'first-come first-serve' basis. Therefore, the majority of patients gather at facilities at early hours and eventually many of them meet doctors at late hours causing long mean waiting-times. Furthermore, the current national doctor to population ratio is quite low, nearly 1:3,297 (Ministry of Health and Family Welfare, 2013), which is even seriously worse in rural areas due to the urban distribution of doctors (WHO, 2015). Thus, low responsiveness is mainly structural in origin.

Empathy was also identified as a strong predictor of CSL in the private and nearly 3times stronger than in the public sector (Table 6). Doctors' inadequate attentiveness to clients' problems was also reported by Rahman et al. (2002). Excess workloads were recognized at both the public and private facilities. The role of GPs in the private sector is not established which in turn increases the monopolist specialist doctors' patientloads, clearly an expected income interest. These may link to low attention to patients. However, the reported lack of behavioral training of doctors (World Bank, 2003) may also adversely affect doctor-patient interaction skills; hence, empathy as well. Further, clients' global expectation of free or cheap treatment remains unmet in both sectors, which is linked to low resource allocation in the public and in the private sector that is not unlikely relating to exploiting profits. Both are counterproductive to the clients' expectations towards doctors' consideration for their financial situation.

Reduction of workloads by adapting a hierarchical referral system with GPs as the gatekeeper, which has been proved effective (e.g. in the UK; the Netherlands), would improve responsiveness and empathy as well as clients' satisfaction. Doctors' training on 'behavioural change communication' would also be effective (World Bank, 2003).

Reliability was a strong predictor of CSL in the private sector only; however, given the current dual-practicing provision of healthcare, it is unclear why this was not the case in the public sector. The practices of supplier-induced demand (i.e. prescribing irrational drugs and/or diagnostics) for exploiting income, especially in the private market, are of public notions. This may relate to the low reliability rating for the private sector. Health professionals' skills and moral breakthrough may improve clients' perception of reliability and satisfaction with the system. Additionally, periodic clinical auditing through an independent multi-actor regulatory body may improve rationale of prescriptions.

Communication was a twice stronger but modest predictor of CSL in the public than in the private sector (Table 6). The public doctors are supposed to treat all indoor and outdoor patients that present themselves on any given day. For this, it is not unlikely that they try to treat all the registered client-crowds within the routine official hours (8.00 to 14.30 ) to save time for private practice. This may explain the reported two times shorter mean consulting time; thus, perception of insufficient communication in the public than in the private clients. 
Tangibility was a relatively weak predictor of CSL only in the private sector (Table 6). This finding contradicts with the study of Andaleeb et al. (2007) that included tertiary level private facilities. It is possible that higher tangibility-related demands of private clients were linked to their better income, housing and education than those in the public clients (Table 2). Additionally, the district level private infrastructures mostly are not constructed as clinics but modified to clinics and visibly inferior to that of public facilities. As a result, the tangible demands of the private clients remain unmet.

\section{Interrelationships among the constructs of the causal linkage pathway}

Perceived specific service quality (PSSQ) being the most influential predictor of perceived utility value (PUV), clients' satisfaction level (CSL), and clients' reaction (CR) was reaffirmed as the prime antecedent to the health clients' satisfaction model that was proposed by Choi et al. (2004). This study also finds that clients' reaction is the ultimate outcome of PSSQ, PUV and CSL. Statistically significant positive beta-values across all the paths including indirect effects of the simple and multiple mediation models indicate that progress in health services quality would improve clients' PUV, satisfaction as well as clients' reaction in favour of adherence to treatment and provider and publicity. Our findings are consistent with other studies (e.g. Oh, 1999; Choi et al., 2004). However, since the indirect effect and the $k^{2}$-statistic of PSSQ on CSL via PUV were the smallest among all the simple mediation models, we suggest a different view of PUV-CSL relationship than other models. For instance, Choi et al. (2004) recognized utility value as a cognitive construct; however, it is logical to think that health clients' satisfaction level may also affect their PUV either as a benefit or a sacrifice. Thus, the PUV is not only a cognitive construct that is strictly antecedent to CSL but in a systemic relation to each other.

Notably, the multiple mediation model (Figure 2: E) showed that PUV mediates the effects of PSSQ on clients' reaction nearly two times stronger than that of CSL. Moreover, clients' overall perception of health benefits was scored markedly high, (3.84). This indicates that technical qualities surpass the social aspects of healthcare services. However, the overall findings suggest that both the structural and process features of healthcare are in substantial need of improvement for the rural people's health and economic safety.

\section{Strengths and weaknesses}

A large number of respondents and nearly equal distributions of participants with diverse socio-demographic characteristics across the public and private sector, female and male, acute and chronic disorders of both out- and in-patient departments are the strong points. Face-to-face interview facilitated participation of illiterate respondents 
and reduced non-response rate. Conducting interviews, mostly at neutral environment, through trained research assistants reduced the risk of social desirability response bias although central tendency bias, a risk of using Likert scale may not be ignored. The using of a contextually adapted holistic model along with triangulating respondents' statements about their expectation, perception and socio-economic conditions was also distinctive features of this study.

In order to reduce the risk of changing doctors' usual manners of dealing with patients as well as to maintain anonymity, we did not inform the doctors whose patients were approached; thus, the doctors were not identified. Alternatively, we identified the patients by discipline (i.e. surgery, medicine and general practice). As a result, we could not control for variations in patients' satisfaction level across individual doctors. Generalizability of the findings may not be claimed since only one out of 64 districts in Bangladesh was included. However, since the health sector of this district is one of the best performers, our findings would be a benchmark of the clients satisfaction for other districts; thus, would be an asset for policy implications. Doctors' roles in health clients' satisfaction is undisputable; however, probing into doctors' opinion was beyond this study that deserves further research.

\section{CONCLUSION}

Clients' low satisfaction in the Bangladesh's district health system is unquestionable. However, the public clients' satisfaction level is significantly lower than in the private clients. Self-experience, WOM-communication and marketing strategies construct clients' expectations and choices of facility utilizations stronger in the private than in the public sector. Prime expectations of the public clients' are structure-centered, e.g. free treatment and availability of drugs and diagnostics; however, in the private clients those are skills, quick response and trustworthy treatment, i.e. provider-concerned. In both sectors, attentiveness was the most frequent process-related global expectation which was affordable treatment among the structural factors with a significantly stronger effect in the private clients.

Improvement of both the structural and process-related service quality factors is pivotal to improve clients' satisfaction to an optimal expected level. The potential structure and process-related predictors of clients' satisfaction are clearly under the influence of the ramification of a unique factor- self-economic interest of the key stakeholders such as state's interests of minimizing healthcare costs, providers' interest of maximizing income, investors' interests of increasing profit, and clients' interests of maximum health benefit with no or minimum payments. In reality, those self-centred interests of the key health actors are mutually exclusive. The growing private health market of the country has been hybridized with the dominant dual-practitioners who are overloaded both in 
the public and private sectors because of the country's socio-demography (overpopulation), and system drawbacks such as under-developed referral system, nonprovision of behavioural training and urban concentration of doctors. Ultimately, the situation is rendering the country's majority rural patients at the potential risks of health and economic loss and adversely affecting doctor-patient relationships as well as social capital in health care. Policymakers, providers and investors need to prioritize patients' health and economic interests to improve the situation.

\section{CONFLICTS OF INTEREST:}

The authors declare that they have no conflicts of interest. 


\section{REFERENCES}

Andaleeb, S. S., Siddiqui, N., \& Khandakar, S. (2007). Patient satisfaction with health services in Bangladesh. Health Policy and Planning, 22(4), 263-273.

Bangladesh Bureau of Statistics. (2013). District Statistics 2011, Joypurhat, (December). Retrieved from http://www.bbs.gov.bd/WebTestApplication/userfiles/Image/District Statistics/Joypurhat.pdf.

Barbier, J., Noronha, A., \& Dixit, A. (2013). Assessing the Economic Value of Making the Right Customer Satisfaction Decisions - and the Impact of Dissatisfaction on Churn. Retrieved from http://www.cisco. com/web/about/ac79/docs/re/Value-of-Customer-Satisfaction.pdf.

Barkat, A., \& Maksud, A. K. M. (2003). The Private Sector Health Services in Bangladesh : An Exploratory Study EngenderHealth, Dhaka, (February). Retrieved from http://www.hdrcbd.com/pcs_pdf/1. Health/15. Private Sector Health Services in Bangladesh_An Exploratory Study.pdf.

Baron, R. M., \& Kenny, D. A. (1986). The Moderator-Mediator Variable Distinction in Social The ModeratorMediator Variable Distinction in Social Psychological Research: Conceptual, Strategic, and Statistical Considerations. Journal of Personality and Social Psychology, 51(6), 1173-1182.

Busch, M. (2008). Adam Smith and Consumerism's Role in Happiness: Modern Society Reexamined. Retrieved from http://business.uni.edu/economics/Themes/Busch.pdf.

Choi, K. S., Cho, W. H., Lee, S., Lee, H., \& Kim, C. (2004). The relationships among quality, value, satisfaction and behavioral intention in health care provider choice: A South Korean study. Journal of Business Research, 57(8), 913-921.

Civil Surgeon Office. (2014). District Annual Reports on private clinics, hospitals and diagnostic centres, 2013; Joypurhat district: The Stationery Office. Joypurhat district.

Crow, R., Gage, H., Hampson, S., Hart, J., Kimber, A., Storey, L., \& Thomas, H. (2002). The measurement of satisfaction with healthcare: implications for practice from a systematic review of the literature. Health Technology Assessment, 6(32), 1-244.

Dagger, T.S. \& Sweeney, J. C. (2006). The Effect of Service Evaluations on Behavioral Intentions and Quality of Life. Journal of Service Research, 9(1), 3-18.

Donabedian, A. (2005). Evaluating the quality of medical care. The Milbank Quarterly, 83(4), 691-729.

Econex. (2011). National Health Systems: Public Service vs . Insurance-Based Models. Retrieved from http://www.econex.co.za/index.php?option=com_docman\&task=doc_download\&gid=89\&ltemid=60.

Field, A. (2014, p.307-347). Discovering statistics using IBM SPSS statistics (4th ed.). London: SAGE Publications Ltd.

Fornell, C., Johnson, M. D., Anderson, E. W., Cha, J., \& Bryant, B. E. (1996). The American Customer Satisfaction Index: Nature, Purposr, and Findings. Journal of Marketing, 60(4), 7-18.

Hafiz-Afifi, N., Busse, R., \& Harding, A. (2003). Regulation of Health Services. In: Harding, A. \& Perker, A.S. (eds.), Private participation in health servces (pp. 219-327). Retrieved from http://books.google.com.bd/ books?id=bZwasbxXSAC\&printsec=frontcover\&source=gbs_ge_summary_r\&cad=0\#v=onepage\&q\&f=true.

Israel, G. D. (1992). Determining sample size. Retrieved from http://scholar.google.nl/scholar_url?url= http://zulsidi.tripod.com/pdf/DeterminingSampleSizes.pdf\&hl=en\&sa=X\&scisig=AAGBfm3TI--

19NxQAhETQhOB89eewl7jJw\&nossl =1\&oi=scholarr\&ved=0ahUKEwitg4Y7a_QAhVCKsAKHRIZAXAQgAMIKCgAMAA

Lewis, B.R., Mitchell, V. W. (1990). Defining and Measuring the Quality of Customer Service. Marketing Intelligence \& Planning, 8(6), 11-17.

Ministry of Health and Family Welfare. (2013). Health Bulletin 2013. Retrieved from http://www.dghs.gov.bd/ images/docs/Other_Publication/HB 2013 final - Full version 1March14.pdf.

Nunnally, J. C. (1978, p.245). Psychometric theory (2nd ed.). New York: McGraw-Hill.

Oh, H. (1999). Service quality, customer satisfaction, and customer value: A holistic perspective. Hospitality Management, 18, 67-82. http://doi.org/10.1016/S0278-4319(98)00047-4.

Parasuraman, A., Berry, L.L., Zeithaml, V. A. (1991). Refinement and reassessment of the SERVQUAL scale. Journal of Retailing, 67(4), 420-50. 
Patterson, P. G., \& Spreng, R. A. (1997). Modelling the relationship between perceived value, satisfaction and repurchase intentions in a business-to-business, services context: an empirical examination. International Journal of Service Industry Management, 8(5), 414-434.

Preacher, K. J., \& Hayes, A. F. (2008). Asymptotic and resampling strategies for assessing and comparing indirect effects in multiple mediator models. Behavior Research Methods, 40(3), 879-891.

Preacher, K. J., \& Kelley, K. (2011). Effect size measures for mediation models: quantitative strategies for communicating indirect effects. Psychological Methods, 16(2), 93-115.

Rahman, M. M., Shahidullah, M., Shahiduzzaman, M., \& Rashid, H. . A. (2002). Quality of health care from patient perspectives. Bangladesh Med Res Counc Bull, 28(3), 87-96.

Robinson, J. C. (2005). Managed Consumerism In Health Care. Health Affairs, 24(6), 1478-1489.

Stevens, J. (2002). Applied Multivariate Statistics For The Social Science (4th ed.). New Jersey: Lawrence and Erlbaum Associates, Inc. Retrieved from http://ypun.org/wp-content/uploads/securepdfs/2015/06/ Stevens-J.P.-Applied-Multivariate-Statistics-part1.pdf.

WHO. (2014). National expenditure on health. Retrieved from http://apps.who.int/nha/database/Key_ Indicators_by_Country/Index/en?COUNTRYKEY=84674.

WHO. (2015). Bangladesh Health System Review. Retrieved from http://www.wpro.who.int/asia_pacific_ observatory/hits/series/bgd_health_system_review.pdf.

World Bank. (2003a). Bangladesh, Private Sector Assessment for Health, Nutrition and Population (HNP) in Bangladesh. Retrieved from http://documents.worldbank.org/curated/en/538491468743377938/Bangla desh-Private-sector-assessment-for-health-nutrition-and-population-HNP-in-Bangladesh.

World Bank. (2003b). Private Sector Assessment for Health, Nutrition and Population (HNP) in Bangladesh. Retrieved from http://wwwwds.worldbank.org/external/default/WDSContentServer/WDSP/IB/2003/12/ 23/000112742_20031223170041/Rendered/PDF/270050BD.pdf.

World Bank. (2013). World Development Indicators: Poverty rates at national poverty lines. Retrieved from http://wdi.worldbank.org/table/2.7.

Zeckhauser, R., \& Sommers, B. (2013). Consumerism in health care: challenges and opportunities. Americal Medical Association Journal of Ethics, 15(11), 988-92.

Zeithaml, V. A. (1988). Consumer perceptions of price, quality, and value: a means-end model and synthesis of evidence. Journal of Marketing, 52(3), 2-22. 


\section{APPENDICES}

(Notes: $\triangle R$ denotes changes in $R^{2}$, and all adjusted $R^{2}$ are the SPSS computed products using Wherry's formula).

Appendix 1: SPSS outputs of the hierarchical approach of multiple regression analysis - perceived specific service quality variables as the predictors of clients satisfaction level in the public sector.

\begin{tabular}{|c|c|c|c|c|c|}
\hline \multirow[t]{2}{*}{ Models } & \multirow[t]{2}{*}{ Predictors } & \multicolumn{2}{|c|}{ Unstandardized Coefficients } & \multirow{2}{*}{$\begin{array}{l}\text { Standardized } \\
6\end{array}$} & \multirow[t]{2}{*}{$p$-value } \\
\hline & & B (95\% Cl) & Stand. Error & & \\
\hline \multirow[t]{2}{*}{1} & Constant & $2.00(1.73,2.26)$ & 0.13 & - & $<.001$ \\
\hline & Availability & $0.44(0.36,0.53)$ & 0.04 & .59 & $<.001$ \\
\hline
\end{tabular}

Model 1 Summary: $R=.588 ; R^{2}=.346 ;$ Adjusted $R^{2}=.343 ; \Delta R=0.346 ; F$ change $(1,198)=104.84 ; P=<.001$

2

Constant
Availability

$.53(0.13,0.94)$

0.04

.009

Accessibility

$.28(0.20,0.36)$

0.06

.37

$<.001$

$.54(0.42,0.66)$

0.20

.48

$<.001$

Model 2 Summary: $R=.727 ; R^{2}=.529 ;$ Adjusted $R^{2}=.524 ; \Delta R=.182 ; F$ change $(2,197)=76.23 ; P=<.001$

3

$\begin{array}{lllll}\text { Constant } & 1.07(0.66,1.47) & 0.04 & - & <.001 \\ \text { Availability } & 0.13(0.04,0.22) & 0.07 & .18 & .004 \\ \text { Accessibility } & 0.33(0.20,0.46) & 0.03 & .30 & <.001 \\ \text { Responsiveness } & 0.20(0.14,0.26) & 0.19 & .42 & <.001\end{array}$

Model 3 Summary: $R=.778 ; R^{2}=.606 ;$ Adjusted $R^{2}=.599 ; \Delta R=.077 ; F$ change $(3,196)=38.21 ; P=<.001$

$\begin{array}{lllll}\text { Constant } & 1.05(0.67,1.43) & 0.19 & - & <.001 \\ \text { Availability } & 0.11(0.02,0.19) & 0.04 & .14 & .012 \\ \text { Accessibility } & 0.27(0.14,0.39) & 0.06 & .24 & <.001 \\ \text { Responsiveness } & 0.12(0.05,0.19) & 0.03 & .26 & <.001 \\ \text { Communication } & 0.19(0.12,0.26) & 0.04 & .32 & <.001\end{array}$

Model 4 Summary: $R=.809 ; R^{2}=.654 ;$ Adjusted $R^{2}=.647 ; \Delta R=.049 ; F$ change $(4,195)=27.34 ; P=<.001$

5

$\begin{array}{lllcc}\text { Constant } & 0.81(0.45,0.18) & 0.18 & - & <.001 \\ \text { Availability } & 0.07(0.01,0.15) & 0.04 & .10 & .053 \\ \text { Accessibility } & 0.18(0.06,0.30) & 0.06 & .16 & .003 \\ \text { Responsiveness } & 0.08(0.01,0.14) & 0.03 & .16 & .018 \\ \text { Communication } & 0.14(0.07,0.20) & 0.03 & .24 & <.001 \\ \text { Empathy } & 0.25(0.17,0.34) & 0.04 & .33 & <.001\end{array}$

Model 5 Summary: $R=.839 ; R^{2}=0.704 ;$ Adjusted $R^{2}=.696 ; \Delta R=.050 ; F$ change $(5,194)=32.63 ; P=<.001$

6

$\begin{array}{lllll}\text { Constant } & 0.56(0.17,0.96) & 0.20 & - & .005 \\ \text { Availability } & 0.06(-0.01,0.14) & 0.04 & .08 & .102 \\ \text { Accessibility } & 0.17(0.06,0.29) & 0.06 & .15 & .004 \\ \text { Responsiveness } & 0.05(-0.01,0.12) & 0.03 & .12 & .098 \\ \text { Communication } & 0.12(0.05,0.19) & 0.03 & .21 & <.001 \\ \text { Empathy } & 0.24(0.15,0.32) & 0.04 & .31 & .005 \\ \text { Reliability } & 0.13(0.04,0.22) & 0.05 & .15 & .001\end{array}$

Model 6 Summary: $R=.846 ; R^{2}=.716 ;$ Adjusted $R^{2}=.707 ; \Delta R=.012 ; F$ change $(6,193)=8.09 ; P=<.001$ 
Chapter 3

\begin{tabular}{|c|c|c|c|c|c|}
\hline \multirow[t]{2}{*}{ Models } & \multirow[t]{2}{*}{ Predictors } & \multicolumn{2}{|c|}{ Unstandardized Coefficients } & \multirow{2}{*}{$\begin{array}{l}\text { Standardized } \\
6\end{array}$} & \multirow[t]{2}{*}{$p$-value } \\
\hline & & B $(95 \% \mathrm{Cl})$ & Stand. Error & & \\
\hline \multirow[t]{8}{*}{7} & Constant & $0.48(0.08,0.89)$ & 0.21 & - & .020 \\
\hline & Availability & $0.05(-0.02,0.13)$ & 0.04 & .07 & .179 \\
\hline & Accessibility & $0.17(0.05,0.28)$ & 0.06 & .15 & .006 \\
\hline & Responsiveness & $0.04(-0.03,0.11)$ & 0.03 & .08 & .247 \\
\hline & Communication & $0.11(0.04,0.18)$ & 0.03 & .19 & .002 \\
\hline & Empathy & $0.23(0.14,0.31)$ & 0.04 & .29 & $<.001$ \\
\hline & Reliability & $0.13(0.03,0.22)$ & 0.05 & .15 & .007 \\
\hline & Tangibility & $0.09(-0.03,0.20)$ & 0.06 & .10 & .148 \\
\hline \multicolumn{6}{|c|}{ Model 7 Summary: $R=.848 ; R^{2}=.719 ;$ Adjusted $R^{2}=.709 ; \Delta R=.003 ; F$ change $(7,192)=2.10 ; P=<.001$} \\
\hline \multirow[t]{9}{*}{8} & Constant & $0.42(0.00,0.84)$ & 0.21 & - & .046 \\
\hline & Availability & $0.05(-0.02,0.13)$ & 0.04 & .07 & .180 \\
\hline & Accessibility & $0.15(0.04,0.27)$ & 0.06 & .14 & .010 \\
\hline & Responsiveness & $0.03(-0.04,0.10)$ & 0.03 & .06 & .386 \\
\hline & Communication & $0.11(0.04,0.17)$ & 0.03 & .18 & .003 \\
\hline & Empathy & $0.22(0.13,0.30)$ & 0.04 & .28 & $<.001$ \\
\hline & Reliability & $0.12(0.03,0.21)$ & 0.05 & .14 & .011 \\
\hline & Tangibility & $0.09(-0.02,0.20)$ & 0.06 & .10 & .134 \\
\hline & Courtesy & $0.05(-0.01,0.12)$ & 0.04 & .07 & .147 \\
\hline
\end{tabular}


Appendix 2: SPSS outputs of the hierarchical approach of multiple regression analysis - perceived specific service quality variables as the predictors of clients satisfaction level in the private sector.

\begin{tabular}{|c|c|c|c|c|c|}
\hline \multirow[t]{2}{*}{ Models } & \multirow[t]{2}{*}{ Predictors } & \multicolumn{2}{|c|}{ Unstandardized Coefficients } & \multirow{2}{*}{$\begin{array}{l}\text { Standardized } \\
-B\end{array}$} & \multirow[t]{2}{*}{$p$-value } \\
\hline & & B (95\% Cl) & Stand. Error & & \\
\hline \multirow[t]{2}{*}{1} & Constant & $2.21(1.85,2.57)$ & .18 & - & $<.001$ \\
\hline & Accessibility & $0.39(0.29,0.48)$ & .05 & .50 & $<.001$ \\
\hline \multicolumn{6}{|c|}{ Model 1 Summary: $R=.500 ; R^{2}=.250 ;$ Adjusted $R^{2}=.247 ; \Delta R=.250 ; F$ change $(1,198)=66.14 ; P=<.001$} \\
\hline \multirow[t]{3}{*}{2} & Constant & $1.12(0.68,1.55)$ & 0.22 & - & $<.001$ \\
\hline & Accessibility & $0.33(0.24,0.41)$ & 0.04 & .42 & $<.001$ \\
\hline & Reliability & $0.33(0.24,0.42)$ & 0.05 & .40 & $<.001$ \\
\hline
\end{tabular}

Model 2 Summary: $R=.639 ; R^{2}=.408 ;$ Adjusted $R^{2}=.402 ; \Delta R=.158 ; F$ change $(2,197)=52.48 ; P=<.001$

$\begin{array}{lllll}\text { Constant } & 0.28(-0.15,0.71) & 0.22 & - & .201 \\ \text { Accessibility } & 0.21(0.13,0.29) & 0.04 & .28 & <.001 \\ \text { Reliability } & 0.25(0.17,0.33) & 0.04 & .30 & <.001 \\ \text { Empathy } & 0.42(0.32,0.52) & 0.05 & .43 & <.001\end{array}$

Model 3 Summary: $R=.746 ; R^{2}=.556 ;$ Adjusted $R^{2}=.550 ; \Delta R=.148 ; F$ change $(3,196)=65.51 ; P=<.001$

$\begin{array}{lllll}\text { Constant } & 0.55(0.18,0.92) & 0.19 & - & .004 \\ \text { Accessibility } & 0.16(0.09,0.22) & 0.03 & .20 & <.001 \\ \text { Reliability } & 0.15(0.08,0.22) & 0.04 & .19 & <.001 \\ \text { Empathy } & 0.30(0.21,0.39) & 0.05 & .31 & <.001 \\ \text { Responsiveness } & 0.21(0.16,0.26) & 0.02 & .42 & <.001\end{array}$

Model 4 Summary: $R=.827 ; R^{2}=.683 ;$ Adjusted $R^{2}=.677 ; \Delta R=.127 ; F$ change $(4,195)=78.05 ; P=<.001$

$\begin{array}{lllll}\text { Constant } & -0.10(-0.51,0.31) & 0.21 & - & .638 \\ \text { Accessibility } & 0.14(0.08,0.20) & 0.03 & .18 & <.001 \\ \text { Reliability } & 0.14(0.08,0.21) & 0.03 & .17 & <.001 \\ \text { Empathy } & 0.23(0.14,0.31) & 0.04 & .23 & <.001 \\ \text { Responsiveness } & 0.20(0.15,0.24) & 0.02 & .39 & <.001 \\ \text { Tangibility } & 0.28(0.18,0.38) & 0.05 & .24 & <.001\end{array}$

Model 5 Summary: $R=.854 ; R^{2}=.728 ;$ Adjusted $R^{2}=.721 ; \Delta R=.045 ; F$ change $(5,194)=32.35 ; P=<.001$

$\begin{array}{lllll}\text { Constant } & -0.26(-0.74,0.22) & 0.24 & - & .288 \\ \text { Accessibility } & 0.14(0.08,0.20) & 0.03 & .18 & <.001 \\ \text { Reliability } & 0.14(0.07,0.21) & 0.03 & .17 & <.001 \\ \text { Empathy } & 0.22(0.13,0.31) & 0.04 & .23 & <.001 \\ \text { Responsiveness } & 0.20(0.15,0.24) & 0.02 & .39 & <.001 \\ \text { Tangibility } & 0.27(0.17,0.37) & 0.05 & .23 & <.001 \\ \text { Availability } & 0.06(-0.03,0.16) & 0.05 & .05 & .208\end{array}$




\begin{tabular}{|c|c|c|c|c|c|}
\hline \multirow[t]{8}{*}{7} & Constant & $-0.30(-0.76,0.16)$ & 0.23 & - & .197 \\
\hline & Accessibility & $0.13(0.07,0.19)$ & 0.03 & .17 & $<.001$ \\
\hline & Reliability & $0.12(0.05,0.18)$ & 0.03 & .14 & $<.001$ \\
\hline & Empathy & $0.20(0.11,0.28)$ & 0.04 & .20 & $<.001$ \\
\hline & Responsiveness & $0.15(0.10,0.20)$ & 0.02 & .30 & $<.001$ \\
\hline & Tangibility & $0.23(0.13,0.33)$ & 0.05 & .19 & $<.001$ \\
\hline & Availability & $0.09(-0.01,0.18)$ & 0.05 & .07 & .062 \\
\hline & Communication & $0.13(0.07,0.18)$ & 0.03 & .20 & $<.001$ \\
\hline
\end{tabular}

Model 7 Summary: $R=.868 ; R^{2}=.754 ;$ Adjusted $R^{2}=.745 ; \Delta R=.023 ; F$ change $(7,192)=18.32 ; P=<.001$

8

$\begin{array}{lllll}\text { Constant } & -0.47(-0.92,-0.02) & 0.23 & - & .040 \\ \text { Accessibility } & 0.10(0.05,0.16) & 0.03 & .14 & .001 \\ \text { Reliability } & 0.10(0.03,0.16) & 0.03 & .12 & .003 \\ \text { Empathy } & 0.17(0.09,0.26) & 0.04 & .18 & <.001 \\ \text { Responsiveness } & 0.13(0.08,0.17) & 0.02 & .26 & <.001 \\ \text { Tangibility } & 0.20(0.10,0.29) & 0.05 & .17 & <.001 \\ \text { Availability } & 0.09(0.00,0.17) & 0.04 & .07 & .053 \\ \text { Communication } & 0.13(0.07,0.18) & 0.03 & .21 & <.001 \\ \text { Courtesy } & 0.14(0.07,0.21) & 0.03 & .17 & <.001 \\ \text { Summary: } R=.880 ; R^{2}=.724 ; \text { Adjusted } R^{2}=.765 ; \Delta R=.020 ; F \text { change }(8,191)=16.75 ; P=<.001\end{array}$




\section{Chapter}

\section{Relationships of work characteristics to job satisfaction, turnover intention, and burnout among doctors in Bangladesh}

Submitted as:

Roy, A., van der Weijden, T., \& de Vries, N. Relationships of work characteristics to job satisfaction, turnover intention, and burnout among doctors in Bangladesh. 


\section{ABSTRACT}

Introduction: Work design integrates work characteristics having organizational, social and job components which influence employees' welfare and also organizational goals. We investigated the effects of work characteristics and other predictors to job satisfaction, turnover intention and burnout, and examined whether or not these differ in doctors of the public primary, public secondary and private facilities of the district health care system of Bangladesh.

Methods: We conducted a quantitative study using a self-administered questionnaire containing mostly structured items among the public and private doctors with a sample size of 384 from 29 out of a total 64 districts of Bangladesh during October and November 2015. All variables including work characteristics and outcomes of interest were based on literatures and measured on 5-point Likert scale. Multivariate analysis of variance, bivariate correlation, and multiple regression were the models operated using SPSS version- 21 .

Results: A total of 354 doctors responded. No significant differences were found between the public primary and the secondary level doctors on combined work characteristics and outcomes variables, which had significant difference between the public and private doctors. Organisational supports (e.g. incentives, managerial support, performance evaluation and career growth) were the strongest predictors with a negative effect on job satisfaction and turnover intention for both public and private doctors; in this regard, the private doctors experienced more support. Despite doctors from both sectors reporting considerably high workloads- with higher loads among the public doctors - this did not explain burnout in either group. The effects of health-professional politics on public doctors' satisfaction, turnover intention and burnout were alarming. Internal social supports had a significantly higher positive correlation with job satisfaction for the private doctors compared to the public doctors.

Conclusion: Work design of the Bangladesh's health system is in need of substantial development. Overall, improvement of organizational supports is crucial; however, other work characteristics components are also important for enhancing doctors' welfare and health system productivity.

Keywords: Work design; job satisfaction; turnover intention; burnout; health system; Bangladesh 


\section{INTRODUCTION}

In many developing countries, inefficient work design and ineffective human resource management (HRM) are among the key barriers to attain the universal goals of the health system i.e. optimal and equitable response to people's needs for health and economic protection (Bhandari, Bagga, \& Nandan, 2010; WHO, 2000). Improvement in work design as well as HRM policy are essential for attaining the key national health policy goal of universal access to primary health care, also in Bangladesh (WHO, 2015).

Bangladesh is one of the 57 countries of the world with a serious shortage of human resource in healthcare with an approximate doctor-population ratio of 3:10,000. Currently to fulfil the WHO standard at least 90,000 more doctors would be needed. In the public-private mixed health system of Bangladesh, nearly $62 \%$ of all doctors are working in the private and the rest in the public sector. The majority of the public doctors are involved in the private sector as dual-practitioners. The private health facilities are mostly urbanized. Also an urban concentration of public doctors is a known problem that renders the rural doctors' posts vacant with consequent high workloads and rural people's poor access to quality health care (WHO, 2015).

Within limitations the health system of Bangladesh has recognizable achievements; for example, reduction in the infant mortality rate and maternal mortality ratio (WHO, 2015). Doctors' are among the key internal clients of the health system and their role in achieving organizational goals is quite important; hence, their fit and satisfaction with the organizational environment are also essential (Bhandari et al., 2010; Kulik et al., 1987). However, some studies reported that doctors' behavioural and technological deficiencies are mainly linked to patients' dissatisfaction in the healthcare system of Bangladesh (e.g. Mendoza Aldana et al. 2001; Andaleeb et al. 2007). Notably, most of those studies were based on patients' opinions only without taking into account doctors' opinions and the wider organizational culture and context which potentially influence their attitude, behaviour and well-being. Since doctors of the district health system are the key service providers to the majority of rural people (who occupy nearly $72 \%$ of over 151 million population of the country, cf. Ministry of Health and Family Welfare, 2013), their views of the impacts of the wider organizational environment deserve investigation.

A raft of empirical evidence has been generated over decades suggesting that strategic work design is essential to improve job holders' attitudinal, behavioural and emotional states to achieve individual and organizational interests and goals (Humphrey et al. 2007; Loher et al., 1985). Conceptually, work design integrates 'work characteristics' such as organizational, social and job components having the potential to determine individual and organizational interests and outcomes (Morgeson \& Humphrey, 2008). Empirically, job-holders' attitude (e.g. satisfaction), behaviour (e.g. turnover intention) 
and well-being (e.g. burnout) states are commonly studied work design outcomes which are under the complex influence of the wider organizational environment (Morgeson \& Humphrey, 2008; Janssen et al., 1999; Houkes et al., 2001; Humphrey et al., 2007). Therefore, we investigated whether or not the work characteristics are associated with any problems in job satisfaction, turnover intention, and burnout in doctors of the district health system of Bangladesh.

Therefore, this study aimed: (i) to identify the relationships of key attributes of work characteristics to job satisfaction, turnover intention, and burnout in the doctors of the district public primary, public secondary, and private health care facilities, and whether or not the relations differ between those groups of doctors, and (ii) to identify the key predictors of work characteristics influencing outcomes of interest in them.

The Figure 1 represents the conceptual model of this study. The key domains and attributes of work design are based on literature (e.g. Morgeson \& Humphrey, 2008; Humphrey et al., 2007; Houkes et al., 2001; Janssen et al., 1999) except healthprofessional politics. The Bangladesh Medical Association (BMA) is the state-affiliated organ of doctors. The democratic leadership of the BMA usually follows national main stream politics. Doctors' transfer, posting and promotion often are based on their political influence resulting in benefits or deprivation. During the design of the study tools, senior doctors suggested to assess doctors' views of the impacts of 'health-professional politics'.

\section{METHODS}

\section{Study design, population and settings:}

A quantitative study was conducted. Doctors of the public primary (i.e. upazilla or subdistrict), public secondary (i.e. district), and private health care facilities (excluding private tertiary level facilities) were the target population. General physicians (GPs), specialist doctors of diverse disciplines and qualified dentists were targeted. Doctors were included if they had at least two years of job experience in an organized private or public facility. For the purpose of a wide geographic representation, doctors from all seven divisions of the country were selected. A convenience sampling method was applied. A sample size of 384 was calculated based on an infinite population size, a $95 \%$ confidence interval and since there was no data available on the issues, we assumed $\pm 5 \%$ precision, and $50 \%$ degree of variability in outcomes. Equal numbers of doctors $(n=$ 128) were to be sampled from each of the private sector, and public primary and secondary levels. 


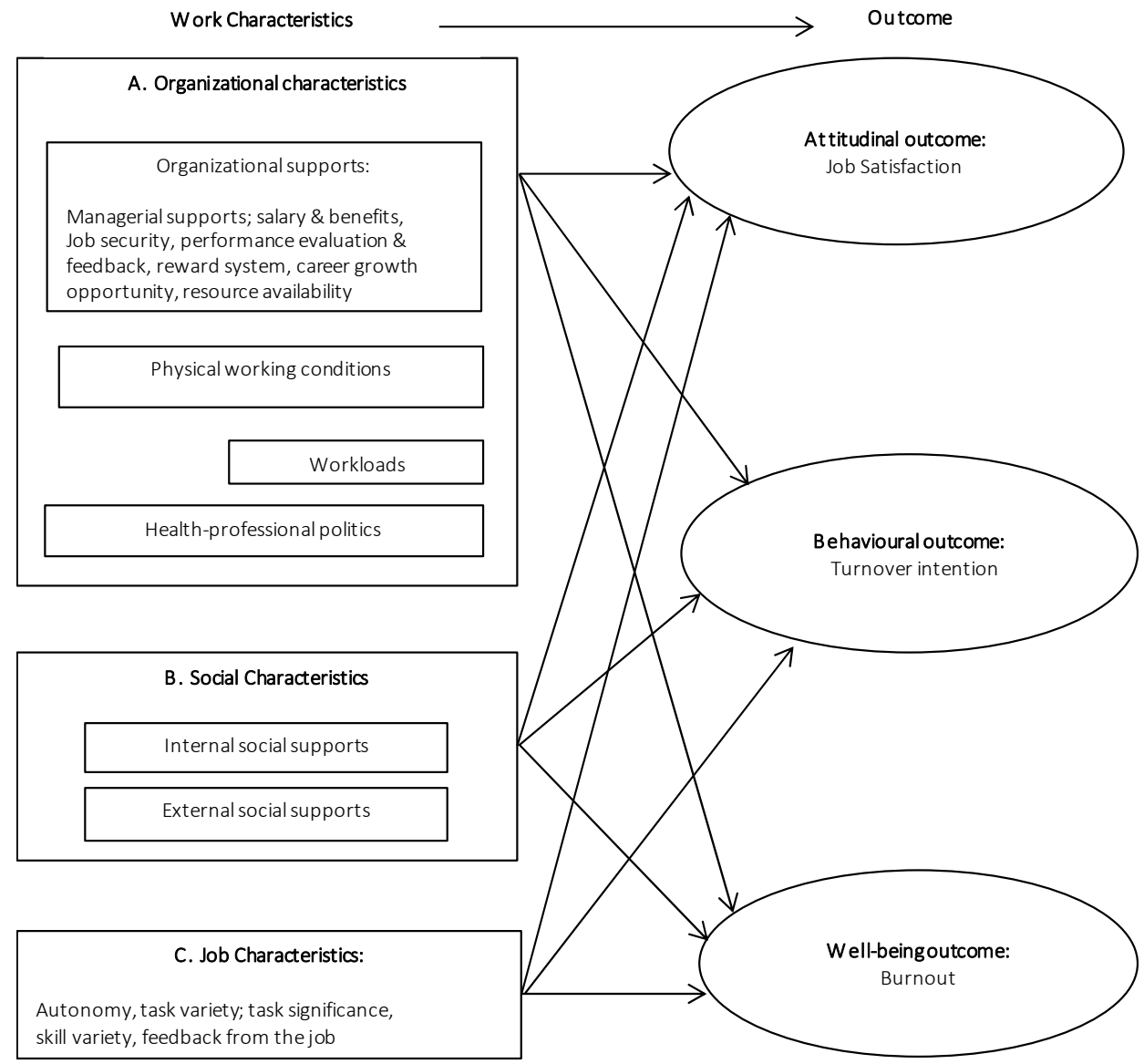

Figure 1: Conceptual model shows domains and attributes of work characteristics and outcomes of work design for the public and private doctors of the district health system of Bangladesh (adapted).

\section{Data collection tools and techniques}

A self-administered questionnaire with mostly closed items was developed by using existing work characteristics inventories (Morgeson \& Humphrey 2006; Warr et al., 1979) and by discussions with twelve senior doctors (public $n=7$; private $n=5$ ). A few qualitative open-ended items were also included; for example, doctors' daily and weekly working hours, and average number of patients they serve daily in the public and/or private sector. Section 1 contained questions about personal and professional background. Section 2 consisted of three work characteristics domains (Figure 1). Content validity of the scales on influence of 'health-professional politics' was ensured through the senior doctors' full consensus. Section 3 contained questions on outcomes: job satisfaction (using the global satisfaction scale of Lichtenstein,1984), turnover intention (using the scale described by Houkes et al., 2001), and burnout (using the inventory of 
West et al., 2009). Quantitative variables were measured with 5-point Likert scales (1 = strongly disagree, 2 = disagree, $3=$ neutral, $4=$ agree, and $5=$ strongly agree). Table 1 presents the composition and internal consistency coefficients of the scales.

The Principal Investigator contacted his colleagues in all regions of the country who volunteered to coordinate data collection. The study objectives and explanations on the questionnaire were presented to them face-to-face and electronically. Questionnaires were sent to the volunteers via postal mails; the volunteers then distributed questionnaires to the 384 selected doctors. Written informed consent was given by all respondents. For confidentiality reason, all respondents sealed the questionnaires in envelopes prior to returning them to the volunteers who finally sent them on to the Principal Investigator via postal mails. Data was collected during October and November 2015.

\section{Statistical analysis}

SPSS (version 21) was used for processing and analyzing the data. Internal consistency of the scales was assessed by Cronbach's a statistic as recommended by Nunnally (1987, pp.245) and was acceptable (Table 1). Linearity and normality were confirmed by partial plot and $p-p$ plots respectively. Presence or absence of outliers was determined using Cook's distance (cut-off point $<1$ ) and that of multicollinearity by variance inflation factors (cut-off point $<10$ ) as well as by tolerance factors (cut-off point $>0.1$ ) as described by Tabachnick \& Fidell (2013, p.124-128). No serious violations of assumptions were noted.

Table 1: Cronbach's $\alpha$ statistics of different variables including number of items

\begin{tabular}{lcc}
\hline $\begin{array}{l}\text { Domains } \\
\text { Variables }\end{array}$ & Cronbach's $\alpha$ & Items \\
\hline Organizational characteristics & .77 & 18 \\
Organizational supports & .83 & 8 \\
Physical working condition & .82 & 5 \\
Workloads & .79 & 2 \\
Health-professional politics & .81 & 3 \\
Social characteristics & .72 & 4 \\
Internal social supports & .68 & 2 \\
External social supports & .65 & 2 \\
Job Characteristics & .72 & 9 \\
Autonomy & .68 & 2 \\
Task variety & .66 & 4 \\
Task significance & - & 1 \\
Feedback from job & - & 1 \\
Skill variety & - & 1 \\
Outcomes & & 3 \\
Satisfaction & .73 & 1 \\
Turnover intention & - & 3 \\
Burnout & .70 & 3 \\
\hline
\end{tabular}


Means and standard deviations were inspected. One-way multivariate analysis of variance was performed to test any significant differences in work characteristics and outcomes between the doctors of the public primary and public secondary level facilities, and between all public and private doctors. Bivariate correlation analyses were conducted to detect the direction and strength of relations between work characteristics and outcomes. We used multiple regression (forward method) to identify the key predictors of the outcomes of interest and $95 \%$ bias corrected and accelerated bootstrap confidence intervals ( $\mathrm{BCa} \mathrm{Cls}$ ) to assess significance of correlation. An online programme (http://vassarstats.net/rdiff.html) was used to test any significant differences in the corresponding correlation coefficients between the public and private sector using Fisher's r-to-z-transformation. A $p$-value $<.05$ was regarded as significant. Missing data were treated by using the 'listwise' option of SPSS.

\section{RESULTS}

\section{Background information of the respondents}

A total of 354 doctors (public primary $n=121$, public secondary $n=117$, and private $n=$ 116) from 29 out of 64 districts in all 7 divisions of Bangladesh responded. The response rate was over $92 \%$. The overall ratio of male to female doctors was nearly 70:30 which matches with the national ratio of $72: 28$ (WHO, 2015). Respondents' mean age was $39.2( \pm 8.3)$ years with an average working experience of $10.8( \pm 7.4)$ years. Table 2 shows background information of the respondents.

\section{Descriptive statistics with multivariate analysis of variance}

Means and standard deviations of variables of work characteristics and primary outcome domains in the public and private sector are presented in Table 3. These are based on significant differences between the public and private sector as identified through multivariate analysis of variance (MANOVA).

MANOVA revealed no significant differences between doctors of the public primary and public secondary facilities on the combined work characteristics variables $\left(F_{7,222}=1.55\right.$; $p=.15 ;$ Wilks' Lambda $=.95 ;$ partial eta squired $=.047)$, and outcomes of interest $\left(F_{3}\right.$, $234=4.67 ; p=.003$; Wilks' Lambda= .94; partial eta squired $=.056$ ). Separate analysis of work characteristics variables found that none of them were significantly different with a Bonferroni adjusted $p$-value of $<.007$. Although Wilks' Lambda was significant for the combined outcome variables; in separate analysis only 'burnout' was found significant ( $p=.002$ ) using a Bonferroni corrected $p$-value of <.017; however, the effect size was quite small (partial eta squared $=.005$ ). So, we treated public doctors as one group. 
Table 2: Background information of the respondents

\begin{tabular}{|c|c|c|c|c|}
\hline $\begin{array}{l}\text { Variables } \\
\text { Categories }\end{array}$ & $\begin{array}{l}\text { Public PHC } \\
(n=121) \\
\text { Number }(\%)\end{array}$ & $\begin{array}{l}\text { Public SHC } \\
(n=117) \\
\text { Number }(\%)\end{array}$ & $\begin{array}{l}\text { Public total } \\
(\mathrm{n}=238) \\
\text { Number }(\%)\end{array}$ & $\begin{array}{l}\text { Private } \\
(\mathrm{n}=116) \\
\text { Number }(\%)\end{array}$ \\
\hline \multicolumn{5}{|l|}{ Job position } \\
\hline Medical Officer & $87(72)$ & $73(62)$ & $160(67)$ & $94(81)$ \\
\hline Junior Consultant & $29(24)$ & $27(23)$ & $55(23)$ & $15(13)$ \\
\hline Senior Consultant & $0(0)$ & $10(8)$ & $10(4)$ & $5(4)$ \\
\hline RMO & $5(4)$ & $5(4)$ & $9(4)$ & $2(2)$ \\
\hline EMO & $0(0)$ & $4(3)$ & $4(2)$ & $0(0)$ \\
\hline \multicolumn{5}{|l|}{ Qualification/specialization } \\
\hline Graduate- MBBS/GP & $82(68)$ & $60(51)$ & $142(60)$ & $82(71)$ \\
\hline Postgraduate/Specialist & $39(32)$ & $57(49)$ & $96(40)$ & $34(29)$ \\
\hline \multicolumn{5}{|l|}{ Dual practice } \\
\hline Yes & $96(79)$ & $89(76)$ & $185(78)$ & $69(59)$ \\
\hline No & $25(21)$ & $28(24)$ & $53(22)$ & $47(41)$ \\
\hline \multicolumn{5}{|l|}{$\begin{array}{l}\text { Geographic distribution by } \\
\text { division (No. of districts) }\end{array}$} \\
\hline Dhaka (5) & $18(15)$ & $11(9.5)$ & $29(12)$ & $24(21)$ \\
\hline Chittagong (6) & $12(10)$ & $25(21)$ & $37(16)$ & $19(16)$ \\
\hline Rajshahi (6) & $26(22)$ & $25(21)$ & $51(21)$ & $23(20)$ \\
\hline Khulna (2) & $19(16)$ & $10(9)$ & $29(12)$ & $19(16)$ \\
\hline Sylhet (2) & $9(7)$ & $11(9.5)$ & $20(8)$ & $7(6)$ \\
\hline Barisal (2) & $16(13)$ & $5(4)$ & $21(9)$ & $7(6)$ \\
\hline Rangpur (6) & $21(17)$ & $30(26)$ & $51(21)$ & $17(15)$ \\
\hline
\end{tabular}

Notes: $\mathrm{PHC}=$ Primary health care; $\mathrm{SHC}=$ Secondary health care; $\mathrm{EMO}=$ Emergency medical officer; $\mathrm{RMO}=$ Residential medical officer; MBBS = Bachelor of Medicine and Bachelor of Surgery; GP = General Physician

We found statistically significant differences between the public and private doctors on the combined work characteristics variables $\left(F_{7,331}=21.48 ; p=<.001\right.$; Wilks' Lambda $=$ .69 ; partial eta squired $=.312)$, and outcomes of interest $\left(F_{3,346}=15.70 ; p=<.001\right.$; Wilks' Lambda $=.88$; partial eta squired $=.12$ ). Separate analysis of work characteristics variables showed that all variables had statistically significant differences with a Bonferroni adjusted $p$-value of <.007 except for workloads; ratings by private doctors were more positive. Of the outcome variables all but turnover intention was found significantly different using a Bonferroni corrected $p$-value of <.017; again private doctors gave more positive judgements.

Among the variables of work characteristics and outcomes having significant differences between the public and private doctors, means of all but health-professional politics and burnout variables were greater in the private than in their public counterparts. In both sectors, combined organizational characteristics were evaluated less positively than social and job characteristics. Of all the variables of work characteristics, organizational supports were scored lowest in both the public and private sectors. Among the 
outcome variables, burnout in the private sector was scored lowest even notably lower than the neutral value (Table 3).

Table 3: Descriptive statistics of work characteristics and outcome variables in the public and private doctors

\begin{tabular}{lcc}
\hline $\begin{array}{l}\text { Domains } \\
\text { Variables }\end{array}$ & $\begin{array}{c}\text { Public }(\mathrm{n}=238) \\
\text { Mean }(\mathrm{SD})\end{array}$ & $\begin{array}{c}\text { Private }(\mathrm{n}=116) \\
\text { Mean }(\mathrm{SD})\end{array}$ \\
\hline $\begin{array}{l}\text { Organizational characteristics } \\
\text { *Organizational supports }\end{array}$ & $2.47( \pm 0.65)$ & $3.24( \pm 0.77)$ \\
*Physical working condition & $2.70( \pm 0.79)$ & $3.58( \pm 0.78)$ \\
$\quad$ Workloads & $3.60( \pm 0.95)$ & $3.50( \pm 1.89)$ \\
*Health-professional politics & $3.74( \pm 0.88)$ & $3.05( \pm 1.12)$ \\
*Grand mean OC & $2.92( \pm 0.49)$ & $3.34( \pm 0.52)$ \\
Social characteristics & & \\
*Internal social supports & $3.53( \pm 0.87)$ & $3.99( \pm 0.79)$ \\
*External social supports & $3.73( \pm 0.75)$ & $4.17( \pm 0.66)$ \\
*Grand mean SC & $3.63( \pm 0.67)$ & $4.08( \pm 0.62)$ \\
Job Characteristics & & $3.76( \pm 0.90)$ \\
*Autonomy & $3.34( \pm 0.85)$ & $3.66( \pm 0.67)$ \\
*Task variety & $3.29( \pm 0.65)$ & $4.42( \pm 0.63)$ \\
Task significance & $4.34( \pm 0.81)$ & $4.15( \pm 0.74)$ \\
*Feedback from job & $3.78( \pm 0.95)$ & $4.12( \pm 0.84)$ \\
Skill variety & $4.13( \pm 0.92)$ & $3.87( \pm 0.48)$ \\
*Grand mean JC & $3.57( \pm 0.52)$ & \\
Outcomes & & $3.24( \pm 0.78)$ \\
*Job satisfaction & $2.95( \pm 0.81)$ & $3.19( \pm 1.24)$ \\
Turnover intention & $3.06( \pm 1.14)$ & $2.09( \pm 1.03)$ \\
*Burnout & $2.89( \pm 1.24)$ & \\
\hline
\end{tabular}

Notes: Asterisks $\left({ }^{*}\right)$ before the variables indicate that those variables are significantly different between the public and private sector. SD = Standard deviation; OC = Organizational characteristics; SC = Social characteristics; JC = Job characteristics.

The reported daily official working hours in the private facilities varied from 8 to 10 hours which is markedly higher than the usual 6.5 hours in the public sector. However, because of also doing private practice, the calculated total working hours/week was marginally higher in public doctors than in their private counterparts, $60.3( \pm 18.5)$ hours versus 57.7 ( \pm 16.4 ) hours respectively. Of all respondents, approximately $58 \%$ worked 6 days/week (public 58\%; private 64\%), 41\% worked 7 days/week (public 42\%; private $35 \%$ ) and only $1 \%$ of private doctors worked 5 days/week. Each public and private doctor treated on average respectively nearly $50( \pm 31)$ patients and $34( \pm 20)$ patients per day. In addition to their public sector patients, the dual-practitioners treated an average of $12( \pm 11)$ patients daily in private practice.

\section{Correlation statistics}

Overall, no significant differences in correlation coefficients between the public and private sector were found except for the relations between health-professional politics 
and job satisfaction. However, considering the organizational contexts, arithmetic differences in the magnitude of $r$ values in the public and private sector seem more meaningful than statistical significance. Table 4 presents the correlation model statistics.

\section{Correlates of satisfaction:}

Organizational supports (i.e. managerial support, salary and benefits, job security, performance evaluation, reward system, career opportunity and resources availability), physical working conditions, internal social supports, and job characteristics had direct and strong relations with satisfaction in both the public and private doctors. Additionally, health-professional politics and external social supports had considerably strong inverse and direct influence respectively on job satisfaction in public doctors. Relations of organizational supports and internal social supports to doctors' job satisfaction were nearly 1.5 -times stronger in the private than in the public sector (Table 4).

\section{Correlates of turnover intention:}

Organizational supports and physical working conditions were negatively related to turnover intention in both sectors. While the strength of relations between organizational supports and turnover intention was nearly identical in both sectors, which for physical working conditions was nearly double in the private than in the public sector. Health-professional politics was found to have a strong positive relation with turnover intension only in the public doctors. Internal social supports and job characteristics had statistically significant negative correlations with turnover intention only in private doctors (Table 4).

\section{Correlates of burnout:}

Organizational supports had a strong and inverse influence on burnout in public doctors only. Oppositely, physical working conditions showed a marginally significant indirect relation with burnout in private doctors. Health-professional politics and workloads had a significant and direct influence on burnout only in the public doctors. In contrast, internal and external social supports showed a significant negative influence on burnout only in the private doctors with a fairly stronger relation with external social supports. Job characteristics had a significant negative correlation with burnout in both the public and private doctors with nearly twice stronger in the latter (Table 4). 
Table 4: Correlations between work characteristics and outcomes variables of work design in the public and private doctors including $95 \% \mathrm{BCa} \mathrm{Cl}$; and $p$-values.

\begin{tabular}{|c|c|c|c|c|}
\hline \multirow{3}{*}{$\begin{array}{l}\text { Work } \\
\text { characteristics }\end{array}$} & \multirow{3}{*}{ Provider } & \multicolumn{3}{|l|}{ Outcome variables } \\
\hline & & satisfaction & Turnover intention & Burnout \\
\hline & & \multicolumn{3}{|c|}{$\begin{array}{l}\text { Pearson's correlation coefficient }-r ; 95 \% \text { BCa Cl; } p \text {-value; } \\
\text { ( } p \text {-values (two-tailed) of differences in transformed } r \text {-to-z between the two sectors) }\end{array}$} \\
\hline \multirow{2}{*}{$\begin{array}{l}\text { Organizational } \\
\text { supports }\end{array}$} & Public & $.370 ;[0.25,0.48] ;<.001$ & $-.420 ;[-0.52,-0.31] ;<.001$ & $-.214 ;[-0.34,-0.06] ; .001$ \\
\hline & Private & $\begin{array}{c}.534 ;[0.35,0.70] ;<.001 \\
(.07)\end{array}$ & $\begin{array}{c}-.375 ;[-0.52,-0.21]<.001 \\
(.64)\end{array}$ & $\begin{array}{c}-.129 ;[-0.30,0.04] ; .17 \\
(.44)\end{array}$ \\
\hline \multirow{2}{*}{$\begin{array}{l}\text { Physical } \\
\text { working } \\
\text { condition }\end{array}$} & Public & $.335 ;[0.20,0.45] ;<.001$ & $-.181 ;[-0.31,-0.06] ; .005$ & $-.083 ;[-0.21,-0.05] ; .20$ \\
\hline & Private & $\begin{array}{c}.338 ;[0.16,0.51] ;<.001 \\
(.97)\end{array}$ & $\begin{array}{c}-.308 ;[-0.49,-0.10] ; .001 \\
(.24)\end{array}$ & $\begin{array}{c}-.184 ;[-0.34,-0.02] ; .05 \\
(.37)\end{array}$ \\
\hline \multirow[t]{2}{*}{ Workload } & Public & $-.018 ;[-0.18,0.17] ; .77$ & $.145 ;[-0.01,0.27] ; .03$ & $.179 ;[0.07,0.28] ; .006$ \\
\hline & Private & $\begin{array}{c}-.010 ;[-0.21,0.20] ; .92 \\
(.97)\end{array}$ & $\begin{array}{c}.014 ; .[-0.20,0.21] ; .88 \\
(.25)\end{array}$ & $\begin{array}{c}.060 ;[-0.15,0.26] ; .32 \\
(.29)\end{array}$ \\
\hline \multirow{2}{*}{$\begin{array}{l}\text { Health- } \\
\text { professional } \\
\text { politics }\end{array}$} & Public & $-.221 ;[-0.37,-0.06] ; .001$ & $.270 ;[0.11,0.41] ;<.001$ & $.210 ;[0.10,0.32] ; .001$ \\
\hline & Private & $\begin{array}{c}.077 ;[-0.12,0.27] ; .42 \\
(.008)\end{array}$ & $\begin{array}{c}.082 ;[-0.29,0.13] ; .39 \\
(.08)\end{array}$ & $\begin{array}{c}.005 ;[-0.15,0.16] ; .96 \\
(.06)\end{array}$ \\
\hline \multirow{2}{*}{$\begin{array}{l}\text { Internal social } \\
\text { support }\end{array}$} & Public & $.224 ;[0.08,0.36] ; .001$ & $-.085 ;[-0.22,0.06] ; .19$ & $-.050 ;[-0.17,0.09] ; .44$ \\
\hline & Private & $\begin{array}{c}.322 ;[0.12,0.54] ; .001 \\
(.35)\end{array}$ & $\begin{array}{c}-.250 ;[-0.40,-0.09] ; .01 \\
(.13)\end{array}$ & $\begin{array}{c}-.222 ;[-0.36,-0.08] ; .02 \\
(.13)\end{array}$ \\
\hline \multirow{2}{*}{$\begin{array}{l}\text { External social } \\
\text { support }\end{array}$} & Public & $.295 ;[0.17,0.40],<.001$ & $-.008 ;[-0.14,0.14] ; .90$ & $-.117 ;[-0.24,-0.002] ; .07$ \\
\hline & Private & $\begin{array}{c}.162 ;[-0.07,0.39] ; .09 \\
(.22)\end{array}$ & $\begin{array}{c}-.093 ;[-0.27,0.09] ; .33 \\
(.46)\end{array}$ & $\begin{array}{c}-.291 ;[-0.45,-0.14] ; .002 \\
(.11)\end{array}$ \\
\hline \multirow{2}{*}{$\begin{array}{l}\text { Job } \\
\text { characteristics }\end{array}$} & Public & $.359 ;[0.20,0.51] ;<.001$ & $-.040 ;[-0.18,0.09] ; .538$ & $-.149 ;[-0.26,-0.03] ; .02$ \\
\hline & Private & $\begin{array}{c}.196 ;[0.02,0.36] ; .04 \\
(.12)\end{array}$ & $\begin{array}{c}-.230 ;[-0.40,-0.06] ; .016 \\
(.08)\end{array}$ & $\begin{array}{c}-.217 ;[-0.38,-0.06] ; .02 \\
(.54)\end{array}$ \\
\hline \multirow{2}{*}{$\begin{array}{l}\text { Satisfaction } \\
\text { (a secondary } \\
\text { outcome) }\end{array}$} & Public & - & $-.427 ;[-0.55,0.27] ;<.001$ & $-.088 ;[-0.21,0.04] ; .17$ \\
\hline & Private & - & $\begin{array}{c}-.358 ;[-0.52,-0.12] ;<.001 \\
(.47)\end{array}$ & $\begin{array}{c}-.162 ;[-0.33,0.01] ; .09 \\
(.51)\end{array}$ \\
\hline
\end{tabular}

Notes: Pub PHC = Public primary health care; Pub SHE = Public secondary health care

Multiple regression: key predictors of work design outcomes

In the public doctors, organizational supports were found the strongest predictor of all outcomes and explained nearly $60 \%$ of a total predicted variance in satisfaction, which in case of turnover intention and burnout were $88 \%$ and $68 \%$ respectively. Notably, the variance in satisfaction and turnover intention in the private doctors was predicted merely by organizational supports, while that in burnout was explained by external social supports. Table 5 presents the values of $R, R^{2}$ changes, standardized betas, and $F$ changes including $p$-values of the key predictors of outcomes in both the sectors. 
Table 5: Multiple regression statistics of key predictors of outcomes of interest in the public and private doctors

\begin{tabular}{|c|c|c|c|c|c|c|c|}
\hline \multirow{2}{*}{$\begin{array}{l}\text { Model } \\
\text { Provider type }\end{array}$} & \multirow[t]{2}{*}{$R$} & \multirow[t]{2}{*}{$R^{2}$} & \multirow{2}{*}{$\begin{array}{l}\text { Standardized } \\
\beta \text { ( } p \text {-value) }\end{array}$} & \multicolumn{4}{|c|}{ Change statistics } \\
\hline & & & & $R^{2}$ change & F change & $\mathrm{df} 1 / 2$ & $\begin{array}{l}\text { Sig. } \\
\text { F change }\end{array}$ \\
\hline \multicolumn{8}{|l|}{$\begin{array}{l}\text { A. Model: satisfaction } \\
\text { Public doctors }\end{array}$} \\
\hline 1. Organizational supports & .371 & .137 & $.19(.006)$ & .137 & 36.32 & $1 / 228$ & $<.001$ \\
\hline 2. Job Characteristics & .439 & .193 & $.23(<.001)$ & .056 & 15.55 & $1 / 227$ & $<.001$ \\
\hline 3. Working condition & .469 & .220 & $.17(.009)$ & .027 & 7.90 & $1 / 226$ & .005 \\
\hline 4. Health-professional politics & .484 & .235 & $-.13(.040)$ & .015 & 4.28 & $1 / 225$ & .040 \\
\hline \multicolumn{8}{|l|}{ Private doctors } \\
\hline 1. Organizational supports & .539 & .290 & $.539(<.001)$ & .290 & 42.91 & $1 / 105$ & $<.001$ \\
\hline \multicolumn{8}{|l|}{$\begin{array}{l}\text { B. Model: turnover intention } \\
\text { Public doctors }\end{array}$} \\
\hline 1. Organizational supports & .416 & .173 & $-.37(<.001)$ & .173 & 47.85 & $1 / 228$ & $<.001$ \\
\hline 2. Health-professional politics & .443 & .196 & $.16(.012)$ & .023 & 6.36 & $1 / 227$ & .012 \\
\hline \multicolumn{8}{|l|}{ Private doctors } \\
\hline 1. Organizational supports & .351 & .123 & $-.35(<.001)$ & .123 & 15.02 & $1 / 107$ & $<.001$ \\
\hline \multicolumn{8}{|l|}{$\begin{array}{l}\text { C. Model: burnout } \\
\text { Public doctors }\end{array}$} \\
\hline 1. Organizational supports & .209 & .044 & $-.16(.019)$ & .044 & 10.41 & $1 / 228$ & .001 \\
\hline 2. Health-professional politics & .255 & .065 & $.15(.023)$ & .021 & 5.23 & $1 / 227$ & .023 \\
\hline \multicolumn{8}{|l|}{ Private doctors } \\
\hline 1. External social supports & .291 & .085 & $-.292(.002)$ & .085 & 9.91 & $1 / 107$ & .002 \\
\hline
\end{tabular}

Note: Sig. indicates significance

\section{DISCUSSION}

This study aimed to identify the relationships of work characteristics to job satisfaction, turnover intention, and burnout among doctors of the public primary, public secondary, and private facilities of the district health system of Bangladesh and whether or not the relations differ among those target groups, and to identify the major predictors of those outcomes of interest in them.

Overall, all significant correlations were quite modest in magnitude; however, since the sample size was adequately large the correlations are meaningful. We found no significant differences between the responses on work characteristics and outcomes of interest in the public primary and secondary level doctors which indicate similar effects of the work characteristics on the public doctors' job satisfaction, turnover intention and 
burnout status; however, there are significant differences between the public and private sector doctors. This section will briefly describe those distinctions.

Organizational supports predicted incomparably high variations in satisfaction and turnover intention in both the public and private doctors. However, the predicted variations in burnout were notably low in both sector doctors (Table 5).

\section{Work characteristics and doctors' job satisfaction}

Empirically, organizational supports such as good managerial support, performance evaluation and feedback, reward systems (promotion, increment), resource availability and career growth opportunity positively influence employees' satisfaction (Ruth, 2001; Campion et al.,1996). Our study findings are consistent with those studies.

In the public health sector of Bangladesh, senior General Physicians (GPs) usually subjugate the administrative sub-cadre without prior administrative/managerial training and are successively promoted as an 'Upazilla (sub-district) Health and Family Planning Officer' (head of a upazilla primary health care system) and then to Civil Surgeon (head of a district health system) and so on. At upazilla and district level hospitals, postgraduate doctors have to work under the administrators who most often are GPs. Tensions between public doctors and administrators are common (WHO, 2015); thus, low organizational and internal social supports are phenomenal.

Low salary, benefits and job security correlate to low satisfaction (Houkes et al., 2001), which likely explains the strong direct correlation between organizational supports and satisfaction in private doctors since their job security, salary, benefits and career growth opportunities are implicitly neglected.

Notably, mean scores of organizational supports were substantially low in both the public and private sectors although lower in the public (Table 3). All these findings indicate the crucial need of improving organizational supports to enhance job satisfaction in both the public and private doctors.

Further, the study of Campion (1988) reported that unpleasant working conditions often are related to low job satisfaction, reflected in favours our findings of significant positive correlations between physical working conditions and satisfaction in both the public and private doctors. Thus, improvement in physical working conditions is necessary to improve doctors' satisfaction in both sectors.

Investigating health-professional politics as a determinant of work design outcomes is unique since only one study of Andaleeb et al. (2007) implicitly addressed the issue that transfer and promotion of public doctors often are influenced by political identity rather than a fair evaluation of performance. Our empirical findings confirm that health- pro- 
fessional politics have a negative impact on satisfaction but direct relations with turnover intention and burnout only in the public doctors.

The degree of internal social supports (e.g. interpersonal relationships with supervisor and co-workers) is directly correlated with job-holders' satisfaction (Janssen et al., 1999; Humphrey et al., 2007). Our study also implies that improvements in the internal social supports would improve doctors satisfaction in both the sectors.

Consistent with the study of Fried \& Ferris (1987) that suggested that job characteristics (e.g. autonomy, feedback from job, task variety, task significance and skill variety) are positively correlated with job satisfaction, we also suggest that there are needs of improving overall job characteristics to improve satisfaction of the public doctors.

\section{Work characteristics and doctors' turnover intention}

There is sufficient evidence of inverse relationships between organizational supports and turnover intention. For example; well-defined career growth reduces turnover intention (Martinez \& Martineau, 1998), and conversely, low salary, benefits, and job security correlate with high turnover intention (Houkes et al., 2001). Our findings are consistent with those studies for both the public and private doctors. Inverse correlations between internal social supports and turnover intention were reported by Janssen et al. (1999) and Humphrey et al. (2007). These studies support our findings for the private doctors.

In Bangladesh, doctors' turnover from the private to the public sector is restricted by the Public Service Commission with an age barrier of no later than 32 years. Oppositely, public doctors are free to leave from public to private service, and turnover is common in the private doctors between private sector facilities. There are examples of public specialist doctors' leaving their jobs for tertiary level private hospitals after completing the minimum service duration criteria for pension. Notably, we found that turnover intentions had wide standard deviations in both the public and private sectors (Table 3 ). This indicates that there are doctors who work with intentions to leave organization (in the public sector) or frequent changing of facilities (in the private sector). Likely, these are the senior specialist doctors experiencing job dissatisfaction and/or high demands with opportunities of high incentives in job markets. This unstable situation is a barrier to optimal output of health sector.

Consistent with the report of Gray-Toft \& Anderson (1981), we also noticed significantly large inverse relations between satisfaction and turnover intention in both sector doctors (Table 4). This indicates that improvement of satisfaction is essential to diminish turnover intention in both sector doctors. 


\section{Work characteristics and doctors' burnout}

Because of their job nature, doctors are among those professionals who often experience high 'job demands' e.g. workload, inferior physical working conditions, time pressure and emotional demands (Morris \& Feldman, 1996). Individual incapability of coping with job demands may lead to job strain including burnout (Meijman \& Mulder, 1998); for instance, excess workload often is related to emotional burnout (Houkes et al., 2001). Further, Bakker et al. (2003) reported that favourable 'job resources' (e.g. organizational and social supports, and autonomy) hold the potential of buffering the stressor effects of job demands. We found that organizational supports are stronger stressors for burnout in the public doctors than in the private; however, in the latter, social supports buffer burnout more strongly.

Considering the long weekly working hours and daily professional activities, workloads are high in both the public and private doctors. However, we found that workloads are quite weak predictor of burnout in both sectors. Reportedly, over $80 \%$ of the public doctors were involved in dual-practice. The common predictor of dual-practice is to supplement low salary in the public sector (Gruen et al. 2002 ; WHO, 2015). In the competitive private market high patient-loads (i.e. workloads) are desirable as directly related to income, which may serve as a buffer against burnout. However, why high workloads are not related to burnout in the private doctors still is not entirely clear.

Overall mean scores of burnout both in the public and private doctors were markedly low (Table 3). Further, our model predicted burnout only weakly. Out of three items of the scale, two items measured burnout indirectly: 'I have become intolerant to my patient since I started my job' and 'I feel a lack of confidence to continue my job effectively and efficiently'. Answers to both scales may possibly be affected by social desirability response bias resulting in low scores. Taking into account the challenges of measuring job stress as described by Bakker \& Demerouti (2007) in critically appraising the two widely used job stress models namely the 'demand-control model' of Karasek, and the 'effort-reward imbalance model' of Siegrist, we realize that measurement of burnout in the doctors of the public-private mixed health system of Bangladesh is also a complex issue. A model integrating organizational, social and job characteristics for direct measuring of burnout with possible other stressors and buffering attributes including individual characteristics and background could be suitable for the Bangladeshi context.

\section{Strengths and limitations}

To the best of our knowledge, this is the first study addressing the work design issues on the health system of Bangladesh. Doctors from all divisions of the country responded with a high response rate. It was impossible to use a random sampling method; thus, selection bias cannot be excluded. However, by sampling doctors from both the public 
and private sectors with a gender distribution similar to the national ratio and with diverse specializations in a unitary health system, we claim that our study results are representative to the key work design issues of the district health system of Bangladesh. The use of a self-administered questionnaire removed the risk of interviewer bias although we cannot ignore the possibility of social desirability response bias on issues relating to professional dignity. We investigated the influence of professional politics on doctors which is an additional issue to other studies of this field. This study would be an essential evidence for policymakers for re-designing the human resource management policy of the health system of Bangladesh as well as of other countries with similar contexts. Further studies are necessary for an in-depth exploration of the opinion of key stakeholders for recommending strategic and sustainable work re-design for the publicprivate mixed health system of the country.

\section{CONCLUSION}

Work design in the health system of Bangladesh is in need of substantial development. Inadequate organizational supports (e.g. lack of performance evaluation and reward system, low salary, benefits and career growth opportunities, inefficient managerial supports, scarce resources) as the most potential predictors exert an adverse influence on satisfaction and turnover intention in both sectors as well as on burnout for public doctors; burnout in private doctors has a significant indirect relation with external social supports. The adverse influence of health-professional politics on satisfaction, turnover intention and burnout in the public doctors is alarming. Physical working conditions have strong adverse effects on job satisfaction in doctors of both sectors and on turnover intention only in private doctors. While internal social supports are found as important determinants of doctors' job satisfaction in both sectors, job characteristics only predicts public doctors' satisfaction.

Overall, improvement of the doctors' job satisfaction in both the public and private sectors is crucial through addressing the organizational supports system, which in turn would reduce turnover intention and burnout as well, since all those outcomes are mostly under the potential influence of similar organizational factors. However, social and job characteristics also have meaningful effects on work design outcomes. Improvement of doctors' overall welfare relating to their job is essential to improve their performance as well as to enhance optimal output of the health system of Bangladesh. 


\section{REFERENCES}

Andaleeb, S. S., Siddiqui, N., \& Khandakar, S. (2007). Patient satisfaction with health services in Bangladesh. Health Policy and Planning, 22(4), 263-273.

Bakkar, A.B., Demerouti, E., Taris, T.W., Schaufeli, W.B. \& Schreurs, P. J. G. (2003). A Multigroup Analysis of the Job Demand-Resources Model in Four Home Care Organizations. International Journal of Stress Management, 10(1), 16-38.

Bakker, A. B., \& Demerouti, E. (2007). The Job Demands-Resources model: state of the art. Journal of Managerial Psychology, 22(3), 309-328.

Bhandari, P., Bagga, R., \& Nandan, D. (2010). Levels of Job Satisfaction among Healthcare Providers in CGHC Dispensaries. Journal of Health Management, 12(4), 403-422.

Campion, M.A., Papper, E. M., \& Medsker, G. J. (1996). Relations between work team characteristics and effectiveness: A replication and extension. Personnel Psychology, 49, 429-452.

Campion, M. A. (1988). Interdisciplinary Approaches to Job Design: A Replication with Methodological Extensions. Journal of Applied Psychology, 73(3), 467-481.

Fried, Y., \& Ferris, G. (1987). The validity of the job characteristics model: A review and meta-analysis. Personnel Psychology, 40(2), 287-322.

Gruen, R., Anwar, R., Begum, T., James R. Killingsworthb, J.R. \& Normand, C. (2002). Dual job holding practitioners in Bangladesh: An exploration [Online]. Social Science and Medicine, 54(2), 267-279.

Houkes, I., Janssen, P.P.M., de Jonge, J. \& Nijhuis, F. J. N. (2001). Specific relationships between work characteristics and intrinsic work motivation, burnout and turnover intention: A multi-sample analysis. European Journal of Work and Organizational Psychology, 10(1), 1-23.

Humphrey, S. E., Nahrgang, J. D., \& Morgeson, F. P. (2007). Integrating motivational, social, and contextual work design features: a meta-analytic summary and theoretical extension of the work design literature. The Journal of Applied Psychology, 92(5), 1332-1356.

Janssen P.P.M., De Jonge, J. \& Bakker, A. B. (1999). Specific determinants of intrinsic work motivation , burnout and turnover intentions : a study among nurses. Journal of Advanced Nursing, 29(6), 13601369.

Jelstad, B. (n.d.). Job characteristics and its outcomes - A comparative work design study of non-profit and profit organizations.

Kulik, C. T., Oldham, G. R., \& Hackman, J. R. (1987). Work design as an approach to person-environment fit. Journal of Vocational Behavior, 31, 278-296.

Lichtenstein, R. (1984). Measuring the job satisfaction of physicians in organized settings. Medical care, 22 (1), 56-68.

Loher, B. T., Noe, R. A., Moeller, N. L., \& Fitzgerald, M. P. (1985). A meta-analysis of the relation of job characteristics to job satisfaction. Journal of Applied Psychology, 70(2), 280-289.

Martinez, J. \& Martineau, T. (1998). Rethinking human resources : an agenda for the millennium. Health Policy and Planning; $13(4), 345-358$.

Meijman, T.F. \& Mulder, G. (1998). Psychological aspects of workload, in: Drenth, P.J.D., Thierry, H., de Wolff, C.J. Handbook of work and organizational psychology (2nd ed.). East Sussex, UK: Psychological Press Ltd.

Mendoza Aldana, J., Piechulek, H. \&, \& Al-Sabir, A. (2001). Client satisfaction and quality of health care in rural Bangladesh. Bulletin of the World Health Organization, 79(6), 512-517.

Ministry of Health and Family Welfare. (2013). Health Bulletin 2013. Retrieved from http://www.dghs.gov.bd/ images/docs/Other_Publication/HB 2013 final - Full version 1March14.pdf

Morgeson, F.P. \& Humphrey, S.E. (2008). Job and Team Design: Toward a More Integrative Conceptualization of Work Design. Research in Personnel and Human Resource Management, 27.

Morgeson, F.P. \& Humphrey, S. E. (2006). The Work Design Questionnaire (WDQ): developing and validating a comprehensive measure for assessing job design and the nature of work. The Journal of Applied Psychology, 91(6), 1321-1339. 
Morris, J. A., \& Feldman, D. C. (1996). The Dimensions, Antecedents, and Consequences of Emotional Labor. The Academy of Management Review, 21(4), 986-1010.

Ruth, W. (2001). How Leaders Foster Self-Managing Team Effectiveness: Design Choices Versus Hands-on Coaching. Organization Science, 12(5), 559-577.

Tabachnick, B.G. \& Fidell, L. S. (2013, p.124-128). Using multivariate statistics (6th ed.). Boston: Pearson Education.

Warr, P., COOK, J. \& Wall, T. (1979). Scales for the measurement of some work attitudes and aspects of psychological well-being. Journal of Occupational Psychology, 52, 129-148.

West, C. P., Dyrbye, L. N., Sloan, J. A., \& Shanafelt, T. D. (2009). Single Item Measures of Emotional Exhaustion and Depersonalization Are Useful for Assessing Burnout in Medical Professionals. Journal of General Internal Medicine, 24(12), 1318-1321.

WHO. (2000). The World Health Report 2000, Health systems: Improving performence. Retrieved from http://www.who.int/whr/2000/en/whr00_en.pdf. [Accessed 24/06/2015]

WHO. (2015). Bangladesh Health System Review. Retrieved from http://www.wpro.who.int/asia_pacific_ observatory/hits/series/bgd_health_system_review.pdf. 


\section{Chapter}

\section{Challenges of satisfaction of key stakeholders of the district health system of Bangladesh and ways to improve: A qualitative study}

Accepted as:

Roy A, van der Weijden $T$, deVries $N$. Challenges of satisfaction of key stakeholders of the district health system of Bangladesh and ways to improve: A qualitative study. Health Syst Policy Res. 2017, 4:2. 


\section{ABSTRACT}

Introduction: A qualitative study was conducted to investigate insights from the key stakeholders of Bangladesh's healthcare system in order to explore determinants of their satisfaction and strategies for improvement.

Methods: Six homogenous focus group discussions were conducted during January 2016, including district public health administrators, private facility owners, public doctors, private doctors, rural patients, and civil society representatives from three districts. An expert translated video-taped sessions from Bengali into English. Two researchers reached consensus on independently coded, validated transcripts. A 'directed content analysis' method was used to analyse the data.

Findings: The primary factors of stakeholders' dissatisfaction were grouped into organizational, political, socioeconomic, market and moral issues. Inefficient management of resources relating to bureaucracy, incompetent local administration, corruption and health-professional politics were the key barriers to satisfaction in the public sector; in the private sector, these were deficient market regulation, and social status gaps. These issues reflect inter-sector tensions, an imperfect market and mistrust in healthcare. Risks of health catastrophe were perceived as likely in both sectors.

Conclusion: Decentralization of governance to a multisectoral body with ample resources and the power to control a public-private mixed district healthcare system would reduce authoritative and collaborative gaps, unethical practices and threats of market failure. Reducing undue political influence and instituting fair performance evaluation are crucial to recovering public doctors' and administrators' motivation and satisfaction. Community involvement in health care would improve people's trust in the health system. Establishing balanced competition between the public and private sectors, and implementing a health insurance system are the priority items to improve efficiency and economic protection in healthcare and ultimately people's health.

Keywords: satisfaction; public-private mixed; health system; health professionals; health administrators; corruption; decentralization; Bangladesh. 


\section{INTRODUCTION}

Satisfaction in health care is a worldwide socioeconomic and political issue. Most studies on satisfaction in healthcare systems are focused on patients' opinions, and consider these to be the key indicator of satisfaction level. However, the satisfaction of other stakeholders such as administrators and doctors is also important, since healthcare system outcomes depend heavily on their roles and interests. For example, without health workers' and especially doctors' adequate fit and satisfaction in organizational settings, patient well-being is at risk (Cockcroft et al., 2011; Bhandari, Bagga, \& Nandan, 2010).

Health care services in Bangladesh are provided through public-private mixed provisions. Whereas the public sector financing is tax-and donor-based, the private sector is market-based. The private health market is rapidly growing since 1980s following adapting the neo-liberal market economy policy. The public sector is the main source of primary health care services, while nearly three-fourths of the total patients receive curative services from the private market. The district health system in Bangladesh plays a significant role in the country's health as well as economic development, as it is the key source of health services to the majority of rural residents, who make up nearly $72 \%$ of a total population of 151 million (Ministry of Health and Family Welfare, 2013). To identify the factors influencing the satisfaction of administrators, doctors and rural patients in the public-private mixed district health system of Bangladesh, we have conducted a series of quantitative studies. The key findings of those quantitative studies are presented below:

(a) Findings of the study on the roles and limitations of administrators in the district public and private health sectors:

Inefficient utilisation of available resources in the centrally regulated public health system was identified as an obvious problem. This was associated with wide power gaps between the central and local authorities, and disparities between supply and demand with consequent wastage and misuse of scarce resources. In the private sector, the effectiveness of cost and quality regulation is sub-optimal. The system of licensing and accreditation of private health facilities is outdated, and hence ineffective. Local authorities' compliance with the stringent central bureaucracy and their satisfaction seem mutually exclusive. Optimal utilisation of the existing primary health care resources is a high priority. A potential market failure could be prevented and controlled by amending the licensing and accreditation rules involving multisectoral public-private mixed regulatory actors. A 'deconcentration' type of regulatory reform which includes increasing the capacity of the local authorities and implementing reward and sanction-based policy seems to be a promising strategy to improve rural people's health and economic well- 
being, as well as to enhance local administrators' satisfaction in healthcare (Roy et al., 2016).

(b) Findings of the study on predictors of satisfaction of rural patients

Clients' satisfaction level (CSL) was identified as low in both the public and private health sectors, with significantly lower satisfaction in the public sector. Accessibility (in financial terms) predicted relatively high variations in CSL both in the public sector (18.2\%) and in the private sector (25.0\%). Availability predicted distinctly higher variations in CSL in the public sector (34.6\%). Structural factors (i.e. tangibility, availability and accessibility) predicted higher variations in clients' satisfaction in the public sector, whereas service process features (i.e. responsiveness, reliability, empathy, communication and courtesy) had a greater influence in the private sector. Financial accessibility poses a crucial risk of impoverishment in the healthcare system. Both structural and process-related features of healthcare are in ample need of reform in order to improve existing low satisfaction among rural patients.

(c) Findings of the study on doctors' job satisfaction, turnover intention and burnout

\section{A brief overview:}

We investigated correlations between work characteristics (i.e. organizational and social supports, and job characteristics) and doctors' job satisfaction, turnover intention and burnout, and examined whether or not these differ for public and private doctors. We also explored predictors of doctors' job satisfaction, turnover intention and burnout.

Organizational supports (e.g. incentives, managerial support, performance evaluation and career growth) were the strongest predictors with a negative effect on job satisfaction and turnover intention for both public and private doctors; in this regard, the private doctors experienced more support. Despite doctors from both sectors reporting considerably high workloads in terms of weekly working hours and patient loads per day - with higher loads among the public doctors - this did not explain burnout in either group. The effects of health-professional politics on public doctors' satisfaction, turnover intention and burnout were alarming. Internal social supports had a significantly higher positive correlation with job satisfaction for the private doctors compared to the public doctors. Overall, improved organizational supports are crucial for enhancing doctors' welfare in both sectors.

Because of multidimensional interests of the key stakeholders, including administrators, doctors, patients and society as a whole, (dis)satisfaction in the public-private mixed health system of Bangladesh has evolved into a complex phenomenon. Deeper insights into the factors identified in the quantitative studies were needed in order to determine stronger evidence-informed policy implications. It was essential to assess key stakeholders' insights and interpretations in an effort to identify strategic policy interventions to improve their satisfaction in healthcare. 
Thus, we considered a qualitative approach aimed at: triangulating the findings of our previous quantitative studies as well as identifying the factors influencing satisfaction in administrators, doctors and rural patients of the public-private mixed district health system through assessing in-depth views of those target groups, including civil society agents; and exploring potential interventions to improve their satisfaction in healthcare. The study findings would be an essential asset to policymakers in gaining a better understanding of the barriers to satisfaction in healthcare. By addressing evidenceinformed interventions to improve satisfaction in the target actors, this study would ultimately contribute to people's access to healthcare and health in rural areas.

\section{METHODOLOGY}

\section{Study design, settings and population}

We conducted a qualitative study involving participants from three northern districts of Bangladesh. The country's key district (i.e. local) public health administrators are the Civil Surgeon and the Upazilla (i.e. sub-district) Health and Family Planning Officer (UHFPO). While the Civil Surgeon is the head of a district health system, the UHFPO is the manager of an upazilla primary health care system, and is therefore accountable to the Civil Surgeon. In a centralized regulatory system, Civil Surgeons ultimately report to the Director General of Health Services through the divisional Director of Health (Ministry of Health and Family Welfare, 2013). Private health administrators are owners of the private facilities, and as such are liable to the Civil Surgeon for initial licensing processes and yearly accreditation of facilities. Public and private doctors are the two distinct types of health care providers. Private practice by public doctors is formally permitted after official public time. Thus, many of these doctors are dual practitioners, i.e. treating patients privately for extra income in addition to a public job (Civil Surgeon Office, 2014; Cockcroft et al., 2011).

We collected data through homogenous focus group discussions (FGDs) with the following key stakeholders: district public health administrators, owners of private health facilities, public doctors, private doctors, rural patients in both the public and private sectors, and civil society representatives. We defined rural patients as residents other than those in the district and upazilla headquarters. For administrators and doctors, at least three years and five years of experience, respectively, were considered essential. Civil society representatives were selected based on their well-known reputations in social activities. Table 1 shows background information for the participants in all six FGDs. 


\section{Sampling technique}

Considering social and professional disparities among the stakeholders, we organized six homogenous groups to enable participants within the group to speak freely. A purposive sampling method was used. The Principal Investigator contacted the defined participants through his professional and social networks. We planned to include six participants in each group, and to arrange all FGDs at one of the three sample district headquarters. For this purpose, potential participants' residences, business and professional links, and visits to that place were considered. Accordingly, ten respondents were initially contacted for each FGD. The first six contactees who agreed to join and matched a common date and time were finally selected. We included adult patients who had been treated and discharged from health facilities at least two weeks but not more than six weeks prior the FGD date. This was done to reduce risk of information bias resulting from immediate reactions to treatment outcomes as well as from short memory. Out of ten rural patients from both the public and private sectors who were identified and contacted through clinics/hospitals and rural NGO workers, seven ultimately joined the FGD.

Table 1: Background information of respondents of six focus group discussions

\begin{tabular}{|c|c|c|c|c|c|}
\hline Data source & Gender & $\begin{array}{l}\text { Respondents' } \\
\text { identity }\end{array}$ & $\begin{array}{l}\text { Experience } \\
\text { in years }\end{array}$ & Position/posting & Background/qualification \\
\hline \multirow{6}{*}{$\begin{array}{l}\text { (FGD1) } \\
\text { Public doctors }\end{array}$} & Male & FGD1- 1 & 14 & District hospital & Cardiologist (MBBS, D. Card.) \\
\hline & Male & FGD1- 2 & 11 & UHC & General Surgeon (FCPS) \\
\hline & Female & FGD1- 3 & 10 & $\mathrm{UHC}$ & Junior Consultant (MBBS, DGO) \\
\hline & Male & FGD1- 4 & 14 & UHC & Junior Consultant (MBBS, DGO) \\
\hline & Male & FGD1- 5 & 17 & District hospital & GP (MBBS) \\
\hline & Male & FGD1- 6 & 12 & District hospital & $\mathrm{GP}(\mathrm{MBBS})$ \\
\hline \multirow{6}{*}{$\begin{array}{l}\text { (FGD2) } \\
\text { Public } \\
\text { administrator }\end{array}$} & Male & FGD2- 1 & 27 & CS & GP (MBBS) \\
\hline & Male & FGD2- 2 & 20 & UHFPO & Public Health (MBBS, MPH) \\
\hline & Male & FGD2- 3 & 20 & UHFPO & Public Health (MBBS, MPH) \\
\hline & Female & FGD2- 4 & 19 & UHFPO & GP (MBBS) \\
\hline & Male & FGD2- 5 & 23 & UHFPO & GP (MBBS) \\
\hline & Male & FGD2- 6 & 34 & Director of Health (Ret) & Public Health (MBBS, MPH) \\
\hline \multirow{6}{*}{$\begin{array}{l}\text { (FGD3) } \\
\text { Private doctors }\end{array}$} & Male & FGD3- 1 & 10 & Private hospital & Dental Surgeon (FCPS) \\
\hline & Male & FGD3- 2 & 21 & Private hospital & GP (MBBS) \\
\hline & Female & FGD3- 3 & 10 & Private hospital & Consultant (DGO) \\
\hline & Male & FGD3- 4 & 13 & Private hospital & GP (MBBS) \\
\hline & Male & FGD3- 5 & 9 & Private clinic & GP (MBBS) \\
\hline & Male & FGD3- 6 & 14 & Private hospital & GP (MBBS) \\
\hline
\end{tabular}




\begin{tabular}{|c|c|c|c|c|c|}
\hline Data source & Gender & $\begin{array}{l}\text { Respondents' } \\
\text { identity }\end{array}$ & $\begin{array}{l}\text { Experience } \\
\text { in years }\end{array}$ & Position/posting & Background/qualification \\
\hline \multirow{6}{*}{$\begin{array}{l}\text { (FGD4) } \\
\text { Private } \\
\text { administrators }\end{array}$} & Male & FGD4- 1 & 9 & Owner & Radiologist (MBBS, DMRD) \\
\hline & Male & FGD4- 2 & 15 & Owner & GP (MBBS) \\
\hline & Male & FGD4- 3 & 14 & Owner & Management (MBA) \\
\hline & Male & FGD4- 4 & 5 & Owner & Banker (MA, Accounting) \\
\hline & Male & FGD4- 5 & 22 & Owner & Lab. Technologist (BSc.) \\
\hline & Male & FGD4- 6 & 13 & Owner & Bachelor of Arts \\
\hline \multirow{7}{*}{$\begin{array}{l}\text { (FGD5) } \\
\text { Civil society } \\
\text { representatives }\end{array}$} & Male & FGD5- 1 & 2 terms* & Municipality Mayor & Bachelor of Arts (Law) \\
\hline & Male & FGD5- 2 & 15 & Journalist & Master of Arts \\
\hline & SMale & FGD5- 3 & 24 & Lawyer & Master of Arts (Law) \\
\hline & Male & FGD5- 4 & 19 & NGO Deputy Director & Master of Arts (DS) \\
\hline & Male & FGD5- 5 & 16 & College Teacher & Master of Arts (English) \\
\hline & Male & FGD5- 6 & 2 terms** & Secretary (District-BMA) & Paediatrician (MBBS, DCH) \\
\hline & & & Types of pro & ovision and disorder & \\
\hline \multirow{7}{*}{$\begin{array}{l}\text { (FGD6) } \\
\text { Patients } \\
\text { (FGD6-a: public } \\
\text { patients; FGD- } \\
\text { b: private } \\
\text { patients) }\end{array}$} & Female & FGD6b- 1 & $\begin{array}{l}\text { Receives dia } \\
\text { private facil }\end{array}$ & $\begin{array}{l}\text { iabetic treatment from } \\
\text { ility }\end{array}$ & Official job \\
\hline & Female & FGD6b- 2 & $\begin{array}{l}\text { Operated ac } \\
\text { private clini }\end{array}$ & $\begin{array}{l}\text { cute appendicitis in a } \\
\text { ic }\end{array}$ & Student \\
\hline & Male & FGD6a- 3 & $\begin{array}{l}\text { Operated ga } \\
\text { district hosp }\end{array}$ & $\begin{array}{l}\text { sall stone in a public } \\
\text { pital }\end{array}$ & Official job \\
\hline & Male & FGD6a- 4 & $\begin{array}{l}\text { Receives hy } \\
\text { from public }\end{array}$ & $\begin{array}{l}\text { ypertension treatment } \\
\text { c facility }\end{array}$ & Retired banker \\
\hline & Female & FGD6b- 5 & $\begin{array}{l}\text { Operated ac } \\
\text { private clini }\end{array}$ & $\begin{array}{l}\text { cute cholecystitis in a } \\
\text { ic }\end{array}$ & Student \\
\hline & Male & FGD6b- 6 & $\begin{array}{l}\text { Operated ga } \\
\text { clinic }\end{array}$ & sall stone in a private & Businessman \\
\hline & Female & FGD6a- 7 & $\begin{array}{l}\text { Operated a } \\
\text { hospital and } \\
\text { incisional he }\end{array}$ & $\begin{array}{l}\text { appendicitis at public } \\
\text { d } \\
\text { ernia at private hospital }\end{array}$ & Housewife \\
\hline
\end{tabular}

Notes: * Indicates 5-years each term; ${ }^{* *}$ Indicates 2-years each term; FGD = Focus group discussion; UHC = Upazilla health complex; MBBS = Bachelor medicine and bachelor of surgery; D. Card = Diploma in cardiology; FCPS = Fellow of the college of physician and surgeon; $\mathrm{MPH}=$ Master of public health; DGO = Diploma of gynaecology and obstetrics; CS = Civil Surgeon; UHFPO = Upazilla Health and Family Planning Officer; GP = General physician; $\mathrm{MBA}=$ Master of business administration; DS = Development studies; $\mathrm{BMA}=$ Bangladesh Medical Association; DCH = Diploma in child health; An explanation of respondent identity: FGD1- 2 refers 'respondent 2 of focus group discussion 1'; FGD6-a = public patients; FGD6-b = private patients.

\section{Data collection}

Discussion topics in the interview guide were based on key issues which we found in our previous three quantitative studies on the satisfaction level of administrators, doctors and rural patients in both the public and private district health sectors. Six interview guides were developed, consisting of common and group-specific topics aimed at engaging participants in free dialogue. Discussion topics were provided to the respondents 
in advance with three purposes, firstly, to ensure free decision making regarding joining the FGD; secondly, to allow them to prepare for meaningful participation; and thirdly, to give feedback on the discussion guidelines. The interview guides were started with open questions to enable the participants to raise any other topics that they felt were missing. Three trained facilitators with public health backgrounds and extensive experience working in the public $(n=2)$ and private $(n=1)$ health sectors facilitated the FGDs. While one of the facilitators focused on a specified FGD, the Principal Investigator acted as a general moderator.

Each session began with some common ground rules of disciplined discussion. Facilitators affirmed confidentiality and anonymity, and explained the need for video recording of the sessions. Informed consent was given by all respondents. To assurance anonymity, we instructed participants to refer to each other's numbers in the dialogues. To ensure everyone's active participation, discussion on each topic was started by a different respondent and others then contributed. However, we ensured participants' rights and autonomy with regard to their response or non-response to any topic. Each session took an average of 90 minutes. All sessions were video recorded. Data was collected during January 2016.

\section{Data analysis}

FGDs were conducted in the local Bengali language and an expert translated all recorded discussions into English. The Principal Investigator checked each translated transcript with video records to ensure validity of the translations of the discussions. The 'manifest coding' method was used for coding the texts, as described by Bernard \& Ryan (2010, p.287-310). Two investigators (AR; TvdW) coded the transcripts independently and then compared their codes. We solved any discrepancies through discussion. We grouped codes into categories and sub-categories and then analysed the text using a 'directed content analysis' approach as described by Hsieh \& Shannon (2005). NVIVO (version 10) was used to analyse the data.

\section{FINDINGS}

Participants did not add any topics to the initial lists that were sent to them. However, the issues of corruption, unethical practice and inter-sector gaps in the health care system were raised during the discussion of other related topics. A high level of agreement, although not on all topics, was noticed among the participants of all FGDs; this increased our interest in the discrepancies.

Overall, lack of coordination between central and local administrators, inefficiency in human and material resource management, and insufficient skills of local administrators 
were identified as the key organizational barriers to satisfaction in the public health sector; in the private sector, these were deficient regulatory oversight, market control and public-private collaboration. Health professional politics (i.e. the reflection of the country's politics and of political allegiance in doctors' professional lives) was recognized as a key adverse influence on the satisfaction of public doctors and administrators. Unethical practices in association with demoralized doctors, private facility owners and pharmaceutical representatives were common threats to patients' economy and the dignity of the health profession. This section presents the stakeholders' views of challenges to their satisfaction as well as the differences between these views, and concludes with their recommendations for improving satisfaction in the health care system.

Public health administrators' and public doctors' views of barriers to satisfaction

We grouped the key barriers to the public health administrators' and doctors' satisfaction into three broad categories: organizational, political, and patient behaviour factors.

\section{Organisational factors}

Central-local power gaps and related effects:

Wide gaps in power and coordination between central and local public health authorities were mentioned by the public administrators and doctors. Along with central dependency, local authorities' inadequate power to purchase drugs and equipment causes delays in supplying medical goods. Additionally, centrally supplied drugs and equipment often do not comply with local authorities' opinions and needs. These issues were linked to misuse of scarce resources as well as limited delivery of and access to health care, all of which cause dissatisfaction among patients, doctors and administrators.

Human resource management in the public health sector:

Local public administrators and doctors mentioned that the central authority transfers doctors, especially those from rural public facilities without taking local authorities' opinions and needs into account. Poor working conditions, inadequate salaries, lack of transport and residence facilities, limited career growth opportunities, lack of performance evaluation and non-provision of incentives for rural work were mentioned in this regard. These issues were claimed to be linked to doctors' disinterest in working in rural areas, which in turn aggravates the existing shortages of doctors. Participants remarked that the subsequent effects included urban distribution of doctors, excess workloads for the acting doctors, poor quality of services (e.g. long waiting time, short consulting times and overall delays in treatment) and the ultimate dissatisfaction among both doctors and patients. 
Procurement and management of material resources:

Public administrators and doctors jointly reported shortages of medicines and diagnostics. Additionally, they stated that the frequent malfunctioning of equipment is disappointing. Local administrators lack the authority to repair equipment without approval from central authorities, which is a lengthy process. Many of their opinions were that unskilled operators and/or intentional mishandling are likely reasons for equipment malfunction; however, there was disagreement on this point and the issue of corruption was raised.

"I do not totally agree that operators intentionally damage equipment. The central procurement system is faulty and corrupted. Supplied machines are defective from the beginning. What can an operator do with a faulty machine? ... The local authority can disagree in receiving any equipment if it does not comply with defined specifications. But there are risks of punishment and harassment" - a public doctor: FGD1- 4.

Skills and compliance in local public health management:

Public administrators and doctors stated nearly identical opinions that most of the local public health administrators (i.e. Civil Surgeons and UHFPOs) have neither postgraduate medical degrees nor administrative training. These administrators have limited management skills that result in poor compliance (e.g. absenteeism) within the local managerial system.

"Postgraduate doctors feel uneasy work under an administrator who is a general practitioner and has no management training"- a public administrator: FGD2- 6.

\section{Political issues}

Both the public administrators and doctors expressed disappointments because of political grouping among doctors (i.e. health-professional politics) and political interference in routine administrative activities. Doctors' transfer and promotion often depend on political identity and backing rather than performance evaluation. This arose as a source of serious discontent.

"The rule is that public doctors must work in rural areas for at least two years. Is it possible for me to leave a rural facility and be posted at an urban facility by myself? The local authority is not empowered to transfer doctors. Who does violate the rule? Politics, corruption and nepotism are the drivers of rule violation"- a public doctor: FGD1- 4.

\section{Patient behaviour factors}

Doctors from both sectors mentioned that patients are not accustomed to the appointment system; patients all crowd into facilities at the same time in the early hours 
of the day, and everyone wants quick service. Hence, some patients receive treatment at late hours and therefore react badly. Patients are often not satisfied, even with a good prognosis, because of the economic consequences. In addition, patients frequently ignore doctors' schedules. These behaviours often complicate doctor-patient relationships.

\section{Private health facility owners' and private doctors views of barriers to satisfaction}

We grouped the key barriers to the private facility owners and doctors' satisfaction into two categories: organizational and market-related factors.

\section{Organizational factors}

Private doctors' well-being:

Private doctors stated that despite their recognizable contribution to health care, they are treated poorly as professionals and employees. Since there is no national policy for private doctors, they lack job security, adequate salaries and benefits (e.g. pension), and career growth opportunities. Private doctors' frustration related to social status and welfare gaps compared to their public counterparts were understood to be fuelled by sharing their income opportunities with dual-practitioners in the private sector.

"Public doctors have good salaries and benefits. They market their profession in public facilities but sell their products in the private sector and become our competitors. However, we are not allowed to practice in public facilities" - a private doctor: FGD3-1.

\section{Private health sector regulation:}

The private facility owners unanimously remarked that dealing with multiple public and local government offices for licensing and accreditation processes is irritating, costly and time-consuming. They pointed out that the national health policy was not officially disseminated to private providers. Non-recognition of the private sector's contributions to health care was mentioned by the private doctors and facility owners.

"The public sector is insufficient to meet the huge healthcare needs of the population. Health system achievements were not possible without the private sector. Also, the major income of public doctors is sourced from the private sector. However, its contributions remain unrecognized" - a private doctor: FGD3- 5. Private administrators expressed displeasure with discriminatory regulations between private and public facilities.

"Only private facilities have to fulfil defined licensing and accreditation criteria of manpower, equipment and environment. But no public health facility fulfils or is required to fulfil such criteria. Many patients stay on the floor in public facilities but we may have to pay charges for the same. It is unfair" - a private facility owner: FGD4- 3. 
Both the private doctors and administrators stated that the private facility inspection team is faulty: it only includes public personnel, and two members of the team treat patients in the facilities under inspection. Due to faulty a regulatory system, bad performers are encouraged; in turn, the cost and quality of services vary widely. These points were also confirmed by public administrators, public doctors, civil society groups and patients. Such issues cause dissatisfaction among good performers.

\section{Market-related factors}

Private administrators remarked that due to high establishment and maintenance costs, high-interest bank loans, and conversely, low profit margins, private facilities need a great deal of time to achieve financial stability. They stated that cost and quality of services were often compromised because of unfair market competition. Patients frequently do not understand the trade-off in cost and quality. These issues were linked to mistrust and disgraceful bargaining between private providers and patients.

\section{Public and private sector patients' views of issues influencing their satisfaction}

We grouped the key influences on patient satisfaction on both sectors into two categories: service process factors and patient background.

\section{Service process factors}

Public sector patients commonly expressed their dissatisfaction because of long waiting times and short consulting times. These were confirmed by public doctors and administrators, who additionally pointed out high patient loads and a shortage of doctors as the explanation. Despite free provision of hotel services and available medicines and the minimum costs of diagnostics, patients stated that there was no guarantee of low-cost treatment in the public sector because of lacking medical supplies. Delayed operative treatment in public facilities was raised as an issue of serious discontent.

"I was admitted to a district hospital with appendicitis. I had to wait for an operation with severe pain because surgery was not considered urgent. When I was operated on, my appendix was found burst. I lost a lot of money and suffered for 22 days there. Lastly, I developed an 'incisional hernia'. Then I went to a private clinic where my hernia operation was done on the same day by the same public hospital surgeon. I recovered within a week. If our doctors can provide good services in private clinics, they can also do the same in government hospitals. But why can't or don't they do so? The government allocates a big health budget. I cannot understand why we are not getting proper services in public hospitals" - a patient: FGD6a-7. 
In contrast, short waiting times along long consulting times and quick surgical treatment were the key drivers of private patients' utilisation of private facilities; however, the issue of quick service has become a topic of debate:

"Quick service does not guarantee good quality service. Operations should have proper justifications. Many operations in private facilities are done without indication because of business interests. In private facilities nearly all pregnant women need caesarean sections. I have doubts about that" - a private patient FGD6a- 4.

High health care costs combined with a lack of information about standard cost and service quality were common concerns of the private patients, and were confirmed by other groups.

\section{Patient background}

Public and private doctor and administrator groups pointed out that many patients are poor and their expectations are high. This causes gaps in supply and demand, and leads to patient dissatisfaction. Doctors from both sectors mentioned that patients are often treated by unqualified practitioners/traditional healers, and come to them at a late stage. The consequent unwanted health and economic outcomes dissatisfy both patients and doctors.

\section{Civil society agents' views on the health care system}

Civil society agents' overall views on the health care situation were quite similar to those of other groups. Additionally, these agents strongly spoke out against unethical practices, and noted flaws in health care system regulation and the roles of the Bangladesh Medical Association, the state-affiliated professional organization of doctors.

\section{Unethical practices in health care}

Civil society agents mentioned that two unethical practices impose financial burdens on the poor patient: firstly, 'referral-fees' which are offered by many diagnostic facilities to doctors for advising unnecessary tests; and secondly, gifts/financial benefits from pharmaceutical representatives for prescribing unnecessary drugs. These issues were confirmed by other groups, and in particular by the private facility owners, who mentioned that referral-fees alone account for a $30 \%$ increase in diagnostic costs for patients. 


\section{Loopholes in health care regulation}

The civil society agents indicated two problems associated with health care regulation threatening people's health and economy: firstly, Civil Surgeons lack sufficient power and are dependent on the central authority; and secondly, health care costs and quality are uncontrolled in the private sector because of weak monitoring and supervision.

\section{The roles of the Bangladesh Medical Association (BMA)}

Civil society representatives' comments on political influence in the health sector were quite similar to those of public administrators and doctors. However, they specifically raised questions about the political and professional roles of BMA.

"BMA started as a non-political professional organization of doctors. Now because of party-based politics, the doctors' community is divided. Transfers and promotions of doctors based on political identity are unfair and not the real role of BMA. BMA should play major roles in stopping immoral practices in healthcare and preserving professional dignity"- a civil society agent: FGD5- 3.

The BMA representative argued that BMA never supports unethical practices. Transfers and promotions are normal administrative procedures. BMA-initiated transfers or promotions of doctors are usually affected to meet the needs of people.

\section{Stakeholders' views on improving satisfaction in health care}

Decentralisation of defined powers, better central-local coordination in human and material resource management, postgraduate training in management or public health for local administrators, and a transparent procurement system were mentioned with regard to addressing key public organizational loopholes. To control health care costs, improve the quality of care and combat unethical practices, the various respondent groups suggested that a multisectoral district health monitoring agent should be installed. Private doctors urged for a policy for their own group. Table 2 presents grouplevel views on addressing problem areas to improve satisfaction in the health care system.

As a general statement, the civil society agents stated that the economic impact for patients in the health care system is a crucial challenge to the country's poverty reduction goal. This issue has to be addressed as a high priority so as to maintain the achievements of the health system and promote the country's development. 
Table2: Stakeholders' recommendations of improving satisfaction in healthcare

\begin{tabular}{|c|c|c|c|}
\hline $\begin{array}{l}\text { Health sector: } \\
\text { Categories of factors }\end{array}$ & Problem areas & Recommended solutions & Source \\
\hline \multirow{13}{*}{$\begin{array}{l}\text { A. Public: } \\
\text { (i) Organizational factors }\end{array}$} & \multirow{6}{*}{$\begin{array}{l}\text { Central-local power } \\
\text { difference and } \\
\text { coordination }\end{array}$} & & \\
\hline & & $\begin{array}{l}\text { Decentralization of specific authorities of purchasing } \\
\text { drugs, and repair and maintenance of equipment } \\
\text { using a defined proportion of local revenue. }\end{array}$ & $\begin{array}{l}\text { FGD1 } \\
\text { FGD2 }\end{array}$ \\
\hline & & $\begin{array}{l}\text { Authority of Civil Surgeons should be increased to } \\
\text { purchase local emergency medical needs. A } \\
\text { multisectoral district purchasing committee could be } \\
\text { formed. }\end{array}$ & FGD5 \\
\hline & & Drugs and equipment should not be supplied & FGD1 \\
\hline & & $\begin{array}{l}\text { without local authorities' opinions and need } \\
\text { assessment. }\end{array}$ & FGD2 \\
\hline & & $\begin{array}{l}\text { Local doctors' involvement in medicine selection and } \\
\text { purchase. }\end{array}$ & FGD1 \\
\hline & \multirow[t]{4}{*}{$\begin{array}{l}\text { Human resource } \\
\text { management }\end{array}$} & $\begin{array}{l}\text { Strict implementation of the existing two-year rural } \\
\text { working rule for public doctors, and no transfer of } \\
\text { doctors without local authorities' concern. }\end{array}$ & $\begin{array}{l}\text { FGD1 } \\
\text { FGD2 }\end{array}$ \\
\hline & & $\begin{array}{l}\text { A completion of two-year rural working could be an } \\
\text { incentive for career development opportunity, }\end{array}$ & FGD1 \\
\hline & & $\begin{array}{l}\text { Provision of transport and low-cost residence } \\
\text { facilities for doctors at rural set-up, } \\
\text { Good working conditions, }\end{array}$ & $\begin{array}{l}\text { FGD1 } \\
\text { FGD2 }\end{array}$ \\
\hline & & $\begin{array}{l}\text { Extension of internee training for a two-year instead } \\
\text { of one year with a mandatory rural working for the } \\
\text { second year, }\end{array}$ & FGD1 \\
\hline & \multirow[t]{2}{*}{$\begin{array}{l}\text { Allocation and } \\
\text { procurement of } \\
\text { material resources }\end{array}$} & $\begin{array}{l}\text { Drug supplies and diagnostic facilities should be } \\
\text { increased, }\end{array}$ & $\begin{array}{l}\text { FGD1 } \\
\text { FGD2 } \\
\text { FGD5 } \\
\text { FGD6 }\end{array}$ \\
\hline & & $\begin{array}{l}\text { Equipment procurement system should be } \\
\text { transparent, }\end{array}$ & FGD1 \\
\hline & Management skills & $\begin{array}{l}\text { Postgraduate management training or Public Health } \\
\text { degree should be mandatory for Civil Surgeons and } \\
\text { Upazilla Health and Family Planning Officers }\end{array}$ & $\begin{array}{l}\text { FGD1 } \\
\text { FGD2 }\end{array}$ \\
\hline $\begin{array}{l}\text { (ii) Service process } \\
\text { factors }\end{array}$ & $\begin{array}{l}\text { Provider-related and } \\
\text { demographic factors }\end{array}$ & $\begin{array}{l}\text { Establishment of good gate-keeping and referral } \\
\text { systems, Increase in number of doctors, }\end{array}$ & $\begin{array}{l}\text { FGD1 } \\
\text { FGD2 }\end{array}$ \\
\hline
\end{tabular}


Table 2 continuation

\begin{tabular}{|c|c|c|c|}
\hline $\begin{array}{l}\text { Health sector: } \\
\text { Categories of factors }\end{array}$ & Problem areas & Recommended solutions & Source \\
\hline \multicolumn{4}{|l|}{ B. Private: } \\
\hline \multirow[t]{15}{*}{ (i) Organizational factors } & \multirow[t]{7}{*}{ Regulatory factors } & Reduction of licensing fees, & FGD3 \\
\hline & & $\begin{array}{l}\text { Provision of an integrated single licensing } \\
\text { organization, }\end{array}$ & \\
\hline & & Private health care costs and quality should & FGD2 \\
\hline & & be standardized and controlled through & FGD3 \\
\hline & & proper monitoring and evaluation system. & FGD4 \\
\hline & & & FGD5 \\
\hline & & & FGD6-b \\
\hline & \multirow{5}{*}{$\begin{array}{l}\text { Public-private } \\
\text { discrimination: facility level }\end{array}$} & \multirow{4}{*}{$\begin{array}{l}\text { A policy defined independent district } \\
\text { healthcare inspection team should be } \\
\text { formed including multiple public-private } \\
\text { representations, }\end{array}$} & FGD2 \\
\hline & & & FGD3 \\
\hline & & & FGD4 \\
\hline & & & FGD5 \\
\hline & & $\begin{array}{l}\text { Public facilities should also be inspected by } \\
\text { the same inspection team with identical } \\
\text { policy criteria, }\end{array}$ & FGD4 \\
\hline & \multirow{3}{*}{$\begin{array}{l}\text { Public-private } \\
\text { discrimination: doctor level }\end{array}$} & A national policy for private doctors to & FGD3 \\
\hline & & $\begin{array}{l}\text { ensure job security, salary, pension and } \\
\text { career growth opportunity, }\end{array}$ & FGD4 \\
\hline & & $\begin{array}{l}\text { Separation of public and private sector by } \\
\text { stopping public doctors' involvement in the } \\
\text { private sector, }\end{array}$ & FGD3 \\
\hline \multirow[t]{2}{*}{$\begin{array}{l}\text { (ii) Market-related } \\
\text { factors }\end{array}$} & Economic factors & $\begin{array}{l}\text { Provision of soft-loan for facility } \\
\text { establishment, }\end{array}$ & FGD4 \\
\hline & Market competition & $\begin{array}{l}\text { Unqualified facilities should be penalized or } \\
\text { closed, }\end{array}$ & FGD4 \\
\hline \multirow{4}{*}{$\begin{array}{l}\text { C. Both public and private: } \\
\text { (i) Moral factors }\end{array}$} & \multirow{4}{*}{ Process-factors } & \multirow{3}{*}{$\begin{array}{l}\text { Referral-fee should be stopped by rules, } \\
\text { and concerned facility and doctors should } \\
\text { be sanctioned, }\end{array}$} & FGD4 \\
\hline & & & FGD5 \\
\hline & & & FGD6-b \\
\hline & & $\begin{array}{l}\text { Culture of gifts/financial benefits between } \\
\text { pharmaceutical company representatives } \\
\text { and doctors should be stopped by rule, }\end{array}$ & FGD5 \\
\hline \multirow{6}{*}{$\begin{array}{l}\text { (ii) Patient-related } \\
\text { factors }\end{array}$} & \multirow[t]{3}{*}{ Socio-economic factors } & \multirow[t]{3}{*}{ Provision of health insurance, } & FGD1 \\
\hline & & & FGD3 \\
\hline & & & FGD4 \\
\hline & \multirow[t]{3}{*}{ Health-seeking behaviour } & $\begin{array}{l}\text { Mass-population health awareness } \\
\text { programme, }\end{array}$ & FGD1 \\
\hline & & Provision of facility-based patient & FGD3 \\
\hline & & & \\
\hline \multirow{5}{*}{$\begin{array}{l}\text { (iii) Politics in health } \\
\text { sector }\end{array}$} & \multirow{5}{*}{$\begin{array}{l}\text { Health-professional politics } \\
\text { in the public sector }\end{array}$} & \multirow{3}{*}{$\begin{array}{l}\text { Transfers and promotions of doctors should } \\
\text { be based on policy-guided performance } \\
\text { evaluation and strictly free from politics, }\end{array}$} & FGD1 \\
\hline & & & FGD2 \\
\hline & & & FGD5 \\
\hline & & $\begin{array}{l}\text { Doctors' commitment is essential to be free } \\
\text { from party-based politics, }\end{array}$ & \\
\hline & & $\begin{array}{l}\text { Doctors should be united for controlling } \\
\text { professional misconducts, }\end{array}$ & \\
\hline
\end{tabular}

Note: FGD = Focus group discussion 


\section{DISCUSSION}

This study aimed to triangulate the findings of our previous quantitative studies on diverse determinants of satisfaction among administrators, doctors and patients in the district health care system through investigating insights from those target groups in addition to civil society agents, and to explore their views on potential interventions to improve satisfaction in the health system of Bangladesh.

Overall, these qualitative study findings have supported the results of our previous quantitative studies and are also consistent with other studies (e.g. Cockcroft et al., 2007; Cockcroft et al., 2011). With the exception of corruption, inter-sector authoritative gaps and moral issues, no notable new issues emerged; however, the insights in this regard were deepened. Organizational, political, social, economic, market-related and moral issues were the main barriers to satisfaction.

\section{Addressing the dynamics of public administrators' and doctors' satisfaction}

\section{Centralised authority versus decentralization}

Due to stringent bureaucracy, the transfer of doctors and supply of medical goods are often based on a command and control system rather than a minimum evaluation of the local authority's opinion or needs. The consequent outcomes of inefficient resource use and dissatisfaction of local administrators are consistent with the report of the National Health Service Confederation (2013) suggesting that a bureaucratic health system design reduces frontline employees' satisfaction and efficiency.

According to public administrators, doctors and civil society representatives, adequate empowerment of local authorities and central-local coordination are crucial. Local authorities' opinion and needs should be prioritised in human and material resources management. Civil Surgeons should have the power to use a certain part of local revenues for emergencies in a transparent system. These recommendations imply administrative decentralization (i.e. deconcentration). Findings from other studies show that decentralization in health systems could be effective if there is ample political and bureaucratic support, managerial capacity and autonomy, and community involvement (Leonard et al., 2013; Jongudomsuk \& Sirsasalux, 2012). In Bangladesh, progress in all these areas is essential; in particular, postgraduate education in public health for local administrators is crucial to improving system compliance.

\section{Corruption versus good governance}

Corruption in the central command and control system is another potential cause of mismanagement of human and material resources. For instance, incidences of coercing 
local authorities into receiving central supplies of faulty equipment without a need assessment, as part of structured corruption, are not uncommon. Corruption is also linked to doctors' transfers and promotion. Good governance is absolutely necessary to mitigate corruption in human and material resource management.

Party-based health-professional politics: a complex issue

Health-professional politics is an influential barrier to public doctors' regular transfer, posting and promotion. Doctors are politically polarised for personal gain since performance is often not measured through fair evaluation. Thus, deprivation combined with tension drives public doctors' and administrators' dissatisfaction.

The Bangladesh Medical Association (BMA) needs to be proactive in controlling professional misconduct (e.g. referral fees) rather than promote political leadership- and interest-based transfer and promotion of doctors. BMA is the right body to control its members' behaviour in order to protect people's economy and professional ethics. This practice of 'self-regulation' has proved to be effective elsewhere, e.g. in Canada (Blackmer, 2007).

A common view was that doctors need to be motivated to avoid party-based politics for the sake of their unity and dignity. Despite strong remarks on professional politics as an unexpected issue that leads to unfair evaluation, disparities and mistrust between public administrators and among doctors, no clear integral solution was suggested.

\section{Challenges versus motivations for retaining doctors in rural settings}

The existing rule of two years mandatory rural service for public doctors is seriously violated. Inadequate physical working conditions, inferior residence and transport facilities, and lack of incentives drive doctors to compete for preterm withdrawal from the rural facilities either by using political backing or resorting to corruption.

A policy for financial and/or non-financial incentives such as assurance of career advancement (post-graduation, promotion), good housing and transport facilities, and pleasant working conditions can retain doctors in rural areas. These findings are consistent with the study of Darkwa et al. (2015) and such incentives have proved effective elsewhere in the world. Additionally, the existing two-year rural working rule should be strictly implemented. Provision of a two-year internship instead of one year, with rural working obligation for the second year, would improve the situation. 


\title{
Addressing the dynamics of satisfaction among private health investors
}

\author{
Private sector contribution versus public regulation, recognition and \\ collaboration
}

The effects of a market economy substantially depend on the public capacity to regulate the market based on public-private collaboration (Jamali, 2004). Having emerged since the 1980s, the private health care sector is one of the fast-growing markets and has captured nearly two-thirds of the country's total health expenditures (WHO, 2015). However, inadequate public-private collaborations in market regulation have resulted in wide variations in costs and quality. The market lacks user-friendly information on standard price and service packages which creates unfair competition and a disgraceful culture of bargaining. Mistrust between providers and patients are common. Unfair competition and information asymmetry lead to market failure.

The private facilities inspection system is ineffective, since the inspectors and dualpractitioners are often the same public officials; thus, good and bad performers are evaluated equally, and service quality is compromised by low costs. In contrast, there are no parallel service quality control criteria for the public health care facilities. This discrimination not only creates authoritative gaps, but also puts patients at risk in terms of health and economic loss in both sectors.

The private sector's contributions to the health system's achievements are undeniable, although they lack proper recognition. Notably, private doctors and owners remain uninformed of their roles in public health goals since the national health policy are not officially disseminated to them. This indicates a major need for public-private collaboration.

A public-private consensus-based policy on the national standard of price and quality of health care services seems essential. To improve regulatory compliance through controlling the cost and quality of health services as well as building collaboration in the health sector, an independent district regulatory body integrating public and private participation would be effective.

Tanzania's experience with the 'Tanzania Essential Health Interventions Project' is an inspiring example of reform through district-level decentralization of authority (de Savigny et al.2004). The stakeholders' recommendations for building the capacity of local administrators and establishing a multisectoral independent oversight body form the basis of the district health system reform. Such a reform seems effective, though it may face resistance from interest groups. However, evidence from the Mumbai (India) shows that legal and political support along with key stakeholders' involvement in policymaking and implementation could resolve tensions (Nandraj, Khot \& Menon, 1999). 
Market establishment and maintenance: economic as well as moral concerns

Establishing and running a private health care facility is challenging because of costly multicentre licensing and accreditation procedures, the costs of human and material resource management and taxation, and insolvency of many patients. This is either solved by securing bank loans or exploiting the health care costs through unnecessary diagnostics and drugs prescriptions. This 'supplier induced demand' has been systematised in collaboration with demoralised private investors, pharmaceutical representatives and doctors. We call it perverse association, which must be strictly prohibited by law. The state provision of soft loans could be effective in controlling need-based distribution of private facilities, cost and quality of health services, a fair information system, providers' ratings, and reinforcement (i.e. rewards for good performers, and support or sanctions for bad performers).

\section{Addressing patients' satisfaction dynamics in the public and private sectors}

Whereas costly but prompt operative treatments in private facilities are often publicly branded as commercially driven rather than based on actual indications, in contrast, free but delayed operations in the public sector are a type of business strategy to shift patients to private facilities. Once a surgical patient is admitted to a public facility, s/he must remain hospitalised until operation; this results in free provision of available drugs, beds and food. Needless prolonged hospital stays not only increase patients' economic burdens, but also waste scarce public resources. Thus, quick or delayed treatments in either sector are a serious concern in terms of health, economy and social capital. After recovering from an acute phase, patients could be discharged with a date of operation; this is practiced in many countries, reducing the costs of hospital stays. Notably, people often feel that they are deprived despite the huge state health budget. However, what they believe to be huge is only one-third of total health expenditures (WHO, 2015). All these facts indicate the need for community involvement in health care.

Overall, patients lack health awareness and display poor health-seeking behaviour. Many poor patients are already unhappy because of health and economic loss related to maltreatment by unqualified/traditional healers. A good prognosis is often not enough to satisfy them because of the mental and economic adversity they suffer.

A well-developed public sector is crucial to solving many problems in the health sector. Establishing this, increasing resource allocation and providing a 'gate-keeping' system and health insurance were common recommendations. However, we think that it is more useful to guarantee efficient use of the available resources than to increase resource allocation. Experiences in developing countries suggest the same (Alliance for Health Policy and Systems Research, 2004). For patients' economic protection, the inspiring evidence of health insurance from developing countries such as 'community- 
based health insurance' in Rwanda (Makaka, Breen \& Binagwaho, 2012), could be used as the basis for a pilot initiative.

\section{Dynamics of the private doctors' satisfaction level}

The non-existence of any policy, along with job insecurity, unstable salaries and benefits, and non-provision of pensions are the key factors distinguishing private doctors from their public counterparts; additionally, competing with public doctors in the private setting aggravates their frustration. A parallel policy for private doctors seems essential in order to reduce the professional, economic and social status tensions as well as the disparities that exist between private and public doctors despite their comparable education and background.

Healthy competition is the essence of a balanced market (Jensen, 1995). However, competition in the public health sector of Bangladesh is discouraged due to the system itself. Public-private division in terms of investment as well as manpower would create competition between the public and private sectors rather than public doctor-led competition within the private sector. Such inter-sector competition could be promoted on a small scale to verify its effects on controlling cost and quality, improving productivity and trust as well as reducing gaps between diverse providers within the health care system.

\section{Strengths and weaknesses}

To the best of our knowledge, this is the first qualitative study on satisfaction with Bangladesh's health care system involving a wide range of stakeholders. By recruiting the stakeholders from three districts with broad social and professional experiences and perceptions, we reduced the risk of selection bias. By arranging homogenous focus groups and assuring anonymity, we effectively encouraged participants to speak freely. In addition to strengthening our previous study findings, this study delves deeper into the facts and challenges in the health care system and addresses solutions based on insights from diverse interest groups. Careful checking and comparing of the translated transcripts with video records reduced the risk of losing the specific meaning of Bengali expressions.

\section{CONCLUSION AND RECOMMENDATIONS}

Confirming the findings of our previous studies, this study has explored deeper insights into factors of dissatisfaction in health care along with ideas for solutions. Wide centrallocal power gaps are the key contributors to the local public health administrators' 
dissatisfaction, while those in the private sector mention authoritative rather than collaborative relationships between the public and private counterparts. Whereas organizational barriers, corruption and managerial incompetence are linked to inefficient resource management in the public sector, the private sector suffers from ineffective oversight relating to wide variations in health care costs and quality, unethical practices and an imperfect market. Furthermore, while private doctors contend for social status and economic security, public doctors compete for better postings and positions, and for surplus income from the private market. Risks of health catastrophe and low social capital are apparent in the health care system.

Strategic decentralization of authority to district level is widely suggested as a method to improve satisfaction in the health sector. Although global experiences of the impacts of various health system reforms are mixed, encouraging examples of strategic reforms with political and bureaucratic supports are known. Taking into account the global experiences with best practices, the overall situation would be improved through gradual decentralization of those centralized authorities which are explicitly linked to dissatisfaction among key stakeholders and the compromised productivity of the health system. Gradually developing each district health system into an integrated decentralized health care unit would improve efficiency. However, the key stakeholders' opinions and overall socio-political contexts reveal that the country's health system needs to be harmonized through the national system of public-private and central-local collaboration, rather than through a command and control approach. A national policy for the district health system should be developed based on a consensus from all potential public and private stakeholders. The policy should be implemented through a single body with broad public, private and professional participation. This district health system regulatory body should have ample capacity, resources and authority.

To control costs and quality in the private health care market, piloting of publicly arranged soft loans for establishments along with reinforcement-based regulation could be promising. However, a well-developed and efficient public sector is adamant that people's health and economy should be protected. A postgraduate public health degree should be obligatory to improve local public health administrators' competence as well as system compliance. Nevertheless, financial and/or non-financial incentives along with strict application of a two-year of rural working are essential for retaining doctors in rural areas. Through compensating dual-practitioners' income interest related to private practice, public-private separation by manpower could also be considered in order to test its effects on the productivity of the public sector. A policy for private doctors' welfare is another high priority.

Health insurance is a crucial priority, both to protect people from the impending threats of health catastrophe as well as to sustain and accelerate the country's economic 
Challenges of satisfaction in Bangladesh's district health system and ways to improve growth. Further research is needed to develop a viable health insurance policy for Bangladesh. 


\section{REFERENCES}

Alliance for Health Policy and Systems Research. (2004). Strengthening health systems: the role and promise of policy and systems research. Retrieved from www.who.int/alliance-hpsr/resources/Strengthening complet.pdf [Accessed 31/07/2016]

Bernard, H. R. \& Ryan, G. W. (2010, p.287-310). Analyzing Qualitative Data, Systematic Approach. London, United Kingdom: SAGE Publications, Inc.

Bhandari, P., Bagga, R., \& Nandan, D. (2010). Levels of Job Satisfaction among Healthcare Providers in CGHC Dispensaries. Journal of Health Management. 12(4), 403-422.

Blackmer, J. (2007). Professionalism and the Medical Association. Retrieved from www.wma.net/en/ 30publications/35whitepapers/White_Paper.pdf [Accessed 01/08/2016].

Civil Surgeon Office. (2014). District Annual Reports on private clinics, hospitals and diagnostic centres - 2013. Joypurhat district: The Stationery Office.

Cockcroft, A., Andersson, N., Milne, D., Hossain, M. Z., \& Karim, E. (2007). What did the public think of health services reform in Bangladesh? Three national community-based surveys 1999-2003. Health Research Policy and Systems. 5(1).

Cockcroft, A., Milne, D., Oelofsen, M., Karim, E., \& Andersson, N. (2011). Health services reform in Bangladesh: hearing the views of health workers and their professional bodies. BMC Health Services Research, 11(Suppl 2), S8. http://doi.org/10.1186/1472-6963-11-S2-S8.

Darkwa, E. K., Newman, M. S., Kawkab, M., \& Chowdhury, M. E. (2015). A qualitative study of factors influencing retention of doctors and nurses at rural healthcare facilities in Bangladesh. BMC Health Services Research, 15(1), 1-12.

de Savigny, D., Kasale, H., Mbuya, C., \& Reid, G. (2004). Fixing Health Systems. Retrieved from dspace.africaportal.org/jspui/bitstream/.../11434/1/Fixing Health Systems.pdf [Accessed 31/07/2016].

Hsieh, H. F., \& Shannon, S. E. (2005). Three Approaches to Qualitative Content Analysis. Qualitative Health Research, 15(9), 1277-1288.

Jamali, D. (2004). Success and failure mechanisms of public private partnerships (PPPs) in developing countires. International Journal of Public Sector Management. 17(5), 414-430.

Jensen, R. (1995). Managed competition: a tool for achieving excellence in government. Retrieved from https://msu.edu/course/prr/371/Privatization and Downsizing/ competion.html [Accessed 31/07/2016].

Jongudomsuk, P., \& Sirsasalux, J. (2012). A decade of health-care decentralization in Thailand: what lessons can be drawn? WHO South-East Asia Journal of Public Health. 1(3), 347-356.

Leonard, D. K., Bloom, G., Hanson, K., et al. (2013). Institutional Solutions to the Asymmetric Information Problem in Health and Development Services for the Poor. World Development. 48, 71-87.

Makaka, A., Breen, S., \& Binagwaho, A. (2012). Universal health coverage in Rwanda: a report of innovations to increase enrolment in community-based health insurance. The Lancet. 380 (S7).

Ministry of Health and Family Welfare. (2013). Health Buletin 2013. Retrieved from http://www.dghs.gov.bd/ images/docs/Publicaations/HB_2014_2nd_Edition_060115.pdf.

Nandraj, S., Khot, A., \& Menon, S. (1999). Accreditation of hospitals, A new Initiative. Kango Tenbo. The Japanese Journal of Nursing Science. 12(1), 8-9.

National Health Service Confederation. (2013). Challenging bureaucracy, The voice of NHS leadership. Retrieved from http://www.nhsconfed.org/ /media/Confederation/Files/ Publications/Documents/ challenging-bureaucracy.pdf [Accessed 30/07/2016].

Roy, A. van der Weijden, T., Hossain, M.E., \& de Vries, N. (2016). The need for regulatory reform to improve rural people's access to healthcare : views of administrators of the public-private mixed health system of Bangladesh. Diversity and Equality in Health and Care. 13(4), 269-278.

WHO. (2015). Bangladesh Health System Review. Retrieved from http://www.wpro.who.int/asia_pacific_ observatory/hits/series/bgd_health_system_review.pdf. 
Chapter

General discussion 

Satisfaction in the health system of Bangladesh is an inadequately researched topic. This dissertation aims to carry out an inclusive investigation of key influencing factors of satisfaction among of administrators, doctors and patients in the district public and private sectors of the country's health system, and to address evidence-informed policy interventions to boost overall satisfaction in order to enhance the rural population's health and economic protection as well as social capital in health care.

Three distinct quantitative studies investigated potential determinants of satisfaction in those target stakeholders; a qualitative study was conducted involving diverse actors in homogenous focus group discussions to triangulate the findings of the quantitative studies and to explore participants' opinions of ways to improve satisfaction in the health system. In addition to exploring inter-sector gaps, corruption and moral issues and addressing policy interventions, the qualitative study reaffirmed and deepened the insights of the findings of the quantitative studies.

In general, private market contributions to filling gaps in the availability and delivery of services in the public health sector are recognised. However, private markets' counterproductive outcomes with respect to health system goals of equity and economic protection in health care have mostly been reported in developing countries without the capacity to regulate. In contrast, good outcomes of mixed-model health systems with adequate stewardship capability have been proven (e.g. in the Netherlands, Switzerland and Colombia). Established public health sectors are essential for achieving the goals of public-private mixed health systems (Rockefeller Foundation, 2009).

Insufficient human, financial and material resources and inefficient governance and regulatory capacity have been identified as challenges in Bangladesh's public health sector (Chapter 2). In such a situation, the private market has been structurally adjusted to supplement gaps in delivery of public health care. Considering the issues of publicprivate mixed provision, this section briefly addresses key findings on satisfaction in the country's health system with policy and other implications.

\section{Public administrators' roles and limitations versus satisfaction in the health system}

Public expenditures on health relative to population size have remained nearly static for decades. The recent countrywide establishment of Community Clinics (each serving 6,000 people) is a remarkable development. However, district hospitals' capacity (100 beds) follows neither individual district population size and growth nor local health needs, despite the fact that these facilities are the main public sources of emergency and secondary health-care services for the majority of districts' populations (Chapter 2). This is clearly an inequity and inefficiency in need-based structuring of district hospitals, 
indicating the necessity of restructuring the district health system based on population size and health needs.

Wide gaps in power and coordination between central and local authorities, local managerial incompetence and corruption are the key barriers to optimising productivity with the available resources (Chapters 2, 5). For decades, public expenditures on health have remained constant at around 3\% of GDP (WHO, 2014). In a country like Bangladesh, to increasing the health budget is challenging due to competing political and economic interests. Moreover, in the current situation, an increase in resource allocation would not guarantee the expected outcome.

Local public administrators are the front-line public role players responsible for meeting people's health needs; however, their capacity to mobilise central resources to meet local needs is limited. As a result, they are at risk of facing unwanted reactions and backlash from people with unmet health needs, and ultimately dissatisfaction among all parties.

Improving governance, adapting evidence-based regulatory practices, reducing centrallocal power gaps and reflecting local opinions in policymaking are indisputable priorities in improving allocative and technical efficiency, and thereby increasing people's access to equitable health care and health as well (Chapters 2, 5).

\section{Human resource management versus satisfaction of doctors}

Barriers to the mandatory two-year rural work requirement for public doctors are caused by inferior working conditions, accommodation and transport facilities, lack of incentives and career growth opportunities, and corruption. Additionally, health professional politics often influence transfers and promotions of doctors. Local authorities hold little clout and decision-making power to either transfer or retain doctors. Moreover, tensions between incompetent managers and specialised doctors are common. These loopholes in the overall management of job resources are explicitly related to dissatisfaction of public administrators and turnover intention among doctors (Chapters $4,5)$. These also act as potential demotivating factors leading to doctors' low satisfaction and performance (Bakker \& Demerouti, 2007), resulting in low-quality services and, ultimately, patient dissatisfaction (Chapter 3). Improvement of organisational supports and local managerial skills, along with evaluations based on performance rather than corrupt interests are of central importance to achieving progress in system compliance and satisfaction in doctors, administrators and patients.

Among private doctors, dissatisfaction is explicitly linked to discrepancies with their public counterparts in terms of low job security, unstable incentives and benefits, and gaps in social status. Considering private doctors' contributions to health care, a nation- 
al policy for these doctors is essential to institutionally securing and equalising their welfare (Chapter 5).

\section{Patient satisfaction in the district health-care system}

Accessibility (in financial terms) is a common strong predictor of patient satisfaction. In the public sector this relates to insufficient availability of drugs and diagnostics, while in the private market these issues include unaffordable health-care costs, immoral practices and induced demand of goods/services. This is also linked to patients' low reliability and empathy, especially in the private market (Chapter 3). Moreover, patients' attitudes towards and explanations of delayed and rushed surgical treatments in public and private facilities, respectively, not only represent reliability issues, but also fuel concerns about health and economic loss and mistrust in the health-care system (Chapter 5). These points to the need for community and patient participation in health care. Community involvement in evaluating health services and local priorities has been effectively implemented in the UK health system (Coulter, 2011, p. 191). Shared decision-making is another effective way of involving patients in treatment processes, which helps in sharing responsibilities and building trusting relationships between doctors and patients (Charles et al. 1999).

Enhancing performance in the global public health system, in terms of both quantity and quality, was one of the key targets of the market-style reforms (WHO, 2007). The average bed occupancy rate in the sample public primary and secondary facilities was over 1.5 times higher than their capacity. Notably, the sample private facilities performed nearly three times more surgeries with a bed capacity 1.4 times smaller than that of the sample district hospitals (Chapter 2). This indicates relatively low performance, but not underutilisation of public facilities. However, the high volume and speed of surgical procedures at private facilities guarantee neither proper care for patients nor good-quality services (Chapter 5 ). This is one risk of shifting client-centred consumerism to providers' interest-led consumerism in an under-regulated health market, as reported by the Rockefeller Foundation (2009). Ultimately, the general population is suspicious of both the quantity and quality of health services in the public and private sectors alike.

Overall, these situations point to incongruities between the population's health needs/demands and the capacity of Bangladesh's health system. In economic theory, high demand of goods/services combined with limited supply brings the threat of price inflation (Witter, 2000, pp. 25-46). This explains investors' interests and consumers' risks in the growing private health market. 'Price elasticity (or inelasticity) of demand' in health care is beyond the scope of this study; however, a considerable number of rural patients (33\%) have to take out loans, sell household goods and receive charity to pay for health-care costs in both sectors (Chapter 3). Van Doorslaer et al. (2006) reported 
that an estimated 3.8\% of people drop below the poverty line each year because of outof-pocket payments for health care in Bangladesh. Thus, health outcomes aside, the psychological, economic and social consequences clients face due to treatment costs are clearly alarming.

\section{Regulation of private market versus satisfaction of stakeholders}

It is not the market-style reform itself, but the state's capability to regulate the market that matters (WHO, 2007). The private sector's contributions to filling gaps in the availability of public health services in Bangladesh are clear (Chapters 2, 5). Unambiguity in regulatory roles and goals and informed rules of law are central to regulator-regulatee relations and the resulting outcomes (Etienne, 2013). In Bangladesh, the private health market regulation is outdated (Chapter 2); furthermore, because of the faulty regulatory structure, the approach to regulation is characterised by a mixture of self-interest, legacy and authoritative relationships between regulators and regulatees. The success of these types of regulatory relations is doubtful (Etienne, 2013). Moreover, monitoring of service quality in the public sector is seemingly non-existent. This raises questions concerning the distinction between public and private facilities' monitoring systems. A judgement relationship with standard collaboration between regulators and regulatees, along with shared regard for facts and values as described by Etienne (2013), is essential in order to improve private health investors' satisfaction.

Lack of information about health-care costs and quality standards, supplier-induced demand and immoral practices clearly lead to threats of impoverishment and mistrust in health care (Chapters 2, 5). Incorporating provider ratings with reinforcement (i.e. rewards for good performers, and support or sanctions for bad performers) may be effective in achieving health goals (Rockefeller Foundation, 2009). The absence of provider ratings discourages and/or demotivates good performers (Chapter 5). Thus, market competition that thrives on profit rather than quality of care is linked to providers' demotivation and/or demoralisation. This carries potential risks of market failure related to weak regulation (Rockefeller Foundation, 2009).

Furthermore, high establishment and maintenance costs often stimulate private investors to increase service supply and demand irrespective of needs. Thus, moral and human values along with clients' financial safety in health care receive less attention (Chapter 5).

Implementing an updated regulation policy which involves multisector actors and is applicable to both sectors is a priority need in order to reduce potential public health and economic threats in the growing private market as well as in the public sector. Periodic clinical auditing, as is practiced in Germany (Hafiz-Affifi et al., 2003), and provision of self-regulation through the Bangladesh Medical Association would encourage pru- 
dent prescribing behaviour and reduce immoral practices in health care. Publicly arranged soft loans for establishing private facilities would be an additional support mechanism to control providers' behaviour.

Public dual practitioners are the key service providers in the private sector. This means that public doctors invest their potential in the competitive private market for reasons of self-interest rather than to advance public sector performance. This situation is obvious if public salaries are disbursed regardless of performance or even absenteeism (Rockefeller Foundation, 2009). Balanced competition between the public and private sectors which secures the interests of potential actors, and especially those of public doctors, would improve performance in the health system.

\section{METHODOLOGICAL CONSIDERATIONS}

A series of quantitative studies was triangulated and thoroughly reaffirmed by a qualitative study that confirms the scientific validity and harmonises the aims of this dissertation. An investigation involving administrators, doctors and patients in the district public and private health sectors along with diverse civil society agents is the first known inclusive approach towards analysing health system satisfaction in Bangladesh. This strategy is not even common in other settings. Such an inclusive approach is considered more complete, and thus superior to exploring patient satisfaction only. This dissertation could contribute to the wider debate on scopes and challenges of market-style reforms in health systems with empirical findings from a developing country setting.

The considerable sample sizes and high response rates of public and private sector doctors, patients and administrators, along with the involvement of countrywide social and professional networks, are encouraging. However, this dissertation identifies some methodological gaps. For example, the complex issue of doctors' burnout requires a more comprehensive model in order to be measured. Patients of other major specialties, such as maternity care, were not included. Stratification based on socio-economic status and health conditions (i.e. acute and chronic disorders) of patients of all major specialties would provide a more representative image of patient satisfaction. This dissertation does not report on stakeholders' satisfaction levels in public and private tertiary-level health facilities. It was also not possible to include all key stakeholders (e.g. nurses). Nevertheless, the need to assess interconnections between individual stakeholders' states of satisfaction in order to understand satisfaction in the overall health system became apparent.

Providing universal access to health through the development of a health insurance system by 2030 is a priority agenda item for the government (Ministry of Health and Family Welfare, 2012). Providers' behaviour (e.g. moral hazards) and trust relations 
between stakeholders are among the key anthropological factors which potentially impact the sustainability of health insurance systems (Dao \& Nichter, 2016). This dissertation could contribute to understanding those socio-cultural factors in the health system of Bangladesh for consideration in future health financing reforms. The methodological approaches and generalisability of the findings of this dissertation would be applicable and comparable to health systems in countries with similar contexts.

\section{CONCLUSION AND RECOMMENDATIONS}

Low satisfaction in the centralised public-private health system of Bangladesh fosters risks to health and economic development and trust relations. However, these are inevitable in the current situation.

The potential factors which pose challenges to the satisfaction of administrators, doctors and patients in the public sector of the district health system of Bangladesh ultimately amount to inefficient allocation and utilisation of human and material resources. These are mostly rooted in weak governance, bureaucracy, health professional politics, low organisational support and inadequate local managerial skills.

In the private sector, an imperfect market (i.e. lack of information about and control over cost and quality), immoral practices, investors' interest in profit-led consumerism, and public-private gaps in collaboration and status are the potential barriers to satisfaction of the key stakeholders. These are linked to weak regulation, and both regulators' and regulatees' ambiguity about roles and goals within the market.

Satisfaction in the health system is not simply an individualistic cognitive construct, but rather an outcome of complex structural and individual dynamics that ultimately impact the country's economy. Based on stakeholders' opinions and evidence-informed practices elsewhere, this dissertation recommends the following policy interventions to address the explicit challenges of satisfaction in the health system of Bangladesh.

\section{Decentralisation}

Defined administrative power should be decentralised (i.e. deconcentrated) to district level in order to reform each of the 64 districts of the country to an integrated health system unit. It is proposed to shift the following powers to a district-level independent body: authority to transfer and promote doctors in the district public health system, which should be strictly based on national policy guidelines; authority for urgent maintenance of medical equipment and the purchase of drugs and medical supplies; authority to use a certain percentage of local revenue for urgent public needs; and authority to maintain the central supply of all drugs and medical equipment based sole- 
ly on local needs and requirements. A system of transparency and accountability should also be put in place.

\section{Advantages:}

District-based decentralised reform would be helpful to monitor and evaluate each district's performance, thereby overseeing ratings, rewards and support. Decentralisation of the abovementioned powers would contribute to the efficient use and productivity of scarce human and material resources, reduce discontent surrounding doctors' transfer and promotion, and improve rural people's access to health care and economic protection. Both the public and private components of the district health system would be monitored and evaluated by the same body, using a similar tool which would reduce inter-sector discrepancies and dissatisfaction regarding service processes.

\section{Disadvantages:}

Shifting authority from the central to the local level could be a challenging political decision. Critics and interest groups may view this reform as a fragmentation of the health system. In the present situation, local public administrators lack the skills and competence needed to carry out the reform process. Corruption may shift along with power to the local level. Reform requires additional financial support.

\section{Implementation strategies:}

An independent body with multisectoral representation including the public and private health sectors, the Bangladesh Medical Association, local government and civil society members must be formed in each district. The structure, powers, responsibility, relations, inclusion and turnover of members of this body should be defined by policy. As the national authoritative body, the central authority of the health ministry would oversee the activities of the district body and harmonise the 64 districts' health systems directly and/or indirectly through regional health authorities. It would also create and amend policies, and conduct financial affairs according to state rules. A central or regional health authority would handle and solve any transgressions in the district management body.

A post-graduate public health or management degree should be a mandatory criterion for the posts of Civil Surgeons and Upazilla Health and Family Planning Officers. The overall process should be executed gradually with adequate local capacity building. Financing for the initial set-up could be sourced through public revenue and donor funds. This decentralisation policy is expected to improve governance and regulation in the public sector, and thus productivity as well. 


\section{Clients' role and participation in health care reform}

Since no consumer platform currently exists, local government and civil society representatives in the district management body will have to be a voice for patients. However, a system which allows patients to freely express their opinions on services in public and private facilities and responds accordingly would be effective to improve their satisfaction. Local client's opinions and priorities should also have a place in policymaking, and patients' involvement in treatment processes should be secured to improve trust in and satisfaction with health care.

\section{Improving efficiency prior to further increases in public health allocation}

Despite existing needs to increase allocation in the public sector, this dissertation strongly advocates ensuring the efficiency of using existing human and material resources prior to further allocation increases.

\section{Upgrading tools and approaches for regulating the private market}

Private health market regulation tools must be updated with participation from both public and private health-sector agents. The national health system policy goals and expected roles of all concerned parties must be clearly communicated. The district health management body will monitor and evaluate the private facilities of the district. A collaborative and reinforcement-based regulation approach would contribute to provider ratings and fair information on standard health-care costs and quality. Additionally, the self-regulatory role of the Bangladesh Medical Association along with the provision of clinical auditing would reduce immoral practices. Public soft loans to establish private facilities could also be piloted in order to test their effects on health outcomes.

\section{Institutional roles to address doctors' dissatisfaction}

A national policy for private doctors is crucial for their job security, incentives, benefits and career growth. Since this issue relates to finance, it may be met with resistance from private investors; however, the involvement of all interest groups in policymaking would reduce such tension. Moreover, efficient market management would lead to the survival of good performers with better market shares and alleviate investors' financial concerns.

Incentives for rural work, adequate working and living conditions, and clear career opportunities linked to successful completion of rural work would support the retention of doctors in public rural facilities. Extending doctors' internship training to two years, with the last year spent carrying out mandatory work in rural and district-level facilities, 
would yield the following contributions: reduction of doctor shortages and workloads in rural areas, improved professional progress and psychological adjustment for young doctors within the rural environment, and increased access to health care for the rural population. Young doctors' possible negative reactions could be resolved through ensuring good transport, accommodation, working facilities and incentives.

\section{Generating balanced competition between the public and private sectors}

Complete separation of the public health sector and the private health market - not only in terms of investments, but also in terms of manpower - seems essential. In doing so, public doctors could be arranged to practice in public facilities rather than in private facilities during a defined time period outside of the routine official public hours. This would address both public doctors' concerns about income and private doctors' discontent relating to public doctors' dominance in the private sector. Notably, public facilities offer options of private services with fixed payments, such as hotel services. The extension and reorganisation of existing private provision in the public sector would be effective in providing services at publicly controlled costs. On the one hand, publicly arranged provision of compensation for public doctors from fee-for-service payments would furnish their extra earnings; on the other hand, payments for hotel services would increase public revenue, which could be earmarked to cover health costs for the poor. Ultimately, balanced competition between the public and private sectors under a single regulatory body would improve productivity and trust in the health care system.

\section{Developing a health insurance system: need for future research}

Since a considerable proportion of the population lives below the poverty level, instituting social solidarity in the OPP health system model is essential. Thus, a health insurance system is a high priority in order to protect people from health-related catastrophe. To establish a contextually suitable and sustainable health insurance system for Bangladesh, this dissertation could serve as the basis for further research. 


\section{REFERENCES}

Bakker, A. B., \& Demerouti, E. (2007). The Job Demands-Resources model: state of the art. Journal of Managerial Psychology, 22(3), 309-328.

Charles, C., Gafni, A., \& Whelan, T. (1999). Revisiting the shared treatment decision-making model. Social Science \& Medicine (1982), 49(5), 651-61.

Coulter, A. (2011). Engaging Patients in Healthcare. England: Open University Press.

Dao, A., \& Nichter, M. (2016). The Social Life of Health Insurance in Low- to Middle-income Countries: An Anthropological Research Agenda. Medical Anthropology Quarterly, 30(1), 122-143.

Etienne, J. (2013). Ambiguity and relational signals in regulator-regulatee relationships. Regulation and Governance, $7(1), 30-47$.

Hafiz-Afifi, N., Busse, R., \& Harding, A. (2003). Regulation of Health Services. In: Harding, A. \& Perker, A.S. (eds.), Private participation in health servces (pp. 219-327). Retrieved from http://books.google.com.bd/books? $\mathrm{id}=\mathrm{bZ}$ wasbxXSAC\&printsec=frontcover\&source=gbs_ge_summary_r\&cad =0\#v=onepage\&q\&f=true.

Ministry of Health and Family Welfare. (2012). Expanding Social Protection for Health: Towards Universal Coverag; Health Care Financing Strategy 2012-2032. Retrieved from http://p4h-network.net/wpcontent/uploads/2013/10/2012_10_HCFS_Bangladesh_2012-2032.pdf.

Rockefeller Foundation. (2009). Public Stewardship of Private Providers in Mixed Health Systems. Retrieved from http://www.resultsfordevelopment.org/sites/resultsfordevelopment.org/files/resources/PublicStewardshi pofPrivateProvidersinMixedHealthSystems_0.pdf.

van Doorslaer, E., O'Donnell, O., Rannan-Eliya, R. P. et al. (2006). Effect of Payments for Health Care on Poverty Estimates in 11 Countries in Asia : An Analysis of Household Survey Data,. The Lancet, 6736 (06), 1357-1364.

WHO. (2007). Globalization, global governance and the social determinants of health a review of linkages and agenda for action. Retrieved from http://www.who.int/social_determinants/resources/gkn_lee_al.pdf

WHO. (2014). National expenditure on health. Retrieved from http://apps.who.int/nha/database/Key_Indica tors_by_Country/Index/en?COUNTRYKEY=84674

Witter, S. (2000, p.25-46). Economics and health care markets. In: Witter, S., Ensor, T., Jowett, M. and Thompson, R. (eds). Health economics for developing countries. Oxford: Macmillan Publishers Limited. 
Chapter

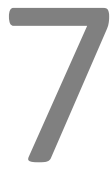

Summary 

Client satisfaction is a common political, social, health and economic concern in health systems all over the world. The relation of clients' (i.e. patients') satisfaction to overall health and economic outcomes and social capital in health care is indisputable. Patients' opinions of service quality are commonly used as a proxy for their satisfaction level as well as for health system performance. Notably, the potential impact of wider macroenvironmental factors often goes unaddressed; these factors include, for example, the influence of politics, policy, provisions, financing and regulation in health care on other key stakeholders such as frontline health administrators and professionals (e.g. doctors). Empirically, without health workers' and especially doctors' adequate fit and satisfaction in organisational settings, patient well-being remains at risk. Since the post1980s market-style reforms in health systems worldwide, the situation has become more complex due to the conflicting interests of diverse actors in health care. In this context, we found the approach of evaluating service quality through assessing only patient satisfaction as rather simplistic, incomplete and likely to aggravate gaps between actors on both the supply and demand sides. Other key stakeholders' opinions and evaluations of their satisfaction in health care should also be taken into account. This research focused on such an investigation in rural Bangladesh, where these problems are severe.

Thus, this dissertation aims to carry out inclusive investigations into potential influencing factors of key health care actors' satisfaction, along with strategies for improvement. The ultimate goal is to improve the rural population's equitable access to health care and health in Bangladesh. Accordingly, we conducted investigations to: (i) identify key determinants of satisfaction among administrators, doctors, investors/owners and rural patients in the public and private sectors of the district health system of the country, in addition to civil society agents; and (ii) explore evidence-informed strategies to address those factors. The approaches and empirical findings of these studies are summarised in this section.

Chapter 2 presents the empirical findings on public health administrators' and private facility owners' explanations of their roles and limitations in ensuring the rural population's access to health care. We conducted an exploratory questionnaire and audit survey in three districts of Bangladesh with 22 public health administrators and 20 private facility owners. Audit data on health care structure, availability and utilisation of services were collected from the public and private facilities' records from 2012. Descriptive statistics and chi-squared tests were used to analyse the data.

In the centrally regulated public health system, inefficient utilisation of available resources was identified as an obvious problem. This was associated with wide power gaps between central and local authorities, and disparities between supply and demand with consequent waste and misuse of scarce resources. In the private sector, the effectiveness of cost and quality regulation is sub-optimal. The licensing and accreditation 
system is outdated, and hence ineffective. Local authorities' compliance with the stringent bureaucracy and their satisfaction seem mutually exclusive. Optimal utilisation of existing primary health care resources is a high priority. A potential market failure could be prevented and controlled by amending the licensing and accreditation rules and implementing these through a district-level multisectoral body with public-private representation. A deconcentration type of regulatory reform which entails improving local authorities' capacity and implementing reward- and sanction-based regulatory policy seems to be a promising strategy to improve the health and economic security of rural populations, as well as to enhance district level health administrators' satisfaction.

Chapter 3 describes the empirical findings of a quantitative study in a remote district which involved interviewing 400 rural patients (public $n=200$; private $n=200$ ). Highlighting key predictors of rural clients' satisfaction level (CSL), this chapter also shows relations between perceived specific service quality (PSSQ), perceived utility value (PUV) and CSL, and clients' reactions (CR) to current providers and future repurchase intention.

CSL was measured using distinct direct and indirect scales. Clients' opinions of PSSQ in terms of health care structure (tangibility, availability and accessibility) and process features (responsiveness, reliability, empathy, communication and courtesy) were measured in order to indirectly assess patients' states of satisfaction. PUV and CR were measured with a mixture of direct and indirect items. Likert scales (5-point) were used to measure PSSQ, PUV, CSL and CR. Multiple regression, mediation, chi-squared tests and independent-sample t-tests were used as statistical models.

Client satisfaction was identified as low in both the public and private health sectors, with significantly lower satisfaction in the public sector. Accessibility (in financial terms) predicted relatively high variations in CSL both in the public sector (18.2\%) and in the private sector (25.0\%). Availability predicted distinctly higher variations in CSL in the public sector (34.6\%). Structural factors predicted higher variations in clients' satisfaction in the public sector, whereas service process-features had a greater influence in the private sector. Clients' reactions were the ultimate outcome of PSSQ, mediated through PUV and CSL. PUV mediated the effects of PSSQ on clients' reactions more strongly than CSL. This indicates satisfactory health achievement despite sacrifices, and also suggests that technical quality surpasses the social quality of health care. Financial accessibility poses a crucial risk of impoverishment in the health care system. Both structural and process features of health care are in ample need of reform in order to improve the existing low satisfaction level among patients in rural Bangladesh.

Chapter 4 describes the findings of a quantitative study on the effects of work characteristics (i.e. organisational, social and job features) and health professional politics on job satisfaction, turnover intention and burnout, and examined whether or not these differed for doctors in the district public primary and secondary levels, and public and private health sectors. We conducted a quantitative study using a self-administered ques- 
tionnaire containing mostly structured items, distributing this to a nationally representative sample of 384 public and private doctors. Respondents were from 29 out of a total of 64 districts of Bangladesh. Work characteristics and outcomes of interest were measured using standardised items on a 5-point Likert scale. Multivariate analysis of variance, bivariate correlation and multiple regression were chosen as statistical models.

A total of 354 doctors responded. No significant differences were found between public primary and secondary-level doctors regarding combined work characteristics and outcome variables, which differed significantly between public and private doctors. Organisational supports (e.g. salary, managerial support, performance evaluation and career growth) were the strongest predictors, with negative effects on job satisfaction, turnover intention and burnout for both public and private doctors; in this regard, the private doctors experienced more support. The effects of health professional politics on public doctors were alarming.

The work design of the health system of Bangladesh is in need of substantial development. Overall, improved organisational supports are crucial; however, other work characteristics are also important for enhancing doctors' welfare and productivity in both sectors.

Chapter 5 describes the empirical findings of a qualitative study. In addition to investigating insights from the key stakeholders of Bangladesh's health system to explore determinants of their satisfaction and strategies for improvement, this study also triangulated the findings of a series of quantitative studies. Six homogenous focus group discussions were conducted with district public health administrators, private facility owners, public doctors, private doctors, rural patients and civil society representatives from three districts. A directed content analysis method was used to analyse the data.

The findings of the quantitative studies were confirmed, and low satisfaction among all health care actors was again undeniable. Organisational, political, socioeconomic, market and moral issues were the primary drivers of stakeholders' low satisfaction. Inefficient management of resources relating to bureaucracy, incompetent local administration, corruption and health professional politics were the key barriers to satisfaction in the public sector; in the private sector, these were deficient market regulation and social status gaps. These findings illustrate inter-sectoral tensions, an imperfect market and mistrust in health care. Risks of a health catastrophe were perceived as likely in both sectors.

Decentralisation of governance to a multisectoral body with adequate resources and power to control a district public-private mixed health system would reduce authoritative and collaborative gaps, unethical practices and threats of market failure. Reduction of undue political influence and implementation of a fair performance evaluation system are crucial to recover public doctors' and administrators' motivation and satisfaction. Establishing balanced competition between public and private sectors and intro- 
ducing a suitable health insurance system are potential points that could improve efficiency along with people's health and economic protection in health care.

Chapter 6 contains the general discussion with conclusions and recommendations. Highlighting the findings of the primary studies, this chapter also compares the findings of other research. Blending the findings of all primary studies, this chapter reflects the states of satisfaction in the public-private mixed district health system of Bangladesh. Policy recommendations are described based on key stakeholders' opinions and evidence-based practices elsewhere. The chapter also presents a critical assessment of the methods employed.

\section{Highlights}

In the current situation, dissatisfaction of key stakeholders with the health system of Bangladesh is inevitable. Systematised corruption and stringent bureaucracy obstruct the efficient use of available resources in the public health sector. Inefficient management of scarce resources hinders access to health care in rural areas. Ineffective control of the growing private sector leads to a threat of market failure. All these factors are primarily rooted in loopholes in the governance, regulation and financing of the health system, which adversely affects the satisfaction of all key players in a vicious cycle; added to these are health-professional politics in the public sector. To improve the situation, policymakers, providers and investors in the health system need to prioritise clients' health and economic interests.

\section{Future research implications}

This dissertation presents solid reasons for inclusive studies that would contribute to a complete view of the multitude of factors challenging the satisfaction with health systems among patients and other stakeholders. This approach is essential in order to not only identify problems, but also to shed light on the underlying dynamics of these problems, thereby providing a pathway to strategic solutions as well. Lastly, this dissertation offers a strong starting point for future researchers to develop a suitable health insurance system for Bangladesh. 
Samenvatting 

De tevredenheid van cliënten is in politiek, sociaal, economisch en gezondheidsopzicht een gemeenschappelijk punt van zorg in zorgstelsels over de hele wereld. Er bestaat geen twijfel over de relatie tussen de tevredenheid van cliënten (d.w.z. patiënten) enerzijds en de totale economische en gezondheidsresultaten en het sociaal kapitaal in de gezondheidszorg anderzijds. De meningen van patiënten over de kwaliteit van dienstverlening worden ook vaak als graadmeter voor hun mate van tevredenheid en het functioneren van het zorgstelsel gebruikt. Opmerkelijk is dat het mogelijke effect van bredere macro-omgevingsfactoren vaak het minst aan bod komt. Hierbij valt te denken aan de invloed van politiek, beleid, financiering en regelgeving in de gezondheidszorg op andere belangrijke stakeholders, zoals bestuurders en professionals in de eerstelijnszorg (bv. artsen). Zonder voldoende inbedding van gezondheidswerkers, en met name artsen, in organisatiestructuren op een manier die bij hen past blijft het welzijn van patiënten in gevaar. Na de wereldwijde marktgerichte zorgstelselher-vormingen vanaf de jaren negentig is de situatie ingewikkelder geworden door tegenstrijdige belangen van diverse spelers in de gezondheidszorg. De methode om de kwaliteit van dienstverlening te evalueren door alleen naar de tevredenheid van patiënten te kijken, vonden wij in dit verband nogal simplistisch en onvolledig. De verschillen tussen de spelers aan de vraagen aanbodzijde dreigen hierdoor bovendien vergroot te worden. Met de meningen van de andere belangrijke stakeholders en de evaluatie van hun tevredenheid in de gezondheidszorg moet ook rekening worden gehouden. Dit proefschrift spitst zich toe op een dergelijk onderzoek op het platteland van Bangladesh, waar de gezondheidsproblemen groot zijn.

Dit proefschrift was dus gericht op representatieve studies naar de mogelijke invloeden van de tevredenheid van belangrijke spelers in de gezondheidszorg en strategieën ter verbetering. Het uiteindelijke doel is gezondheidsbevordering door gelijke toegang van de plattelandsbevolking tot gezondheidszorg in Bangladesh. Zodoende hebben we belangrijke beïnvloedende factoren op de tevredenheid van bestuurders, artsen, investeerders, patiënten in de publieke en private sector van het districtszorgstelsel op het platteland, en vertegenwoordigers van de burgermaatschappij van Bangladesh onderzocht evenals evidence-informed strategieën voor de aanpak van die factoren. De methode en empirische bevindingen worden hieronder per deelvraag samengevat.

Hoofdstuk 2 beschrijft de empirische bevindingen met betrekking tot de verklaringen van bestuurders in de openbare gezondheidszorg en eigenaren van privé-instellingen over hun rollen en beperkingen om de toegang van de plattelandsbevolking tot gezondheidszorg te garanderen. Wij werkten met een vragenlijst en dossieronderzoek in drie districten van Bangladesh onder 22 bestuurders in de openbare gezondheidszorg en 20 eigenaren van privé-instellingen. Dossiergegevens over de zorginfrastructuur, de beschikbare diensten en het gebruik ervan werden verzameld op basis van verslagen van de openbare en privé-instellingen in 2012. Beschrijvende statistieken en een chikwadraattoets werden gebruikt om de gegevens te analyseren. 
In het centraal geregelde stelsel van openbare gezondheidszorg werd de ondoelmatige benutting van beschikbare middelen als een duidelijk probleem vastgesteld. Dit hield verband met grote machtsverschillen tussen de centrale overheid en de lokale overheden en met onevenwichtigheden tussen vraag en aanbod, met verspilling en misbruik van schaarse middelen tot gevolg. In de particuliere sector zijn de kosteneffectiviteit en kwaliteitsregeling suboptimaal. Het vergunningen- en accreditatiestelsel is verouderd en daarom ondoeltreffend. De naleving van de strenge bureaucratische regels door de lokale overheden lijkt omgekeerd evenredig met hun tevredenheid. Optimale benutting van de bestaande middelen binnen de eerstelijnszorg is een hoge prioriteit. Een mogelijk marktfalen kan voorkomen en in de hand gehouden worden door de vergunningsen accreditatieregels te wijzigen en via een multisectoraal districtsorgaan met publiekprivate vertegenwoordiging toe te passen. Hervorming van de regelgeving door deconcentratie, waaronder het versterken van de capaciteit van lokale overheden en het uitvoeren van regelgevingsbeleid op basis van boetes en beloningen, lijkt een veelbelovende strategie om de gezondheid en economische zekerheid van de plattelandsbevolking te verbeteren en de tevredenheid van lokale bestuurders over de gezondheidszorg te vergroten.

Hoofdstuk 3 beschrijft de empirische bevindingen van een kwantitatief onderzoek in een afgelegen district waarbij 400 patiënten op het platteland werden ondervraagd (publiek $n=200$; privaat $n=200$ ). Dit hoofdstuk, dat belangrijke voorspellers van het tevredenheidsniveau van cliënten (CSL) op het platteland laat zien, toont daarnaast ook verbanden tussen de waargenomen specifieke kwaliteit van dienstverlening (PSSQ), waargenomen nutswaarde (PUV), CSL, en reacties van cliënten (CR) op huidige aanbieders en heraankoopintentie in de toekomst.

CSL werd gemeten met directe en indirecte schalen. De mening van cliënten over PSSQ met betrekking tot de zorginfrastructuur (beschikbaarheid, toegankelijkheid) en proceskenmerken (responsiviteit, betrouwbaarheid, empathie, communicatie en beleefdheid) werd indirect gemeten door de mate van tevredenheid van patiënten te beoordelen. PUV en CR werden gemeten door een combinatie van directe en indirecte items. Likertschalen (5-punts) werden gebruikt om PSSQ, PUV, CSL en CR te meten. Meervoudige regressie, chi-kwadraattoets en t-toets voor onafhankelijke steekproeven waren de statistische modellen.

Zowel in de publieke als in de private zorgsector werd een laag tevredenheidsniveau van cliënten vastgesteld, waarbij de tevredenheid in de publieke sector significant lager was. De toegankelijkheid (in financiële zin) voorspelde relatief hoge variaties in CSL, zowel in de publieke sector $(18,2 \%)$ als in de private sector $(25,0 \%)$. De beschikbaarheid verklaarde duidelijk variatie in CSL in de publieke sector (34,6\%). De infrastructuur verklaarde variatie in de tevredenheid van cliënten in de publieke sector, terwijl de proceskenmerken een grotere invloed hadden in de private sector. De reactie van cliënten was 
het eindresultaat van PSSQ, gemedieerd door PUV en CSL. PUV medieerde de effecten van PSSQ op de reactie van cliënten sterker dan CSL. Dit duidde op een bevredigend gezondheidsresultaat in verhouding tot de investeringen, terwijl de technische kwaliteit bovendien de sociale kwaliteit van de gezondheidszorg leek te overtreffen. De financiële ontoegankelijkheid vormt een zeer belangrijk risico op verarming in het zorgstelsel. Zowel de infrastructuur als de proceskenmerken van de gezondheidszorg moeten dringend hervormd worden om de bestaande lage tevredenheid onder patiënten op het platteland van Bangladesh te verbeteren.

Hoofdstuk 4 beschrijft de bevindingen van een kwantitatief onderzoek naar de effecten van arbeidskenmerken (d.w.z. organisatorische, sociale en functie-eigenschappen) en vriendjespolitiek op de arbeidsvreugde, de intentie om een andere baan te zoeken (turnover intentie) en burn-outs, en onderzoekt of deze al dan niet verschillen voor artsen in de openbare eerste- en tweedelijnsdistrictszorg en de publieke en de private zorgsector. Een zelf in te vullen vragenlijst met hoofdzakelijk gestructureerde items werd uitgezet onder een landelijk representatieve steekproefgrootte van 384 artsen in de publieke en de private sector. De respondenten kwamen uit 29 van de in totaal 64 districten van Bangladesh. De arbeidskenmerken en belangrijke uitkomsten werden gemeten aan de hand van gestandaardiseerde items op een 5-punts Likertschaal. Multivariate variantieanalyse, bivariate correlatie en meervoudige regressie waren de statistische modellen.

In totaal reageerden 354 artsen. Tussen de artsen in de openbare eerste- en tweedelijnszorg werden geen significante verschillen in gecombineerde variabelen van arbeidskenmerken en resultaten gevonden, terwijl die tussen de artsen in de publieke en de private sector wel significant verschilden. Ondersteuning vanuit de organisatie (bv. salaris, steun van managers, prestatiebeoordeling en loopbaanontwikkeling) was de sterkste voorspeller met negatieve effecten op de arbeidsvreugde, turnover-intentie en burn-outs voor de artsen in de publieke zowel als de private sector. De artsen in de private sector ervoeren in dit opzicht meer ondersteuning. De effecten van vriendjespolitiek op artsen in de publieke sector waren alarmerend.

De arbeidsorganisatie van het zorgstelsel in Bangladesh moet zich substantieel ontwikkelen. Een betere ondersteuning vanuit de organisatie is over het algemeen cruciaal, maar ook andere elementen van de arbeidskenmerken zijn belangrijk om niet alleen het welzijn van artsen in beide sectoren maar ook hun productiviteit te verbeteren.

Hoofdstuk 5 beschrijft de empirische bevindingen van een kwalitatief onderzoek. Hierbij werden de inzichten van de belangrijkste stakeholders van het zorgstelsel van Bangladesh geïnventariseerd om bepalende factoren voor hun tevredenheid en strategieën ter verbetering te achterhalen. Hiermee werden ook de bevindingen van de eerdere kwantitatieve onderzoeken door middel van triangulatie gevalideerd. In zes homogene focusgroepen werd gediscussieerd met districtsbestuurders in de openbare gezondheids- 
zorg, eigenaren van privé-instellingen, artsen in de publieke sector, artsen in de private sector, patiënten op het platteland en vertegenwoordigers van de burgermaatschappij uit drie districten. Om de gegevens te analyseren, werd een directed content analysis als methode toegepast.

De bevindingen van de kwantitatieve onderzoeken werden bevestigd, de lage tevredenheid bij alle spelers in de gezondheidszorg was onmiskenbaar. Organisatori-sche, politieke, sociaaleconomische, morele en marktkwesties waren de voornaamste categorieën van oorzaken voor de lage tevredenheid van de stakeholders. Een ondoelmatig middelenbeheer in verband met de bureaucratie, een incompetent lokaal bestuur, corruptie en vriendjespolitiek vormden de belangrijkste belemmeringen voor tevredenheid in de publieke sector. In de private sector waren dat een gebrekkige marktregulering en verschillen in sociale status. Deze bevindingen illustreren spanningen tussen de sectoren, een onvolmaakte markt en wantrouwen jegens de gezondheidszorg. Het risico van een gezondheidscatastrofe werd in beide sectoren niet als onwaarschijnlijk beschouwd.

Decentralisatie van het bestuur naar een multisectoraal orgaan met voldoende macht en middelen om een gemengd publiek-privaat districtszorgstelsel te controleren zou het gebrek aan gezag en samenwerking, de onethische praktijken en het dreigende marktfalen kunnen verminderen. De vermindering van ongepaste politieke invloed en de invoering van een eerlijk prestatiebeoordelingssysteem zijn cruciaal om de motivatie en tevredenheid van artsen en bestuurders in de publieke sector te herstellen. De totstandbrenging van een evenwichtige concurrentie tussen de publieke en de private sector en de invoering van een geschikt zorgverzekeringsstelsel werden genoemd als mogelijkheden om naast de economische en gezondheidsbescherming van de bevolking ook de doelmatigheid in de gezondheidszorg te verbeteren.

Hoofdstuk 6 bevat de algemene bespreking met conclusie en aanbevelingen. Dit hoofdstuk vat de bevindingen van de primaire onderzoeken over de mate van tevredenheid in het gemengde publiek-private districtszorgstelsel van Bangladesh samen en vergelijkt deze met de bevindingen van andere, vergelijkbare studies. Op basis van de meningen van belangrijke stakeholders en evidence-based praktijken elders zijn beleidsaanbevelingen opgesteld. Tevens wordt een kritische beoordeling van de toegepaste methoden gepresenteerd.

\section{Kernpunten}

In de huidige situatie is ontevredenheid van de belangrijkste stakeholders in het zorgstelsel van Bangladesh onvermijdelijk. De stelselmatige corruptie en strenge bureaucratie blokkeren een doelmatige benutting van de beschikbare middelen in de openbare gezondheidszorg. Het ondoelmatige beheer van schaarse middelen belemmert de toe- 
gang van de plattelandsbevolking tot de gezondheidszorg. De ondoeltreffende beteugeling van de groeiende private sector leidt tot een dreigend marktfalen. Al deze factoren worden vooral veroorzaakt door de mazen in het bestuur, de regelgeving en de financiering van het zorgstelsel, waardoor de tevredenheid van alle belangrijke spelers nadelig wordt beïnvloed en in stand wordt gehouden als in een vicieuze cirkel. In de openbare gezondheidszorg komt daar nog eens vriendjespolitiek bij. Om de situatie te verbeteren moeten beleidsmakers, aanbieders en investeerders in het zorgstelsel voorrang geven aan de economische en gezondheidsbelangen van de cliënten.

\section{Implicaties voor toekomstig onderzoek}

Dit proefschrift bevat steekhoudende redenen voor diepgravende onderzoeken om een compleet beeld te krijgen van de ijsberg van factoren die de tevredenheid van patiënten en andere stakeholders in zorgstelsels op de proef stellen. Deze benadering is essentieel om niet alleen problemen vast te stellen, maar ook de onderliggende dynamiek van die problemen te beschrijven en zou daardoor tevens aan strategische oplossingen kunnen bijdragen. Tot slot biedt dit proefschrift een goed uitgangspunt voor toekomstige onderzoekers om een geschikt zorgverzekeringsstelsel voor Bangladesh te ontwikkelen. 



\section{Valorisation}





\section{INTRODUCTION}

Patient satisfaction is a widely used indicator of health system performance, and is often measured based on patients' perception of service quality. With a background in medicine and global public health, the author of this dissertation is aware that patient satisfaction is not such a simple issue that it can be measured by patients' opinions only; instead, it is the product of influences of a complex set of macro-environmental factors on key stakeholders in health care and their roles, interests and limitations. Moreover, the usual approach of measuring patient satisfaction is neither complete nor balanced for policy interventions; indeed, it may fuel dissatisfaction among key stakeholders in the health system. Empirically, patient dissatisfaction is linked to health and economic loss, which has become problematic in the public-private mixed out-of-pocket payments model of health systems globally, and especially in developing countries like Bangladesh. Thus, patient (dis)satisfaction is a topic of interest to health and economic development as well as to social capital in health care, and one that merits inclusive investigation.

\section{Target audience}

In health care, the health and economic protection of rural residents - who make up nearly three-fourths of Bangladesh's total population - are among the key determinants of the sustainability of the country's current economic growth, since the links between health-care costs and poverty are explicit. This dissertation aims to explore key influences on the satisfaction of administrators, doctors and rural patients in the district public-private mixed health system of Bangladesh, along with policy interventions to improve this satisfaction. Thus, policymakers, public administrators and doctors, and private investors and doctors in the health system, are the prime target audiences of this dissertation, while the rural patient is the ultimate beneficiary.

\section{Products and contents related to results}

This dissertation has determined that threats of health catastrophe and low social capital exist in Bangladesh's health system, which is linked to dissatisfaction among the target stakeholders. The empirical findings suggest that stakeholders' dissatisfaction is mainly linked to weak governance, regulation and financing, along with strict command and control in the health system as well as health professional politics. In the public sector, these structural factors are accompanied by allocative and technical inefficiencies and unfair performance evaluation. In the private sector, related issues include under-regulation of providers' behaviour, health-care costs and quality. Ultimately, the health system goals of ensuring equity and the health and economic protection of people in need are compromised in both the public and private sectors. 
To improve efficiency in the allocation and use of scarce human and material resources, reducing central-local power gaps and implementing efficient and transparent management of human and material resources in the public sector are high priorities. Furthermore, improved public-private collaboration and clear goal-oriented and reinforcement-based market regulation are crucial to facilitate desired outcomes from the private sector. Based on the opinions of the target stakeholders and effective evidencebased practices elsewhere, this dissertation argues that district-based health reforms involving decentralisation of defined authorities to a multisectoral body with ample resources and power would improve regulatory efficiency and reduce unethical practices in the health system. These steps would promote the efficient use of scarce public resources as well as equitable access to health care for rural populations. A gradual move towards complete separation of human resources in the public sector (i.e. doctors) from the private market while compensating their economic interests would generate balanced inter-sector competition and productivity in the health system. Additionally, instituting a national policy for private doctors' welfare would reduce their dissatisfaction. This dissertation addresses loopholes in the overall design of the health system and proposes strategies to close them (Chapter 3 ).

\section{Dissemination of products}

Effective implementation of the research findings is contingent on motivation on the part of policymakers, capacity building for local public managers, adequate financing, policy creation, and consensus building among key stakeholders. Based on context and feasibility, the following approaches are chosen to disseminate the research findings. The key findings of the dissertation will be discussed with and submitted to the Director General of Health Services for policy support, as well as to the regional Directors of Health services. To further disseminate the findings, a workshop will be arranged involving civil surgeons, Upazilla Health and Family Welfare Officers, doctors and private facility owners, representatives of the Bangladesh Medical Association and journalists of national newspapers. Additional workshops will be arranged involving members of the scientific community from several recognised organisations with a proven track record of contributions to policymaking, such as ICDDR'B, BRAC University and Pundra University of Science and Technology of TMSS. The dissertation will be presented both to the country's development partners, including the World Bank, WHO, the European Union and the Ambassador of the Kingdom of the Netherlands in Bangladesh, and at international conferences. This will be helpful to facilitate advocacy for mobilising policymakers, gathering financial and technical support and promoting capacity building for local public health administrators in piloting the decentralisation process. The candidate will play an active role in disseminating the results within one year following successful completion of the PhD project. 


\section{Projected impacts}

The methodology of the inclusive approach to investigating health system satisfaction has a number of social and scientific implications, as it empirically addresses macro and micro-environmental factors of health system (dis)satisfaction. The methodological approaches and findings will be applicable in cross-border settings with similar contexts. The strategies for improving key stakeholders' satisfaction are based on their opinions, and the effects of these measures will be cross-checked with effective practices elsewhere. Moreover, a complete and in-depth understanding of dissatisfaction in the public and private sectors will reduce frustrations and mistrust among key health-care actors. This project also illustrates the effects of market-style reform in a developing country like Bangladesh and the factors underpinning these; additionally, being funded by the Dutch Government, this research itself serves as valuable input in the debate on the impact of globalisation. This dissertation will provide a solid foundation for future researchers to investigate an appropriate health insurance system for Bangladesh. Successful implementation of the recommendations with the necessary adaptations will ultimately contribute to equitable access to health care and health for rural populations, as well as to their economic development.

Lastly, the candidate's self-motivation to play a role in promoting the health of the global population through research and involvement in academia also contributes to achieving the vision and mission of Maastricht University. 

Acknowledgements 

First of all, I would like to thank almighty God for His guidance across the PhD trajectory.

I feel honoured to dedicate my deepest respect and gratitude to my diligent promoters Prof. dr. Nanne K. de Vries and Prof. dr. Trudy van der Weijden not only for moral and scientific supports but also for their strategic ways to guiding me; I reflect that as the great value of improving my skills to be an independent researcher to contribute in developing global health and health systems. I also respectfully remember the valuable supports of Prof. Dr. Md. Elius Hossain, department of Economics, University of Rajshahi, Bangladesh for fulfilling the roles as the local supervisor and providing moral supports.

I am privileged to convey my gratitude to the government of the Netherlands for generous support to my PhD study through awarding the NUFFIC scholarship. I owe my thanks to NUFFIC for arranging smooth and transparent access to the award through a compliant system; this also leads me to extend my sincere recognition to Ms. Lori Mees. I do remember the notable cooperation of the competent staff of the HR department of Maastricht University for arranging my residence permit in the Netherlands.

I am thankful to the secretarial and technical staff of the department of Health Promotion for providing a homely environment. I also respectfully remember all the PhD course faculties of the department of statistics, and epidemiology for competent and passionate dissemination of their subject knowledge. I remember my colleagues for their collaboration and sharing cross cultural views and experiences in a multicultural environment.

I would like to convey my thanks and admiration to the personnel of the public and private health sectors, my organization, colleagues and friends at home for their precious supports in conducting the research in local settings, collecting data from remote areas, and translating a lot of Bengali transcripts into English.

I express my love and gratitude to all my family members, especially our daughter Alethea Roy, for their sacrifice during my study abroad. 

Curriculum vitae 

Ashim Roy (Andrew) was born on 24 June 1967 in Khulna, a south-eastern regional district of Bangladesh. Having started in 1973, he completed his primary and secondary schools and higher secondary (college) education by 1985 with first grades in all public exams.

During 1986, Roy studied Physics in University of Dhaka, Bangladesh. In 1987, he was admitted in Sher-e-Bangla Medical College, Barisal (under University of Dhaka) and started studying medicine; a milestone on the way of fulfilling his career-goal of being a doctor, which he conceived in his childhood. Scoring the highest in the final professional examination in 1994, he was awarded the Bachelor of Medicine and Bachelor of Surgery (MBBS) degree.

Over two decades since 1995, he has been working with for-profit and not-for-profit private health organizations. During the period, he successfully conducted his responsibilities as a competent Family Physician, community health organizer, Chief Medical Officer, and Director of hospitals, and Chief Executive Officer cum assistant professor of community health of a social welfare-based health institution in Bangladesh.

During 2005 and 2009, he was appointed as director of a missionary hospital having 120 beds and a senior nursing training school. The remarkable global and local economic inflation during that period also affected this hospital. Being in the leadership position, it was quite challenging to meet the poor patients' expectations and to satisfy the staff as well. He found that most of the poor patients were suffering from disorders which are largely preventable by changing their lifestyle and behaviour. He was convinced that treating individual patient's symptoms is not enough at all to address the root causes of the mass population's health problems. He decided to study public health which was influenced by one of his well-wishers - Dr. Ratu. G. Saha (an international leader of the World Vision International).

Accordingly, in 2009, Roy was awarded a NUFFIC scholarship and in 2010, he successfully completed the Master of Public Health programme of the Royal Tropical Institute (under Vrije University), Amsterdam. In 2012, he won a Commonwealth scholarship for obtaining the degree of Master of Science in 'Global Health: Noncommunicable Diseases' at the University of Edinburgh, the UK. In 2013, he was awarded a NUFFIC grant for PhD studies at Maastricht University, the Netherlands. Roy conducted both the MSc and PhD projects simultaneously and was successfully awarded the MSc degree in 2015.

He served the Christian Medical Association of Bangladesh for about nine years (three terms) as an elected honorary national General Secretary, and as a member of the Medical Board of the National Council of Churches of Bangladesh for six years (three terms) as a part of his social activities. He attended seven international professional conferences. He is an alumnus of the Royal Tropical Institute, Amsterdam; Netherlands Alumni Association of Bangladesh; and the Global Health Academy of the University of Edinburgh, the UK. 
Roy is currently involved in tutoring international students of the Global Health programme of Maastricht University. He is keen to contribute to develop health care systems and people's health from local to global level through research and teaching in his future career. 


\section{Publication lists}

\section{PEER-REVIEWED JOURNAL ARTICLES}

1. Roy, A., van der Weijden, T., Hossain, ME., de Vries N. (2016). The need for regulatory reform to improve rural people's access to healthcare : views of administrators of the public-private mixed health system of Bangladesh. Divers Equal Heal Care.13(4):269-78.

2. Roy, A., Shengelia, L. (2016). A Review on Situation of Congenital Disorders and Access to Community Genetics Services in Bangladesh. Annals of Clinical and Laboratory Research, 4(2), 1-4.

3. Roy, A., Shengelia, L., Dupont, HB. (2016). Towards harm reduction of injecting drug users: A Priority Action for Preventing HIV in Bangladesh. Journal of Drug Abuse. 2(3), 1-5.

4. Roy, A., Shengelia, L. (2016). An Analysis on Maternal Healthcare Situation in Bangladesh : A Review. Divers Equal Heal Care. 13(5), 360-364.

\section{PhD research article accepted}

1. Roy, A., van der Weijden, T., \& de Vries N. Challenges of satisfaction of key stakeholders of the district health system of Bangladesh and ways to improve: a qualitative study.

PhD research articles under review

1. Roy, A., van der Weijden, T., \& de Vries N. Predictors and consequences of rural clients' satisfaction level in the district health care system of Bangladesh.

2. Roy, A., van der Weijden, T., \& de Vries N. Relationships of work characteristics to job satisfaction, turnover intention, and burnout among doctors in Bangladesh, and

Masters' thesis

1. Roy, A. (2010). Towards a better understanding and control of HIV: A critical analysis of HIV transmission in Bangladesh. A thesis submitted in partial fulfilment of the 
requirement for the degree of Master of Public Health. KIT Library catalog, Amsterdam.

Supervisors: Pam Baatsen (MSc); Dr. David Plummer (MBBS, PhD).

2. Roy, A. (2015). Challenging obesity: promoting physical activity in primary school children in Dhaka, Bangladesh. A thesis submitted for fulfilment of the requirement for the degree of Master of Science in Global Health. The Edinburgh University Library catalog, Edinburgh.

Supervisors: Dr. Elizabeth Grant (PhD); Dr. Graham Baker (PhD). 
